\title{
Monopolar and Bipolar Membranes in Organic Bioelectronic Devices
}

Erik O. Gabrielsson 


\section{Monopolar and Bipolar Membranes in Organic Bioelectronic Devices}

Erik O. Gabrielsson

During the course of the research underlying this thesis, Erik O. Gabrielsson was enrolled in Forum Scientium, a multidisciplinary doctoral program at Linköping University, Sweden.

Linköping Studies in Science and Technology. Dissertations. No. 1620

(C2014 Erik O. Gabrielsson unless otherwise noted

Typeset by the author using IATEX

Cover by Erik O. Gabrielsson

Printed by LiU-Tryck, Linköping, Sweden, 2014

ISBN: 978-91-7519-244-4

ISSN: 0345-7524

Electronic publication: http://www.ep.liu.se 
It never gets easier, you just go faster.

- Greg LeMond 



\section{Abstract}

In the 1970s it was discovered that organic polymers, a class of materials otherwise best know as insulating plastics, could be made electronically conductive. As an alternative to silicon semiconductors, organic polymers offer many novel features, characteristics, and opportunities, such as producing electronics at low costs using printing techniques, using organic chemistry to tune optical and electronic properties, and mechanical flexibility. The conducting organic polymers have been used in a vast array of devices, exemplified by organic transistors, light-emitting diodes, and solar cells. Due to their softness, biocompatibility, and combined electronic and ionic transport, organic electronic materials are also well suited as the active material in bioelectronic applications, a scientific and engineering area in which electronics interface with biology. The coupling of ions and electrons is especially interesting, as ions serve as signal carriers in all living organisms, thus offering a direct translation of electronic and ionic signals. To further enable complex control of ionic fluxes, organic electronic materials can be integrated with various ionic components, such as ion-conducting diodes and transistors.

This thesis reports a background to the field of organic bioelectronic and ionic devices, and also presents the integration of ionic functions into organic bioelectronic devices. First, an electrophoretic drug delivery device is presented, capable of delivering ions at high spatiotemporal resolution. The device, called the organic electronic ion pump, is used to electronically control amyloid-like aggregation kinetics and morphology of peptides, and offers an interesting method for studying amyloids in vitro. Second, various ion-conducting diodes based on bipolar membranes are described. These diodes show high rectification ratio, i.e. conduct ions better for positive than for negative applied voltage. Simple ion diode based circuits, such as an AND gate and a full-wave rectifier, are also reported. The AND gate is intended as an addressable $\mathrm{pH}$ pixel to regulate for example amyloid aggregation, while the full-wave rectifier decouples the electrochemical capacity of an electrode from the amount of ionic charge it can generate. Third, an ion transistor, also based on bipolar membranes, is presented. This transistor can amplify and control ionic currents, and is suitable for building complex ionic logic circuits. Together, these results provide a basic toolbox of ionic components that is suitable for building more complex and/or implantable organic bioelectronic devices. 



\section{Populärvetenskaplig Sammanfattning}

Italienaren Luigi Galvani experimenterade under 1700-talet med vad han kallade animalisk elektricitet, eller bioelektricitet. Genom att vidröra en död grodas benmuskler med olika metallelektroder kunde Galvani framkalla rörelser i grodans ben. Detta kan anses vara starten för användandet av elektricitet för att studera, mäta eller stimulera levande biologiska system och processer. Det senaste århundradets tekniska utveckling har gett oss flera medicinska applikationer där elektroder används, exempelvis i pacemakers för att reglera hjärtmusklernas sammandragning.

För vissa biologiska användningsområden är dock inte metallelektroder ideala. Detta gäller för implantat av elektroder i hjärnan då det kan bildas ärr runt elektroden som både skadar vävnaden och försämrar elektrodens förmåga att stimulera eller mäta. Konjugerade polymerer är en annan typ av elektrodmaterial som har visat sig vara användbar i biologiska applikationer. Dessa är plastmaterial uppbyggda av kolkemi, och är därför relativt lika biologiskt levande material. Till skillnad från isolerande plaster kan konjugerade polymerer göras elektriskt ledande. Detta upptäcktes av Alan J. Heeger, Alan G. MacDiarmid och Hideki Shirakawa på 1970-talet och belönades med Nobelpriset i kemi år 2000. De elektriskt ledande konjugerade polymererna används idag i bland annat transistorer, lysdioder och solceller. De är mjukare än metaller och är därför mer mekaniskt kompatibla med exempelvis (den ännu mjukare) hjärnan, och kan implanteras och användas under lång tid utan att ärrbildning sker.

I konjugerade polymersystem kan elektriska och joniska laddningar integreras och ge kombinerad elektrisk och joniska ledningsförmåga. Små och stora joner finns överallt i levande organismer, och den joniska ledningsförmågan i polymerer ger oss därför en möjlighet att översätta biologiska joniska signaler till elektroniska, och vice versa. En annan typ av jonledande material är jonselektiva membran. Dessa är också polymerer, och innehåller fasta orörliga positiva eller negativa joniska laddningar. De fasta laddningarna attraherar joner av motsatt polaritet, medan joner med samma polaritet repelleras. Därmed är det främst laddningar av motsatt polaritet som transporteras i det jonselektiva membranet. Om två membran med motsatt jonselektivitet kombineras, fås ett bipolärt membran som kan användas för att bygga joniska dioder och transistorer.

I denna avhandling kombineras konjugerande polymerer med jonselektiva membran för att ge ökad kontroll över jontransport. Först visas hur enkla jonselektiva membran kan användas för att leda en ström av joner till ett mikrometerstort utlopp, varifrån jonerna sedan diffunderar ut. Den lokala ökningen i jonkoncentration används för att elektroniskt kontrollera bildningen av amyloid-liknande proteinaggregat. Amyloida plackstrukturer 
återfinns i flera sjukdomar, främst då i åldersrelaterade demenssjukdomar som Alzheimers och Parkinsons sjukdom. Möjligheten att kunna kontrollera hur och var aggregeringen sker kommer förhoppningsvis att vara ett användbart redskap i sökandet efter orsaken till varför amyloider bildas och hur det kan förhindras.

Vidare beskrivs jondioder och jontransistorer baserade på bipolära membran. Dessa fungerar likt sina elektroniska förlagor, men kan likrikta respektive modulera joniska strömmar. Jondioderna används för att skapa joniska kretsar; en AND-grind och en helvågslikriktare. AND-grinden används som en adresserbar pixel för att skapa $\mathrm{pH}$-signaler, och är exempelvis lämplig för att inducera amyloidaggregering av proteiner. Helvågslikriktaren löser ett vanligt förekommande problem i applikationer där kontinuerliga jonströmmar behövs under längre tid. För att åstadkomma dessa strömmar används ofta elektrokemiska reaktioner vid metallelektroder, varpå oönskade sidoreaktioner ger upphov till gasbildning, pH-avvikelser eller giftiga sidoprodukter. Genom att istället periodiskt växla strömriktnignen hos ett par konjugerade polymerelektroder och sedan likrikta strömmen med den joniska helvågslikriktaren undkommer man dessa problem. Därmed kan generering av en konstant jonström frikopplas från den elektrokemiska kapaciteten hos elektroderna som används.

Tillsammans ger dessa resultat en verktygslåda av jonledande komponenter som lämpar sig för att öka möjligheten att joniskt kommunicera med levande organismer, exempelvis i framtida implanterbara biomedicinska komponenter. 


\section{Acknowledgements}

This thesis would not have been possible without help and support from people around me. For this I like to express my sincere gratitude to:

Magnus Berggren, my main supervisor, for giving me the opportunity to work in the Laboratory of Organic Electronics and to evolve as a scientist, and for your optimism and great ideas.

Edwin Jager and Daniel Simon, my first and second co-supervisors, for their support and for sharing their knowledge in bioelectronics.

Peter Nilsson and Per Hammarström, for their invaluable knowledge in amyloids, their enthusiasm, and experimental help.

Sophie Lindesvik, for being such a great and friendly administrator.

Lars Gustavsson, Bengt Råsander, Anna Malmström, and all the other personal that ensures that the cleanroom remain tidy and up-andrunning.

All present and former members of the Laboratory of Organic Electronics for their part in creating an amazing and friendly research environment. Especially, I would like to thank: Klas, "Dr. Iontronic", for his expertise in ion transport, and for all the fun times (not only in the lab). Pelle, for being such a truly nice guy with awesome pipetting skills. Malti, for the fun friday experiments and coffee table discussions. Anders Hentzell for the Friday lunches. Maria and Kristin, for the great times on conferences and study visits. Astrid, for the enthusiastic help with the A $\beta$ experiments. Amanda and Theresia for their contribution in development of new processes and materials. Xiaodong and Skomantas for sharing office with me, and making sure I never wanted my own room.

The staff of Acreo in Norrköping, especially Anurak Sawatdee for the hugs and company during commutes, David Nilsson for his expertise in inkjet printing, and Mats Sandberg for discussions and help regarding everything related to chemistry.

Annelie Eveborn and Olle-Jonny Hagel at Thin Film Electronics for advise on cleanroom processing.

Forum Scientum and Stefan Klintström, for arranging both scientifically valuable and fun activities. 
The cycling team CK Hymer and all my other cycling friends, for the amazing and fun hours training and competing, in sunshine, rain, headwinds, and snow.

All my friends, for their friendship and fun times. Special thanks to Rebecka, Stina, Amie, and Gustav for making Linköping such a nice town.

My family; my sister, my brothers, and my parents Kerstin and Lennart, for all love and support.

Annika, for love and being loved and for understanding me, and to our wonderful "kleiner Mann" Wilhelm for bringing so much joy.

\section{Tack!}




\section{Included Papers}

\section{Paper I}

\section{Spatially Controlled Amyloid Reactions Using Organic Electronics}

Erik O. Gabrielsson, Klas Tybrandt, Per Hammarström, Magnus Berggren, and K. Peter R. Nilsson

Small 6, pp. 2153-2161 (2010)

Contribution: Contributed to the experiment design, performed most experimental work, wrote the first draft, and contributed to the editing of the final manuscript.

\section{Paper II}

\section{Controlled Microscopic Formation of Amyloid-Like A $\beta$ Aggregates} Using an Organic Electronic Device

Erik O. Gabrielsson, Astrid Armgarth, Per Hammarström, K. Peter R. Nilsson, and Magnus Berggren

Manuscript in preparation

Contribution: Designed experiments, performed and supervised parts of the experimental work, and wrote the first draft.

\section{Paper III}

\section{Ion diode logics for $\mathrm{pH}$ control}

Erik O. Gabrielsson, Klas Tybrandt, and Magnus Berggren

Lab on a Chip 12, pp. 2507-2513 (2012)

Designed experiments, performed all experimental work, wrote first draft of manuscript, and contributed to the editing of the final manuscript. 


\section{Paper IV}

\section{Polyphosphonium-Based Bipolar Membranes for Rectification of}

lonic Currents

Erik O. Gabrielsson and Magnus Berggren

Biomicrofluidics 7, 064117 (2013)

Contribution: Designed experiments, performed all experimental work, and wrote most of the manuscript.

\section{Paper V}

\section{A Four-Diode Full-Wave Ionic Current Rectifier Based on Bipolar Membranes: Overcoming the Limit of Electrode Capacity}

Erik O. Gabrielsson, Per Janson, Klas Tybrandt, Daniel. T. Simon, and Magnus Berggren

Advanced Materials 26, pp. 5143-5147 (2014)

Contribution: Designed experiments, performed most experimental work, and wrote most of the manuscript.

\section{Paper VI}

\section{Polyphosphonium-Based Ion Bipolar Junction Transistors}

Erik O. Gabrielsson, Klas Tybrandt, and Magnus Berggren

Submitted manuscript

Contribution: Designed experiments, performed most experimental work, and wrote most of the manuscript. 


\section{Related Work}

Toward Complementary lonic Circuits: The npn Ion Bipolar Junction Transistor

Klas Tybrandt, Erik O. Gabrielsson, and Magnus Berggren

Journal of the American Chemical Society 133, pp. 10141-10145 (2011)

Ultra-low voltage air-stable polyelectrolyte gated $\mathrm{n}$-type organic thin film transistors

Abdellah Malti, Erik O. Gabrielsson, Magnus Berggren, and Xavier Crispin Applied Physics Letters 99, 063305 (2011) 



\section{Contents}

\section{Background}

1 Introduction 1

1.1 Ions and Organic Bioelectronics . . . . . . . . . . . . . . . 1

$1.2 \quad$ Aim of Thesis . . . . . . . . . . . . . . . . . . . . . 1

1.3 Outline of Thesis $\ldots \ldots \ldots \ldots \ldots \ldots$

2 Conjugated Polymers 3

2.1 Orbitals . . . . . . . . . . . . . . . . . . . 3

2.1 .1 Atomic Orbitals . . . . . . . . . . . . . . . . 3

2.1 .2 Molecular Orbitals . . . . . . . . . . . . . . . . . . 4

2.1 .3 Hybridization . . . . . . . . . . . . . . . . . 4

2.2 Conjugated Polymers . . . . . . . . . . . . . . . . . . 5

$2.2 .1 \quad$ Electronic Structure . . . . . . . . . . . . . . 5

2.2 .2 Charge Carriers and Transport . . . . . . . . . . . 7

2.2 .3 Doping $\ldots \ldots \ldots \ldots \ldots \ldots$

$\begin{array}{lll}3 & \text { Ion Transport } & 11\end{array}$

3.1 Ion Transport Processes . . . . . . . . . . . . . . . . . 11

3.1 .1 Migration and Diffusion . . . . . . . . . . . . . . 12

3.1 .2 Transport Numbers $\ldots \ldots \ldots \ldots$

3.2 Ion Selective Membranes . . . . . . . . . . . . . . . . . . . 12

3.2 .1 Donnan Potential . . . . . . . . . . . . . . . . . 14

3.2 .2 Junction Potential . . . . . . . . . . . . . . . . . . 15

3.2 .3 Membrane Potential . . . . . . . . . . . . . . . . 15

3.2 .4 Concentration Polarization . . . . . . . . . . . 15

3.3 Bipolar Membranes . . . . . . . . . . . . . . . . . . . . . . . 16

$3.3 .1 \quad$ Forward Bias Regime $\ldots \ldots \ldots \ldots \ldots$

3.3 .2 Reverse Bias Regime . . . . . . . . . . . . . . . . . . 18

3.3 .3 Rectification . . . . . . . . . . . . . . . . . 18

3.3.4 Electric Field Enhanced Water Dissociation . . . . . . 18

3.4 Electrodes in an Electrolyte . . . . . . . . . . . . 20

4 Amyloids 23

$4.1 \quad$ Amyloid Composition and Structure . . . . . . . . . . . . . 23

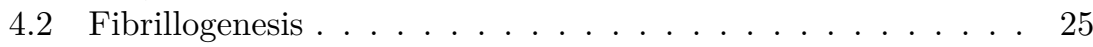

4.3 Factors for Amyloid Formation . . . . . . . . . . . . . . 27

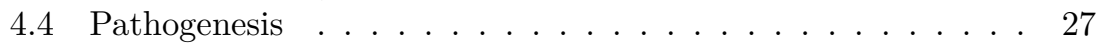

$4.4 .1 \quad$ Neurophatic Amyloid Diseases . . . . . . . . . . . 28 
4.4.2 $\quad$ Non-Neurophatic and Systematic Amyloid Disease . . 28

4.4 .3 Functional Amyloids . . . . . . . . . . . . . . . . . . 28

4.5 Detection Methods . . . . . . . . . . . . . . . . . . 28

$4.6 \quad$ Amyloids as Nano-Structural and Functionalized Material . . 30

4.7 Lab-on-a-Chip Technology in Amyloid Research . . . . . . . . 30

$\begin{array}{lll}5 & \text { Organic Bioelectronics } & 31\end{array}$

5.1 Sensors . . . . . . . . . . . . . . . . 31

5.2 Actuators . . . . . . . . . . . . . . . . . . . . 33

$5.2 .1 \quad$ Electronic Stimulation . . . . . . . . . . . . . . . . 33

5.2 .2 Mechanical Actuators . . . . . . . . . . . . . . . 33

5.2 .3 Surface Switches . . . . . . . . . . . . . . . . 34

$5.2 .4 \quad$ Drug Delivery Systems . . . . . . . . . . . . . 35

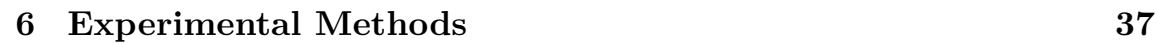

6.1 Microfabrication Techniques . . . . . . . . . . . . . . . . . 37

6.1 .1 Spin coating . . . . . . . . . . . . . . 37

$6.1 .2 \quad$ Photolithography . . . . . . . . . . . . . . . . . . . . . . . . . . . . . . . .

6.1 .3 Dry Etching. . . . . . . . . . . . . . . . . . . . . . . . . . . . . . . . . . . . . . .

6.1 .4 Inkjet Printing . . . . . . . . . . . . . . . . . . . . . . . 40

6.2 Synthesis of Anion Exchange Membranes . . . . . . . . . . . 40

$6.3 \quad$ Fabrication of Ion Pumps, Diodes, and Transistors . . . . . . 41

\begin{tabular}{|ll|}
\hline & Devices in Papers \\
\hline
\end{tabular}

7.1 General Design . . . . . . . . . . . . . . . . . . . . . 45

7.2 Organic Electronic Ion Pumps. . . . . . . . . . . . . . . . . . 45

7.2 .1 In Vitro Stimulation of Cells . . . . . . . . . . . . . . 46

7.2 .2 In Vivo Stimulation of Tissues . . . . . . . . . . . . . 46

7.2.3 Formation of Amyloid-Like Aggregates (Papers I-II) . 47

7.3 Ion Diodes . . . . . . . . . . . . . . . . . . . . . 48

7.3 .1 The IBMDs $($ Papers III-IV) . . . . . . . . . . . . . . . . 48

7.3.2 Alternatives toliBMDs . . . . . . . . . . . . . . 51

7.4 Ion Diode AND Gate (Paper III) . . . . . . . . . . . . . . . . . 52

7.5 Ion Diode Full-Wave Rectifier (Paper V) . . . . . . . . . . . . 54

$7.6 \quad$ Ion Bipolar Junction Transistors (Paper VI) . . . . . . . . . . 55

8 Concluding Remarks $\quad 59$

8.1 From Amyloids to Full-Wave Rectification . . . . . . . . . . . 59

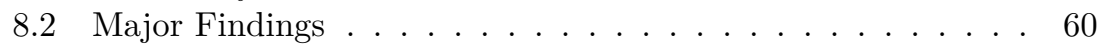

8.3 Future Outlook . . . . . . . . . . . . . . . . . . . 61

\begin{tabular}{ll}
\hline References & 63
\end{tabular}

\begin{tabular}{ll}
\hline Acronyms & 75
\end{tabular}

\section{Papers}


Part I

Background 



\section{Chapter 1}

\section{Introduction}

\section{1 lons and Organic Bioelectronics}

In 1771 Luigi Galvani discovered what he called "animal electricity". In the associated experiments he applied metal electrodes to detached frog legs and caused twitching movements in the legs. Galvani's work laid the ground for studies of electronic stimulation of biological system, and conversely, also the recording of neuronal signals. Centuries later, electrodes are, for example, used for stimulation of heart rhythm in pacemakers, combined with biological enzymes to provide glucose sensing for diabetic patients, and for recording of membrane potential changes in signaling neuronal cells. The research field in which electronic devices is used to record and regulate biological processes is today know as bioelectronics.

Traditional materials for electronic devices are metals and silicon, which provide high conductivity and can be patterned at high resolution. Unfortunately, metal and silicon have some important limitations with respect to the integration with biology. For example, metals and silicon are hard materials, while most biological tissues are soft. A possible solution to the hard/soft-incompatibility problem was found in the 1970's when Alan J. Heeger, Alan G. MacDiarmid, and Hideki Shirakawa discovered that polyacetylene could be rendered electronically conductive through treatment with iodine; a discovery that was awarded the Nobel price in chemistry in 2000. As polyacetylene is a carbon-based polymeric material the new research field of conductive polymers was called organic electronics. Today, the field of organic electronics has produced numerous technologies and devices, such as organic light emitting diodes, organic field effect transistors, organic solar cells, and organic memories.

The polymeric materials used in the field of organic electronics have some unique properties that are not typically found in regular silicon based electronics, such as solution processing, softness and flexibility, and a combined electronic and ionic conductivity. Their softness, carbon-based chemistry, and possibility for chemical alterations enable the organic electronic materials to be highly biocompatible. Further, the importance of ions, as signals in biological systems, make the ion- and electron-conducting polymers a perfect translator of signals in bioelectronic stimulation and sensing applications. The fruitful combination of organic electronics in bioelectronic applications became known as organic bioelectronics.

\subsection{Aim of Thesis}

This thesis aims to explore the combination of ion-conducting membranes and organic electronics to allow for greater control of ionic currents in 
bioelectronic devices. The possibility to direct a flux of ions into a spatially well-defined release point is presented as a novel method to study ion-induced aggregation of amyloid proteins. Additionally, ion conductive membranes with opposite polarity are used to realize devices with function similar to electronic semiconductor diodes and transistors, but for ionic currents and signals. These non-linear ionic devices are further investigated for constructing chemical circuits where the current within the circuit is entirely ionic to its nature.

\subsection{Outline of Thesis}

The first part of this thesis describes the background to the field of organic bioelectronics, with a focus on ionic components and applications within the field of amyloid research, followed by a more in-depth description and explanation of the function of novel bipolar membrane (BM) based ionic devices. In the next chapter, Chapter 2 the concept of conjugated polymers (CPs) and why they can be electronically conductive, is explained. Chapter 3 aims at presenting a similar theoretical background to ion conductivity in electrolytes, with emphasis on ion exchange membranes (IEMs) Chapter 4 provides a short introduction to the field of amyloids, and Chapter 5 gives a brief survey over the field of organic bioelectronics. The experimental techniques used in this work are described in Chapter 6. Chapter 7 presents the background and function of the ionic devices used in the included papers, giving a detailed view of the work produced for this thesis. The last chapter, Chapter 8 serves to provide my own reflections of the presented work, with some analysis of its impact and thoughts about future development of ionic devices as well as their potential applications.

The second part of the thesis includes the manuscripts written and published during the work towards this thesis. Papers I-II describe the use of the organic electronic ion pump to produce amyloid-like protein aggregates with spatiotemporal control. Papers III-V present the development, challenges, and improvements of ion diodes based on BMs, as well as the integration of said diodes into simple ionic circuits (AND logic gate in Paper III, full-wave rectifier in Paper V). Paper VI details the development of ion transistors, also based on $\mathrm{BMs}$, where the transistor performance is improved by reducing the dimensions of the BM. 


\section{Chapter 2}

\section{Conjugated Polymers}

Polymers are macromolecules consisting of several (poly) repetitions of small subunits (mers). Many polymers are materials that we encounter in our everyday life and typically describe as plastic insulating materials. Some polymers however, namely CPs can be electronically conducting. The difference between an insulating polymer and a $\mathrm{CP}$ is in the electronic structures, i.e. the nature of the molecular bonds between the atoms in the polymers. This chapter describes how these bonds are formed and how CPs can be made electronically conducting.

\subsection{Orbitals}

\subsubsection{Atomic Orbitals}

An atom contains positively charged protons, negatively charged electrons, and (most often) neutral neutrons. The number of protons and electrons are equal, so that the total charge of the atom is zero. Protons and neutrons are located at the center of the atom, forming the nucleus, and electrons form a cloud surrounding the nucleus. By describing the atom using quantum mechanics, discrete states of the electrons are obtained [1]. These are arranged into atomic orbitals (AOs), defined by shell and orbital type. The shells (K, $\mathrm{L}, \mathrm{M}, \mathrm{N}$, etc. or $1,2,3,4$, etc.) describe the distance of the orbital from the nucleus, where $\mathrm{K}$ or 1 is the innermost shell. Each shell can contain a number of orbital types (s, p, d, etc.) with different spatial distribution.

Quantum mechanics dictates that each $\mathrm{AO}$ can only be occupied by two electrons and only if they have different spin (up or down). Further, the energy for an electron in an $\mathrm{AO}$ is typically increased with shell number and orbital type (e.g. $2 \mathrm{~s}$ have higher energy than $1 \mathrm{~s}, 2 \mathrm{p}$ have higher energy than $2 \mathrm{~s}$ ). Therefore, electrons fill the innermost shells first to minimize the energy of the atom, resulting in the ground state of the atom. For a carbon atom, with 6 electrons, this gives a ground state configuration of $1 \mathrm{~s}^{2} 2 \mathrm{~s}^{2}$ $2 \mathrm{p}^{2}$ (Figure 2.1). The superscript denotes the number of electrons in each orbital. Electrons located in the outermost shell, the valence shell, are called valence electrons. The chemistry of atoms and molecules is highly dictated

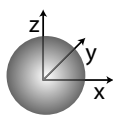

2s



$2 p_{x}$

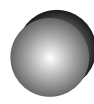

$2 p_{y}$

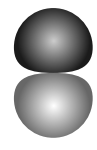

$2 z$

Figure 2.1: Illustrations of the valence atomic orbitals of carbon. 




Figure 2.2: Energy diagram for two 1s orbitals (e.g. two hydrogen atoms) forming a $1 \sigma \mathrm{MO}$ and a $1 \sigma^{*} \mathrm{MO}$ The electrons from the $1 \mathrm{~s}$ orbitals occupy the $1 \sigma \mathrm{MO}$ forming a bond (e.g. a hydrogen molecule). Constructive interference between the AOs results in lower $\mathrm{MO}$ energy $(1 \sigma)$, while destructive interferance results in higher $\mathrm{MO}$ energy $\left(1 \sigma^{*}\right)$.

by interactions between valence electrons. In most organic molecules the valence orbitals are formed from s and p orbitals.

\subsubsection{Molecular Orbitals}

Molecules are formed by atoms bonding to each other. When two atoms are brought close to each other their valence orbitals start to overlap and the valence electrons can interact. The interaction can be approximated by a linear combination of the individual AOs, and the result is formation of molecular orbitals (MOs) (Figure 2.2] [2]. MOs are shared across the participating atoms, and are populated by the electrons from the contributing AOs. Depending on the involved AOs different MOs are formed. A $\sigma$ orbital is formed if the bonding $\mathrm{AOs}$ are arranged along the axis of the bond, and a $\pi$ orbital if the arrangement is perpendicular to the bond axis. The $\sigma$ and $\pi$ orbitals have spatial similarities to s and p orbitals, respectively.

The interaction between $\mathrm{AOs}$ results in MOs of different energy as the energy levels split up into bonding and antibonding orbitals. A bonding $\mathrm{MO}$ has lower energy than the individual AOs and stabilizes the interaction between atoms to form a bond. An antibonding orbital, denoted with an asterisk $\left(^{*}\right)$ has, on the other hand, higher energy and destabilizes the bond. Thus, a molecular bond is only stable if the energy of the electrons in the bonding and antibonding MOs is lower than in the original AOs. The occupied MO with highest energy is called highest occupied molecular orbital \begin{tabular}{|l|l|l|l|l|}
\hline (HOMO $)$ & The orbital directly above the HOMO in energy is the lowest \\
\hline
\end{tabular} unoccupied molecular orbital (LUMO).

\subsubsection{Hybridization}

According to valence bond theory [3] some atoms form hybridized orbitals when forming bonds, for example carbon. Here, one s and one, two, or all three of the $\mathrm{p}$ orbitals of carbon (Figure 2.1) can form hybridized $\mathrm{sp}, \mathrm{sp}^{2}$, or $\mathrm{sp}^{3}$ orbitals (Figure 2.3). The hybridized orbitals can form $\sigma$ bonds with other atoms, while the non-hybridized p orbitals (for $\mathrm{sp}$ or $\mathrm{sp}^{2}$ hybridization) 




$\mathrm{sp}$

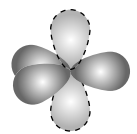

$\mathrm{sp}^{2}$

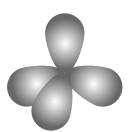

$\mathrm{sp}^{3}$

Figure 2.3: Illustrations of hybridized orbitals (shaded) formed by carbon. The orbitals with dotted outline are non-hybridized $p$ orbitals.

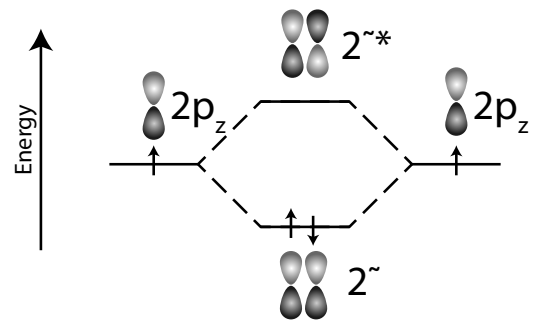

Figure 2.4: Energy diagram of two $p$ orbitals forming $\pi \mathrm{MOs}$

can form $\pi$ orbitals. The formed $\pi$ orbitals are either bonding or antibonding Figure 2.4.

Each occupied $\mathrm{MO}$ between two atoms represents a bond. More than one bond can be formed between two atoms in a molecule, for example by occupation of both $\sigma$ and $\pi \mathrm{MOs}$ giving a double bond. In ethane, all bonds are single bonds (Figure 2.5a) formed by $\sigma \mathrm{MOs}$, while in ethylene an additional $\pi \mathrm{MO}$ between the carbons results in a double bond (Figure 2.5b)

\subsection{Conjugated Polymers}

\subsubsection{Electronic Structure}

The difference between an insulating polymer, such as polyethylene Figure 2.6a), and an electronic conductive $\mathrm{CP}$, such as polyacetylene (Fig-

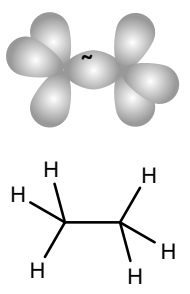

(a) Ethane $\mathrm{C}_{2} \mathrm{H}_{6}$

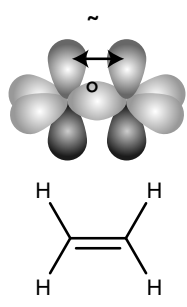

(b) Ethylene $\mathrm{C}_{2} \mathrm{H}_{4}$

Figure 2.5: The molecule (a) ethane consists of only single bonds, while (b) ethylene also has a double bond. 
<smiles>CC(C)(C)CCC(C)(C)C</smiles>

(a) Polyethylene $\left(\mathrm{C}_{2} \mathrm{H}_{4}\right)_{n} \mathrm{H}_{2}$<smiles>CC=CC(C)C</smiles>

(b) Polyacetylene $\left(\mathrm{C}_{2} \mathrm{H}_{2}\right)_{n}$

Figure 2.6: Structures of (a) the insulating polyethylene, containing only single bonds, and (b) the conductive polyacetylene, containing alternating single and double bonds.

ure 2.6b), is the hybridization of the carbon atoms. In polyethylene, the carbons are $\mathrm{sp}^{3}$ hybridized, and all valence electrons are involved in forming $\sigma$ bond, either to other carbons or to hydrogens. In polyacetylene the carbons are $\mathrm{sp}^{2}$ hybridized. This allows for three $\sigma$ bonds, two to other carbons and one to hydrogen. The remaining $\mathrm{p}$ orbital is free to form a $\pi$ bond with a neighboring carbon atom with an unoccupied p orbital. Thus, in polyacetylene an alternating pattern of double bonds is formed, called a conjugated structure. $\pi$ orbitals across a polymer can overlap to give further electronic interaction (Figure 2.4), resulting in additional bonding and antibonding orbitals across the polymer. As more $\pi$ orbitals interact the orbital energy levels split up. The number of available levels depends on the number of carbon atoms in the polymer (Figure 2.7). As the number of carbon atoms in the backbone of a polymer increases, the energy levels of the orbitals form bands.

If the lengths of single and double bonds were equal in a $\mathrm{CP}$ chain, bonding and antibonding energy levels would eventually form one continuous energy band and give metallic conductivity to the polymer. However, as described by Peirel's theorem, bond lengths are not equal between single and double bonds. Alteration of bond lengths in a $\mathrm{CP}$ minimizes the energy,

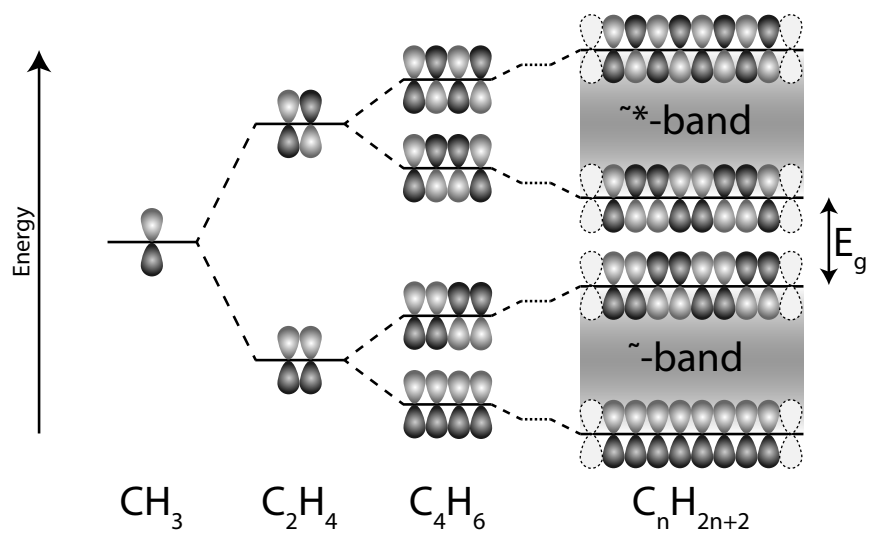

Figure 2.7: Energy diagram for the formation of $\pi$ orbitals i polyacetylene of various lenght. The number of possible combinations of constructuve and destructive interference increase with length, thus splitting the energy levels. 
and is thus the preferred arrangement. This has a stabilizing effect on the bonding orbitals while destabilizing the antibonding orbitals. The energy levels of bonding and antibonding orbitals therefore separates into two bands, the $\pi$ and the $\pi^{*}$ band. The HOMO is then located at the top of the $\pi$ band, while the LUMO is on the bottom of the $\pi^{*}$ band. The difference in energy between HOMO and LUMO is the band gap. A small band gap is representative for a semiconducting material, and for CPs the band gap is typically $1.5-3 \mathrm{eV}$ [4]. For an insulating material, such as polyethylene, the band gap is larger.

\subsubsection{Charge Carriers and Transport}

Electronic conduction requires charge carrierss to be present in the material. Depending on the structure of the polymer chain, the charge carriers in a $\mathrm{CP}$ are either solitons or polarons [5].

\section{Solitons}

If the location of single and double bonds in a $\mathrm{CP}$ can be interchanged without altering the system energy, the polymer is said to have a degenerate ground state Figure 2.8. As both configurations are equal in energy they also have equal probability of occurring. Both configurations can even exist on the same chain. This gives a transition region between the two configurations with modified bonds, a soliton. Solitons give two energy states inside the band gap and can have either neutral, positive, or negative charge.

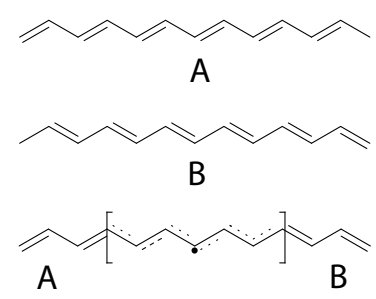

Figure 2.8: The $A$ and the $B$ bond configuration of polyacetylene have equal probability to occur. If both exist on the same chain a soliton is formed.

\section{Polarons}

Most CPS do not have a degenerate ground level, i.e. interchanging single and double bonds alters the polymer's energy. An example for which this is true is the polythiophenes. The ground state of a polythiophene is the aromatic configuration where the double bonds are located in aromatic rings (Figure 2.9a). By interchanging single and double bonds, the higher energy quinoid configuration is obtained (Figure $2.9 \mathrm{~b}$ ).

Solitons are not observed in these polymers as alternation of bond gives different energy. However, by introducing a charge to the polymer, a local deformation of the bond conjugation is obtained. This is called a polaron (Figure 2.10, and can be regarded as a local quinoid configuration, i.e. alteration of single and double bonds around a limited number of bonds. If several polarons exist on the same chain it is sometimes energetically 


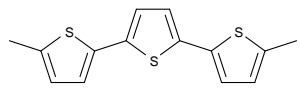

(a) Aromatic

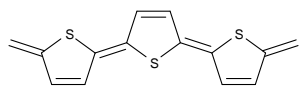

(b) Quinoid

Figure 2.9: The (a) aromatic form of a polythiophene, where the double bonds are located inside the ring, has lower energy than the (b) quinoid form.

favorable to locate them close together to form bipolarons. Polarons are either positive or negative depending on the charge added to the $\mathrm{CP}$. The energy levels of the polarons lie between the $\pi$ bands, giving the doped polymer chain a reduced band gap.(Figure 2.11.

\section{Charge carrier transport}

Solitons and polarons can with ease move along the chain of a polymer, but this motion is naturally restricted to the chain length of the polymer. To achieve charge transport over longer distances charge carriers also need to move between polymer chains. This motion is typically characterized by thermally activated hopping of the charge carriers between chains, and this process limits the electronic mobility of a $\mathrm{CP}$. The energy requirement can be reduced by increasing the $\pi$ overlap between chains, such as obtained for highly crystalline films. Because of the difference in $\pi$ overlap charge mobility can vary from $10 \times 10^{-5}$ to $10 \times 10^{-4} \mathrm{~cm}^{2} /(\mathrm{V} \mathrm{s})$ for amorphous poly(3-hexylthiophene) [6] to $0.2-0.6 \mathrm{~cm}^{2} /(\mathrm{Vs})$ for a single-crystal polythiophene-derivate with side groups designed for promoting crystallization 7 .

\subsubsection{Doping}

The relative large band gap of an intrinsic (undoped) CPs results in few thermally excited charge carriers and limited conductivity. Higher conductivity can be obtained by introducing more charge carriers into the polymer chain in a process called doping [8]. Doping involves electron transfer between a dopant species and the polymer. If electrons are transferred from the dopant to the polymer, i.e. reduction of the polymer, n-doping occurs. Conversely, transferring electron from the polymer to the dopant, i.e. oxidation of the polymer, is called p-doping. The population of charge carriers, i.e. polarons and/or solitons, increases with doping level. The introduced charge in the polymer is compensated by an ion with opposite charge.

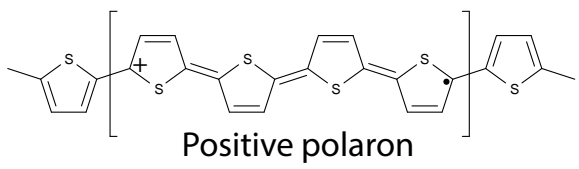

Figure 2.10: A local quinoid configuration gives a (positive) polaron on the chain. 


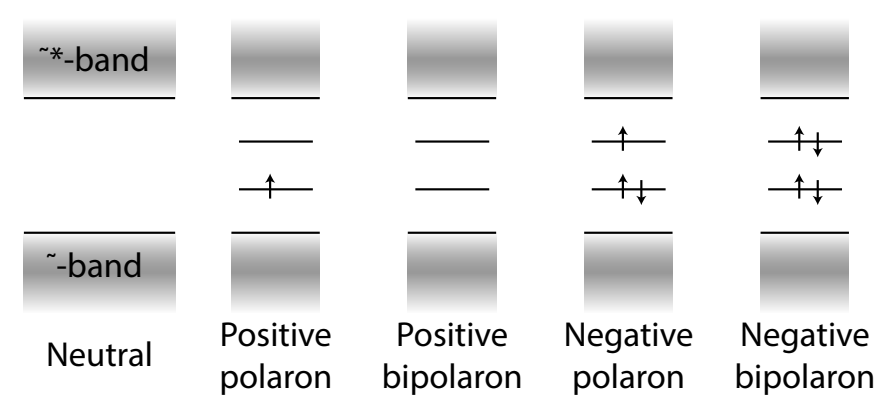

Figure 2.11: Energy diagrams of positive and negative polarons and bipolarons.

In chemical doping, the dopant molecule has a HOMO LUMO higher/ lower than the LUMOHOMO of the polymer, and is therefore oxidized/ reduced. The oxidized/reduced dopant becomes the compensating positive/ negative ion to the charge introduced in the $\mathrm{CP}$ chain. The halogen doped polyacetylene studied by Shirakawa et al. [9 is an example of a chemically doped conducting polymer.

Electrochemical doping is performed by submerging a $\mathrm{CP}$ electrode in an electrolyte [10]. By applying a voltage between the $\mathrm{CP}$ electrode and a working electrode, electric charge is introduced into the $\mathrm{CP}$ through electrochemical oxidation or reduction. The introduced charges are compensated by ions from the electrolyte.

For a partially doped $\mathrm{CP}$ electrode only a small voltage change (vs. a counter electrode) is needed to change the oxidation/reduction state of the polymer electrode, i.e. the doping level can be changed with ease. This is advantageous for numerous applications, among them bioelectronic devices [11], as a small change in potential at the electrode interface can lead to an observable change in electronic properties of the $\mathrm{CP}$ electrode. 



\section{Chapter 3}

\section{Ion Transport}

An electrolyte is a solution containing dissolved ions, i.e. positive cations (e.g $\mathrm{K}^{+}$) and negative anions (e.g $\mathrm{Cl}^{-}$). Each ion can have one or multiple charges, but the number of positive and negative charges in the electrolyte must to be equal to maintain electroneutrality. The ions can be simple metal ions (Figure 3.1a), more complex organic molecules such as charged biomolecules, or a polymer chain containing repetitive charges (as in a polyelectrolyte, Figure 3.1b). A binary electrolyte contains two ionic species in the same amount, e.g. $\mathrm{KCl}$. A ternary electrolyte contains three ionic species, e.g. a solution of $\mathrm{NaCl}$ mixed with $\mathrm{KCl}$ or a polyelectrolyte in $\mathrm{NaCl}$. The conductivity of an electrolyte increases with the ion concentration as long as the ions do not form ion-pairs 12 .

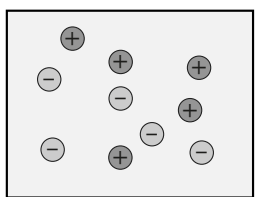

(a) A simple electrolyte

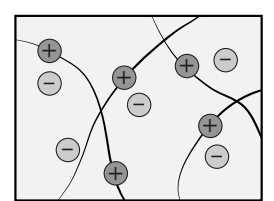

(b) A polyelectrolyte

Figure 3.1: Examples of electrolytes. The black lines represents polymer chains, onto which (positive) charges are fixated

\subsection{Ion Transport Processes}

In an electrolyte, ions can move by three processes; migration, diffusion, and convection [13. Migration occurs in presence of an electric field (Figure 3.2a), net transport by diffusion occurs along concentration gradients (Figure 3.2b), and convection occurs due to fluid movement (Figure 3.2c).

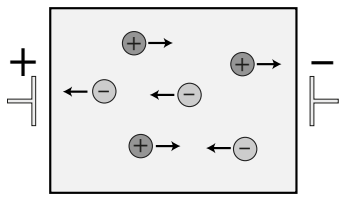

(a) Migration

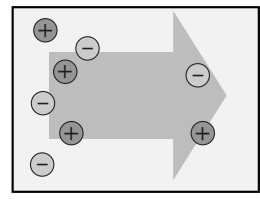

(b) Diffusion

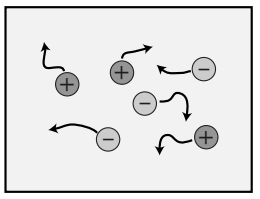

(c) Convection

Figure 3.2: Modes of ion transport in an electrolyte, either through (a) the application of an electric field, (b) existence of a concentration gradient, or (c) fluid movement. 


\subsubsection{Migration and Diffusion}

In a solution with a concentration difference $\Delta c$, random motion of molecules gives diffusion, where the net movement of molecules will strive to level any concentration difference. For example, if a volume with high electrolyte concentration is put into contact with a volume with low concentration, ions will diffuse from high to low concentration. Flick's first law describes the diffusional flux $(J)$ of molecules due to a concentration gradient $\Delta c$ as:

$$
J=-D \Delta c
$$

where $D$ is the diffusion coefficient, a property which describes the ability of a molecule to move in its solvent.

A potential difference $\Delta \phi$ in an electrolyte gives an electric field that will exert a force on the ions in the electrolyte, resulting in ion migration. For cations $(z=+1)$ the migration is in the direction of the electric field, and vice versa for anions $(z=-1)$.

Migration and diffusion are linked for charged species such as ions: A flux of ions due to migration creates a concentration gradient, resulting in a diffusive component for the involved ions. Similarly, diffusion of two oppositely charged ions at different speed induces an electric field in the electrolyte, giving migration. The total flux of an ion in an electrolyte is described by the Nerst-Planck equation:

$$
J=-D \Delta c+\frac{z F}{R T} D c \Delta \phi
$$

where $z$ and $c$ the charge and concentration of the ion, respectively, $F$ is Faraday's constant, $R$ is the gas constant and $T$ is the temperature. The first part of the equation describes diffusional flux and the second part describes migrational flux.

\subsubsection{Transport Numbers}

As an electrolyte is composed of two or more types of ions, the total ionic transport through the electrolyte is described by the sum of all individual fluxes. Ions in an electrolyte can have different $z, D, c$, or $\Delta c$, and they therefore contribute differently to the total flux. The transport number defines the fraction of the total flux for a specific ion the electrolyte. For electrolytes containing ions with roughly equal diffusion coefficients (e.g. for $\mathrm{KCl}, D=2.0 \times 10^{-5} \mathrm{~cm}^{2} / \mathrm{s}[14]$ ) and no concentration gradients, the transport numbers for both cation and anion are approximately 0.5. For a $\mathrm{HCl}$-electrolyte, where the diffusion coefficient for $\mathrm{H}^{+}$is significantly larger $\left(D=9.3 \times 10^{-5} \mathrm{~cm}^{2} / \mathrm{s}\right)$ the transport number of $\mathrm{H}^{+}$is higher than for $\mathrm{Cl}^{-}$ $\left(t_{\mathrm{H}^{+}}=0.821\right.$ vs. $\left.t_{\mathrm{Cl}^{-}}=0.179\right)[15$.

\subsection{Ion Selective Membranes}

Membranes are often used to separate electrolytes. Some membranes are non-selective, i.e. all species in the electrolytes can pass freely (Figure 3.3a), while others offer higher permeabeability to specific species [16]. An IEM, 


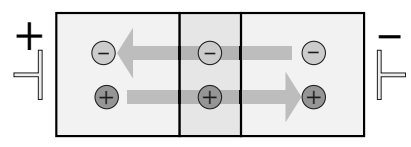

(a) Neutral membrane

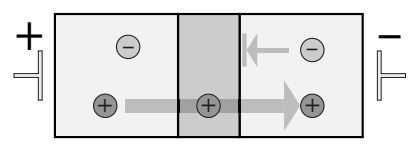

(b) CEM

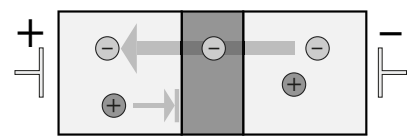

(c) AEM

Figure 3.3: Migrational transport through a (a) non-selective membrane, a (b) CEM and an (c) AEM. In the IEMs, ions are blocked or let through based on their polarity.

separating two electrolytes, offer higher permeabeability for ions with certain charge to cross between the electrolytes, i.e. is either a cation exchange membrane (CEM) (Figure 3.3b) or an anion exchange membrane (AEM) (Figure 3.3c). The ion selectivity in an IEM often arises from fixed ion charges in the membrane in the form of a polyelectrolyte. Commonly used fixed charge groups are the negatively charged sulfonate group and the positively charged quaternary amine group (Figure 3.4 [17.<smiles>[R17]S(=O)(=O)[O-]</smiles>

(a) Sulfonate<smiles>[R2][N+]([R1])([R])[ClH+]</smiles>

(b) Quaternary amine

Figure 3.4: Common (a) negative and (b) positive fixed charged groups in polyelectrolyte-based IEMs

The non-fixed ions in the membrane are called mobile ions, and are either of same charge (co-ions) or opposite charge (counter-ions) to the fixed charges. Local electroneutrality dictates that the sum of ionic charges should be zero. The fixed charges are therefore compensated by an equal amount of counter-ions from the electrolyte. At the same time, the fixed charges repel the similarly charged co-ions. This creates an unequal distribution of co-ions and counter-ions in the membrane; there are more counter-ions than co-ions. The fraction of counter-ions in an IEM can be calculated based on the fixed 
charge concentration $X$ and external electrolyte concentration $c_{s}$ :

$$
\frac{c_{\text {cou }}}{c_{\text {cou }}+c_{\text {co }}}=1 / 2+\frac{1}{4 \sqrt{1 / 4+\left(c_{s} / X\right)^{2}}}
$$

where $c_{c o u}$ and $c_{c o}$ are the counter- and co-ion concentration in the membrane, respectively 18. For a membrane with $X=1 \mathrm{M}$ and $c_{s}=0.1 \mathrm{M}$, the counterion fraction is $\sim 99 \%$ of the total amount of mobile ions.

The concentration difference increases the counter-ion transport number and decreases the co-ion transport number as compared to a free electrolyte. As the fixed charges in the membrane cannot move, an ionic current through the membrane is carried by the mobile ions, and predominantly by the counter-ions as they have higher concentration, i.e. the membrane is selective to counter-ions. The selectivity will depend on concentration of fixed charges in the membrane, surrounding electrolyte concentration, and magnitude off the ionic current through the membrane [16]. Typical highly charged IEMs have fixed charge concentrations of $1-3 \mathrm{M}$ and counter-ions account for 95-99\% [19] of the current, while for less charged membranes the selectivity drops.

\subsubsection{Donnan Potential}

When an IEM is in contact with an electrolyte, there will be a concentration gradient for both counter- and co-ions between the membrane and the electrolyte; the concentration of counter-ions is (typically) higher in the membrane than in the electrolyte and vice versa for co-ions 18 . This leads to counter-ions and co-ions striving to diffuse out of and into membrane, respectively, and bending the concentration profiles near the interface. The movement of ions charges the interface, giving an electric field that opposes the diffusion (Figure 3.5a). The produced potential drop over the membrane interface is called the Donnan potential and is described by:

$$
\varphi_{\text {Don }}=\frac{R T}{z F} \ln \frac{c^{s}}{c_{\text {cou }}}
$$

where $z$ and $c^{s}$ is the charge and electrolyte concentration of the counter-ion.



(a) Donnan potential

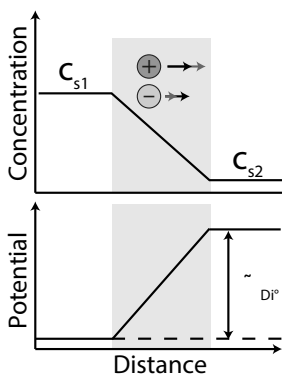

(b) Junction potential

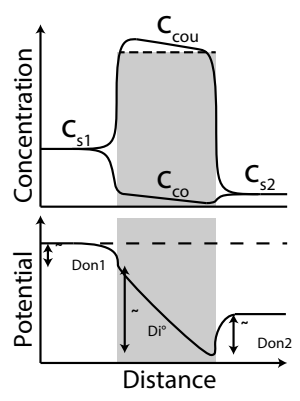

(c) Membrane potential

Figure 3.5: Potentials arising across a (cation-selective) membrane. 


\subsubsection{Junction Potential}

If a concentration gradient exists in an electrolyte (e.g. if a membrane separates two electrolytes of different concentrations) ions will diffuse from higher to lower concentrations [18. Under zero-current conditions, i.e. when no net-charge is transported through the membrane, the flux of cations and anions need to be equal to maintain electroneutrality. Therefore, the flux of an ion with higher diffusion coefficient cannot be larger than for its counter-ion. This creates a potential difference along the concentration gradient that opposes the diffusion of the faster ion (Figure 3.5b). This potential is called the junction or diffusion potential and is described by:

$$
\varphi_{\text {diff }}=\left(t_{-}-t_{+}\right) \frac{R T}{z F} \ln \frac{c^{s_{2}}}{c^{s_{1}}}
$$

where $t_{-}$and $t_{+}$are the transport numbers of the anion and cation in the electrolyte and $c^{s_{1}}$ and $c^{s_{2}}$ are electrolyte concentrations. For a $\mathrm{HCl}-$ electrolyte, with $t_{+}=0.821$ and $t_{-}=0.179$, this gives $\varphi_{\text {diff }}=-38.0 \mathrm{mV}$ per decade of $c^{s_{2}} / c^{s_{1}}$ at $25^{\circ} \mathrm{C}$, while for $\mathrm{KCl}\left(t_{+}=0.4906, t_{-}=0.5094\right)$ $\varphi_{\text {diff }}=+1.1 \mathrm{mV}$ per decade 15 .

\subsubsection{Membrane Potential}

In total, three potentials exist across a membrane separating two electrolytes; two junction potentials, at either side of the membrane, and one diffusion potential across the membrane (Figure 3.5c [18]. The sum of these potentials can be measured using electrodes immersed into the electrolytes, and is called the membrane potential:

$$
\varphi_{m}=\varphi_{\text {diff }}+\varphi_{D o n^{2}}-\varphi_{D o n^{1}}
$$

If the electrolyte has similar diffusion coefficient for both anions and cations (as for $\mathrm{KCl}$ ) the membrane potential is approximately reduced to two Donnan potentials. These are dependent on electrolyte concentrations, and can for an ideal membrane be written as:

$$
\varphi_{m}=\frac{R T}{z F} \ln \frac{c^{s_{1}}}{c^{s_{2}}}
$$

The membrane potential is related to the transport number of the membrane 20]:

$$
\varphi_{m}=\left(2 t_{\text {cou }}-1\right) \frac{R T}{z F} \ln \frac{c^{s_{1}}}{c^{s_{2}}}
$$

Thus, transport numbers inside a membrane can be calculated from measurements of the membrane potential. For example, an ideal IEM with $t_{\text {cou }}$ $=1$ yields a $\varphi_{m}$ of $+17.8 \mathrm{mV}$ at $25^{\circ} \mathrm{C}$ when immersed between two $\mathrm{KCl}$ electrolytes with $c^{s_{1}} / c^{s_{2}}=2$, while a less selective membrane with $t_{c o u}=$ 0.8 gives $+10.7 \mathrm{mV}$.

\subsubsection{Concentration Polarization}

When a current is applied across an IEM the difference in transport number for counter-ions and co-ions results in more counter-ions passing through 


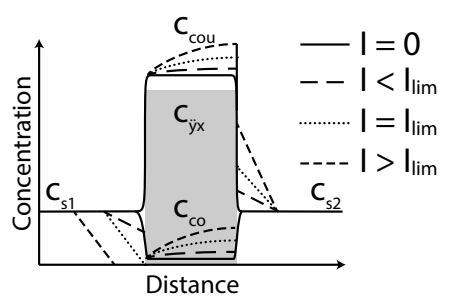

Figure 3.6: Concentration polarization across an IEM

the membrane than co-ions in the opposite direction. This gives rise to concentration polarization across the membrane [21]. At the feeding side of the membrane, this results in a lower ion concentration (compared to the bulk electrolyte), as counter-ions and co-ions move in opposite directions away from the membrane interface (Figure 3.6). At the opposite side, there is a corresponding increase in ion concentration. The concentration gradients become more pronounced with the applied current, i.e. lower/higher concentration at the interface and reaching farther out from the membrane. For a specific current level, the limiting current $\left(\mathrm{I}_{\mathrm{lim}}\right)$, the concentration at the feeding interface approaches zero. For current levels above $I_{\lim }$ the zero-concentration point moves farther out and introduces an additional potential loss [22]. Thus, the resistance of the IEM] differs below and above $\mathrm{I}_{\lim }$

\subsection{Bipolar Membranes}

A $\mathrm{BM}$ is constructed by layering two IEMs of opposing polarity (i.e. one CEM and one AEM Figure 3.7a. Frilette studied this structure in 1956 by pressing two commercial oppositely charged membranes, and he observed asymmetric behavior depending on the applied voltage polarity 23. The two oppositely charged IEMs, with fixed charge concentration $c_{f i x}$ and $c_{f i x+}$, defines two regions where either cations or anions are counter-ions and majority mobile species $\left(c_{+}\right.$and $\left.c_{-}\right)$and the respective co-ions $\left(c_{-}\right.$



(a) Sandwiched structure

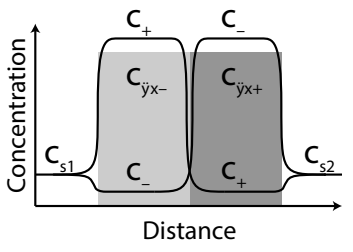

(b) Concentration profile

Figure 3.7: (a) Structure of a $\mathrm{BM}$ with a $\mathrm{CEM}$ (medium grey) and an $\mathrm{AEM}$ (dark grey) region. The interface can either be well-defined or with a neutral layer inbetween. (b) The concentration profile of a BM shows two regions with opposite mobile charge concentrations. 


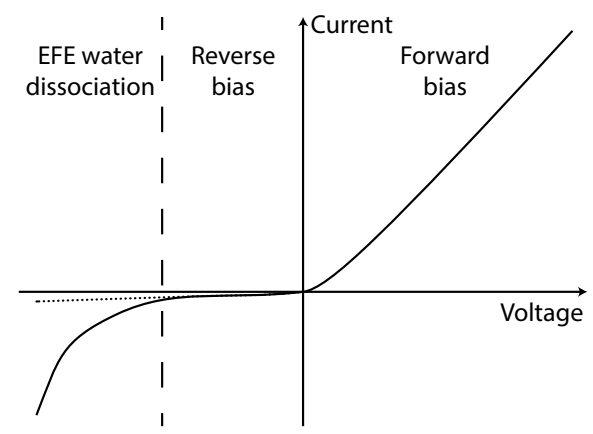

Figure 3.8: Typical current-voltage profile for a $\mathrm{BM}$ with (solid line) and without (dotted line) EFE water dissociation.

and $c_{+}$, respectively) are repelled (Figure 3.7b $[24]$. Thus, the majority mobile species in one region cannot easily enter the next. The area where the ion selectivity changes is called the junction of the BM. In some BMs there is a neutral region situated in the junction, separating the two IEMs (Figure 3.7a). This region can either be intentionally included or a defect caused by the fabrication of the BM.

Unlike monopolar membranes, the mechanism for ionic transport in a BM will vary depending on the ion current's direction, i.e. on the voltage bias applied across the BM. In general, three bias regimes are defined for BMs forward bias, reverse bias, and electric field enhanced (EFE) water dissociation regime. These regimes give BMs a distinct current-voltage profile (Figure 3.8 24.

\subsubsection{Forward Bias Regime}

In the forward bias regime, a positive voltage is applied at the CEM side of the BM vs. the AEM side. This enables mobile counter-ions on both sides of the $\mathrm{BM}$ to migrate towards the middle of the BM (Figure 3.9a). Additional counter-ions can enter the BM from either side of the BM. Thus, in the forward bias regime an ionic current, composed of anions and cations on either side of the BM. can flow in through the BM. The main voltage drop in the forward bias is due to the bulk resistance of the IEMs, and the current (below $\mathrm{I}_{\mathrm{lim}}$ is therefore expected to be linearly dependent on the applied voltage (Figure 3.8).

\section{Ion accumulation and co-ion crossing}

Counter-ions reaching the zone where the polarity of the $\mathrm{BM}$ changes cannot easily continue migrating in the electric field as they then become co-ions. This causes an accumulation of ions inside the junction [25], as illustrated in Figure 3.9b However, selectivity of an IEM is dependent on the surrounding ion concentration Equation 3.3. As ions accumulate at the junction, co-ion transport increases and ions start to cross the BM 25] (Figure 3.9c). A large neutral region inside a $\mathrm{BM}$ lowers the ion concentration and delays the onset for co-ion transport. 


\subsubsection{Reverse Bias Regime}

Reversal of the applied bias over the $\mathrm{BM}$ has a major impact on the ion transport process through the BM] as this reverses the migration direction of the two counter-ions in the system. The counter-ions will thus move from the junction towards either end of the BM Figure 3.10a. As the amount of ions in the junction is finite and only a small flux of new ions can be supplied to the junction by co-ion migration, the ion concentration in the junction will decrease. Eventually, the low ion conductivity in the junction, due to the low ion concentration, limits the current through the BM. The main potential drop then occurs across the BM junction. As in the forward bias regime, the reverse bias current through the BM will approximately be linearly dependent on the applied voltage, but with a higher resistance than observed in the forward bias regime as the transport is dependent on co-ions (Figure 3.8).

\section{Ion accumulation hysteresis}

The process of changing a BM from forward bias to reverse bias regime includes depleting the junction of ions, and is thus dependent on the amount of ions stored in the junction (figures $3.10 \mathrm{~b} 3.10 \mathrm{~d}$ ). For a junction where high ionic charge can be stored without inducing significant co-ion leakage, e.g. if a neutral layer is present inside the BM the amount of ions that need to be extracted to reach the reverse bias regime vs. the amount of ions injected during forward bias can reach close to $100 \%$ [26]. This causes a delay in the forward bias/reverse bias transition of the BM as the charge needed to switch from forward bias to reverse bias is dependent on the charge inserted into the BM during forward bias.

\subsubsection{Rectification}

The ability of a $\mathrm{BM}$ to rectify an ionic current, i.e. work as a diode and conduct better in the forward bias regime than the reverse bias regime, primarily originates from the difference in concentration in the junction between the two regimes. The current, and the rectification, through the BM is thus primarily dictated by the conductivity of the bulk of the IEMs in the forward bias regime and by the conductivity of the junction in the reverse bias regime. If co-ion transport in the $\mathrm{BM}$ is zero, the minimum conductivity of a $\mathrm{BM}$ in the reverse bias regime is dictated by the presence of protons and hydroxide ions due to self-ionization of water. This equilibrium reaction splits a water molecule into a proton and a hydroxide ion $\left(\mathrm{H}_{2} \mathrm{O} \rightleftharpoons \mathrm{H}^{+}+\mathrm{OH}^{-}\right)$ and gives $10 \times 10^{-7} \mathrm{M}$ of protons and hydroxide ions at $\mathrm{pH}$.

\subsubsection{Electric Field Enhanced Water Dissociation}

A commonly observed phenomenon in BMs is that in the reverse bias regime, over a certain threshold voltage, the conductivity increases dramatically and non-linearly with voltage [27]. This gives a clear deviation from the low current reverse bias regime (Figure 3.8). At the same time $\mathrm{pH}$ changes are observed at the ends of the BM the CEM side turns acidic and the 


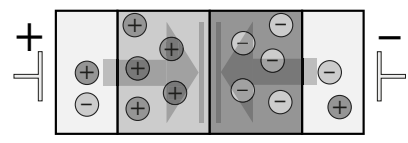

(a) Forward bias

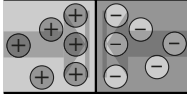

(b) Accumulation

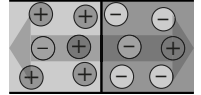

(c) lon crossing

Figure 3.9: (a) lon motion in a BM during forward bias, and subsequent (b) accumulation of ions and (c) co-ion crossing the BM due to high ion concentration.

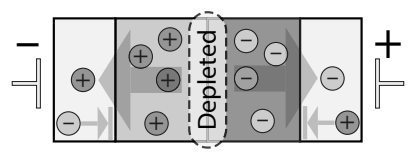

(a) Reverse bias


(b) Accumulated junction

(c) Ion extraction

(d) Depleted junction

Figure 3.10: (a) lon motion in a $\mathrm{BM}$ during reverse bias. If ions have (b) accumulated in the junction, these ions must to be (c) extracted before the junction is (d) depleted.

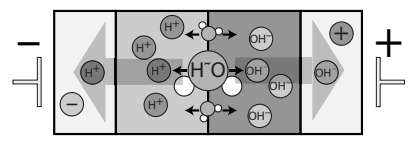

Figure 3.11: $E F E$ water dissocation. Water molecules in the $\mathrm{BM}$ juinction are split up into water ions, i.e. $\mathrm{H}^{+}$and $\mathrm{OH}^{-}$. 
AEM side alkali. This process, commonly called EFE water dissociation 1 is attributed to an increased transport of $\mathrm{H}^{+}$and $\mathrm{OH}^{-}$from the junction at a rate not explained by water self-ionization (Figure 3.11). EFE water dissociation has not only been observed for reversed biased BMs but also for IEMs, primarily anion-selective, above the $I_{\text {lim }}$ density where an ion depleted zone is produced at the feeding side of the membrane 21.

\section{The chemical reaction model}

The mechanism for EFE water dissociation is not fully understood, but, as the name implies, the electric field is a main driving factor. In the chemical reaction model the increased water dissociation is attributed to a combination of the electric field and protonation-deprotonation reactions between catalytic species in the membrane and water molecules 24]. The local electric field across a depleted BM can be in the order of $10 \times 10^{8}-10 \times 10^{9} \mathrm{~V} / \mathrm{m}$, and is thought to increase the forward reaction rate of water ionization [24]. Additionally, in the presence of a weak base (B) the following mechanism can occur 28]:

$$
\begin{aligned}
\mathrm{B}+\mathrm{H}_{2} \mathrm{O} & \rightleftharpoons \mathrm{BH}^{+}+\mathrm{OH}^{-} \\
\mathrm{BH}^{+}+\mathrm{H}_{2} \mathrm{O} & \rightleftharpoons \mathrm{B}+\mathrm{H}_{3} \mathrm{O}^{+}
\end{aligned}
$$

where the net reaction produces one $\mathrm{OH}^{-}$and one $\mathrm{H}_{3} \mathrm{O}^{+}$(i.e. $\mathrm{H}^{+}$) from one water molecule. In the AEM of a BM the weak base can be a tertiary amine. Similar mechanisms can be written for other types of catalytic groups, such as acids in a CEM or metal complexes, in the BM or for monopolar membranes.

\section{Avoiding EFE water dissociation}

EFE water dissociation is used in industrial applications to produce acids and bases [29], and it is therefore commercially interesting to develop membranes and catalysis groups for efficient EFE water dissociation 30, 31. There are fewer reports on how to lower the EFE water dissociation. It has however been shown that AEMs composed of only quaternary amines and no tertiary amines does not produce the EFE water dissociation effect as long as the quaternary amines are not degraded to tertiary [32. Non-amine based membranes, formed by immobilizing alkali ions to crown ethers, also show no EFE water dissociation [33. A neutral layer inside the BM can also reduce the EFE water dissociation, as this increases the distance over which the potential drop occurs and thus lowers the electric field 3436 .

\subsection{Electrodes in an Electrolyte}

When an electrode is immersed into an electrolyte, electrons in the electrode and ions in the electrolyte interact. An electric potential difference between electrode and electrolyte will cause the formation of a polarized region along

\footnotetext{
${ }^{1}$ The term "water splitting" is also often used to describe this phenomena, but is easily confused for the electrochemical reaction that can occur at an electrode immersed in aqueous electrolyte.
} 


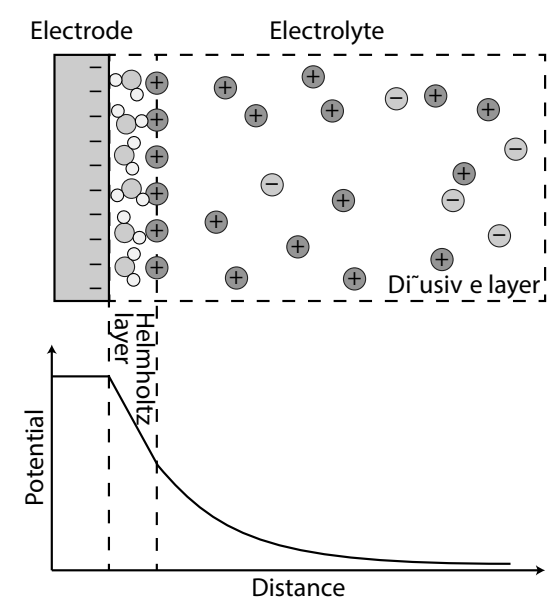

Figure 3.12: An EDLformed outside of a negatively charged electrode. The negative charges on the electrode are compensated by cations in the Helmholtz layer, and an altered ion concentration profile in the diffusive layer.

the electrode-electrolyte interface called the electric double layer (EDL) 15. The EDL consists of electric charges along the surface of the electrode compensated by an excess of oppositely charged ions outside of the electrode, i.e. a rearrangement of ions outside of the electrode (Figure 3.12).

In the Coüy-Chapman-Stern model, the electrolyte outside the electrode is divided into two layers: the Helmholtz layer and the diffuse layer. In the Helmholtz layer, the electronic charge on the surface of the electrode is compensated by oppositely charged ions that approach the electrode surface as close as possible and approximately at equal distance, forming the Helmholtz plane. The distance from the surface to the Helmholtz plane is dependent on the size of the ions, also taking in account their hydration shell. Due to the charge separation in the Helmholtz layer, which forms two oppositely charged planes with a small and well-defined separation, the potential drop across the Helmholtz layer is linear and steep.

The diffuse layer is located outside the Helmholtz layer and differs significantly from the Helmholtz layer in that it is composed of a gradient distribution of both anions and cations extending farther out into the electrolyte. In the diffuse layer, the electrode charge is compensated by an excess of oppositely charged ions and a shortage of same-charge ions (relative to the undisturbed bulk of the electrolyte). Compared to the Helmholtz layer, the potential drop in the diffuse layer extends farther out from the electrode and has en exponential decay.

By application of a potential between the electrode and the electrolyte (through a second electrode in the electrolyte), the charge of an EDL can increase, decrease, or change polarity. Charging of an EDL has a capacitive nature and the current associated with building up the EDL is thus called a capacitive, or non-Faradic, current. If no electrochemical active species are present in the electrolyte, or if the applied potential is lower than the 
decomposition potential of the available species so that no electrochemical reaction can take place, no further current will flow through the systems once the EDL is fully formed. Such electrode is said to be polarizable within this potential range.

An EDL will also form if electrochemical active species, with decomposition potential inside the applied potential, are present. The electrochemical reactions at the electrode, for example electrolysis of water, will give rise to an additional, Faradic, current. The Faradic current can be maintained even after the decay of the capacitive current. As the electrochemical reaction only occurs close to the electrode surface, and the reaction consumes available active species in this region, the Faradic current is often limited by diffusive transport of active species from the bulk electrolyte towards the electrode. 


\section{Chapter 4}

\section{Amyloids}

Rudolph Virchow coined the term amyloid in 1854 to describe abnormal deposition found in tissues after staining with iodine [37]. The deposits were believed to contain starch, so the word amyloid, derived from the Greek word for starch, amylon, was used as the term for these structures. The content of amyloids were later discovered to not be starch but entirely represented by proteins. Amyloids are found in tissue samples from patients suffering from a variety of diseases. This lead to a classification of amyloid-related diseases based on the localization of the amyloid deposit [38]. Localized amyloidosis is organ or tissue specific, such as to the brain or heart. If the amyloid are not localized to a specific organ it is a systematic amyloidosis, i.e. amyloids are affecting a larger part of the body.

Further, specific proteins were found to generate the structural elements of the amyloids occurring in specific diseases. This lead to a second classification of the amyloids, which is based on the assigned protein included. Numerous diseases causing dementia are coupled to proteins that forms amyloid deposits in the brain [39], for example the amyloid beta $(\mathrm{A} \beta)$ peptide in Alzheimer's disease and the Alpha-synuclein peptide in Parkinson's disease. Due to the projected burden on society for care taking of the increasing amount of people suffering of dementia and similar diseases as life expectancy increases 40], understanding, preventing, and curing amyloid related diseases is an important and active research topic today.

\subsection{Amyloid Composition and Structure}

The morphology of an amyloid can be stepwise divided into a macroscopically amorphous deposit (plaque), typically 1-100 $\mathrm{m}$ in size, containing highly ordered nm-sized fibrils, that are composed of protein chains that have adopted a specific structure in the sub-nm domain (Figure 4.1).

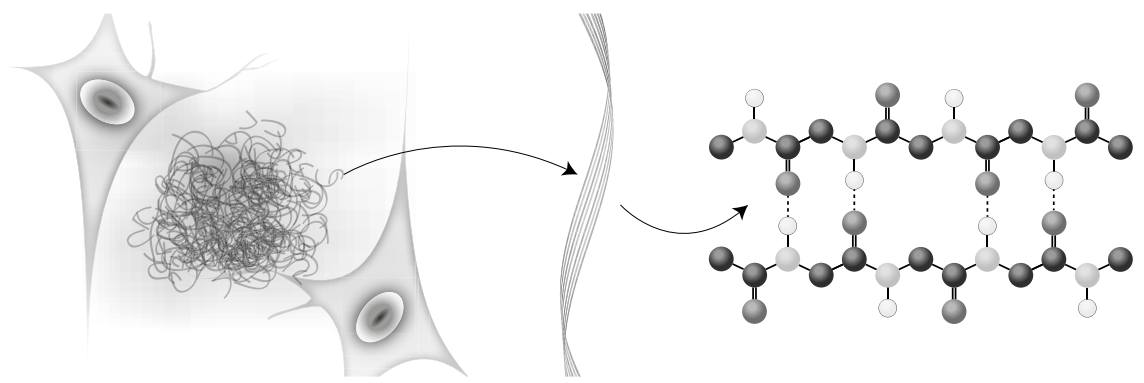

Figure 4.1: Morphology of an amyloid. The plaque (surrounded by neuron cells) has a fine fibrillar structure containing protein chains. 


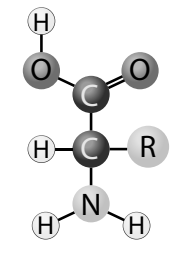

(a) Amino acid

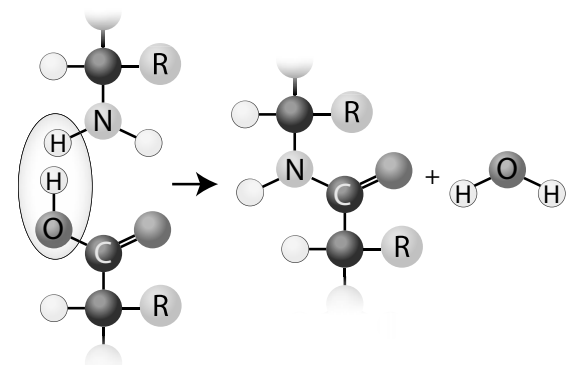

(b) Peptide bond

Figure 4.2: (a) Structure of a generic amino acid and (b) formation of a peptide bond between two amino acids through a condensation reaction. $R$ represens the amino acid side chain.

\section{Proteins}

Proteins are biological macromolecules present in all living cells and organisms. They serve a range of important functions such as catalyzing chemical reactions (enzymes), mediating intra- and extracellular signaling, or providing structural properties [41]. The building blocks of a protein are the amino acids Figure 4.2a). These contain a carboxylic acid, an amine, and a side chain. The composition of the side chain defines the nature and function of the amino acids. Amino acids are joined through peptide bonding to form short (i.e. peptides) or long (i.e. proteins) polymer chains (Figure 4.2b).

Proteins are synthesized by cell ribosomes, using the genetic code of DNA, to yield well-defined sequences of amino acids in the chain. The sequence of the amino acids is the primary structure of the protein (Figure 4.3a). Local secondary structures, such as $\alpha$ helixes (Figure 4.3b), $\beta$ sheets (Figure 4.3c), and turns, are formed through interaction between amino acids at different locations in the chain. The secondary structures, together with other nonlocal interactions between specific amino acids, define the tertiary structure, or fold, of the protein (Figure 4.3d). Multiple folded peptides can associate to form a quaternary structure. Some proteins do not adopt well-defined secondary or tertiary structures, but instead show a random-coil structure in their native state.

\section{Structure of proteins in amyloids}

In an amyloid, the folded or random-coiled protein has lost its native fold and/or function, and instead adopt a new, amyloid specific, fold 43]. This fold will vary by the nature of the protein and also by the microenvironment conditions. But, a key feature is a typical increase in $\beta$ sheet or single $\beta$ strand secondary structures (Figure 4.4). A second key feature of amyloids is the association of $\beta$ sheets or $\beta$ strands between proteins, yielding an extended $\beta$ sheet structure perpendicular to the $\beta$ strand direction. Such structures are called protofilament, and a bundle of protofilaments builds up the final fibril structure. Thus, the typical amyloid fibril appearance, with 


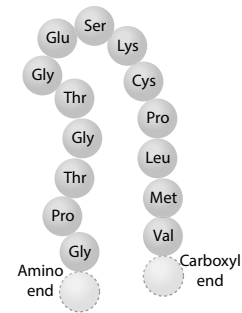

(a) Primary



(b) $\alpha$ helix

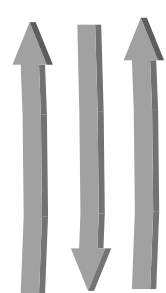

(c) $\beta$ sheet

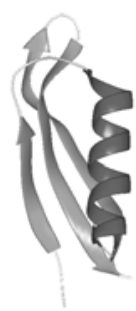

(d) Tertiary

Figure 4.3: (a) Primary, (b-c) secondary, and (d) tertiary structure of a protein. Data for tertiary structure obtained from Kong et al. [42].

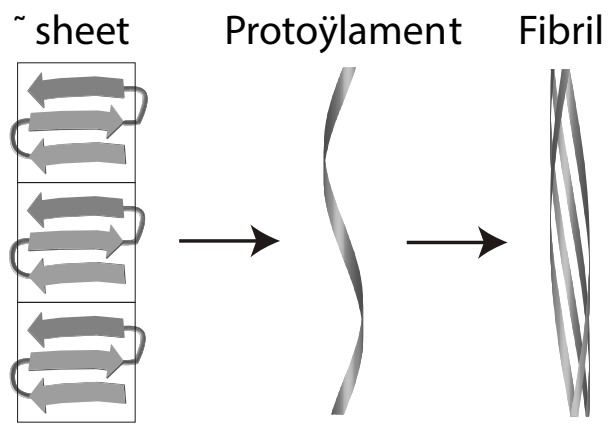

Figure 4.4: An extensive protein $\beta$ sheets structure forms protofilaments, a subunit in a amyloid fibril.

lengths in the range of $\mu \mathrm{m}$ and widths of tenths of $\mathrm{nm}$, originates from long, often parallel, $\beta$ sheets, where the individual $\beta$ strands are short. Due to the rich $\beta$ sheet structure the formed supramolecular assembly shows high stability.

\subsection{Fibrillogenesis}

Fibrillogenesis is the formation of fibers from its monomeric part, i.e. proteins, 44] and can be studied in vivo or, experimentally simpler, in vitro 45]. The specific molecular pathway to form amyloids differ from protein to protein and is not fully understood or known for all amyloidic proteins. A general pathway with common features can however be described, see Figure 4.5

\section{Nucleation growth}

During in vitro studies of protein conversion into amyloid fibrils, a lag phase followed by a growth phase is typically observed [43. In the lag phase no or little signs of fibrils are found, while during the growth phase fibrils are formed at an exponential rate (Figure 4.6). The cause of the lag phase is widely established to be the formation of a nucleus [43]. To form nucleus, a folded protein needs to partially unfold and adopt a new structure that has 


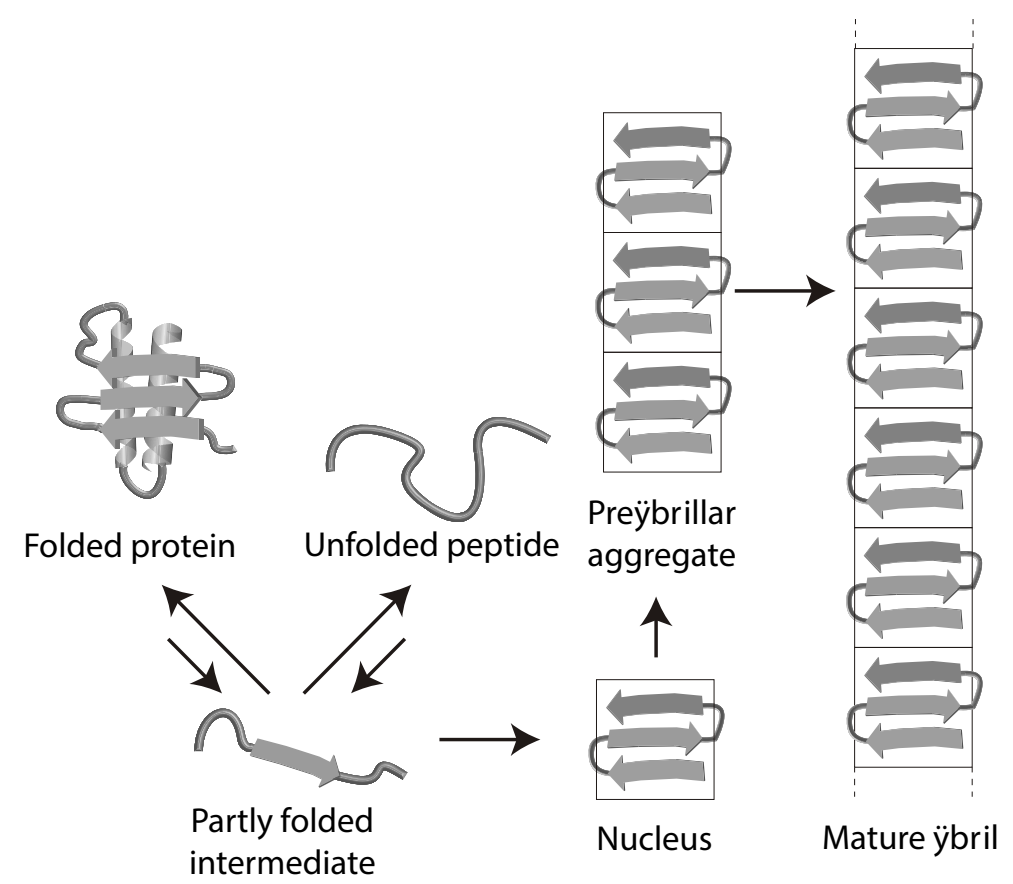

Figure 4.5: Fibrillogenesis, formation of amyloid fibrils from folded or unfolded protein chains, is a stepwise process.

some propensity to later form the $\beta$ sheets. Similarly, a natively unfolded peptide needs to acquire such intermediate fold through partial folding. The rate of formation for the nucleus is typically slower than the elongation rate of the fibril [46], and this causes the lag phase. The lag phase can be shorten or removed by using conditions that increase the rate of nucleus formation or by adding preformed growth phase fibrils already containing nucleuses ("seeding") 47.

\section{Prefibrillar aggregates}

In the lag phase oligomers and/or protofibrils ${ }^{1}$ are typically observed [48]. Oligomers are often nm-sized spherulites and may or may not bear resemblance to the structure found in the mature fibrils. Protofibrils of $\mathrm{A} \beta$ on the other hand contain $\sim 20$ monomers and show extensive $\beta$ sheet structure. Protofibrils are highly cytotoxic, more so than mature fibrils, and might thus be the primary cause of the neurodegenerative damage observed in amyloid dementia diseases 49 .

\section{Mature fibrils}

After nucleation, either by formation of oligomers or protofibrils, longer assemblies are formed by elongation with monomeric or oligomeric proteins [50]. The growing amyloid fibers can also combine with each other to form bundles.

\footnotetext{
${ }^{1}$ Should not be confused with protofilament, which is a more "mature" structure.
} 


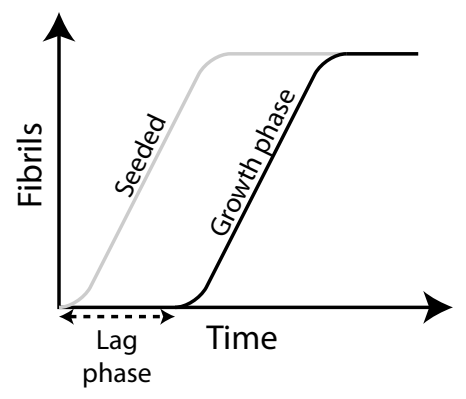

Figure 4.6: Typical kinetics for amyloid aggregation, showing a lag phase followed by a growth phase. By seeding the lag phase can be shortened.

The end result of this process is mature, insoluble fibers. In vivo, the fibers clump together to form plaques.

\subsection{Factors for Amyloid Formation}

Due to the wide diversity of amyloid forming proteins and the lack of correlation between primary and secondary structures for these proteins, it has been suggested that the ability to form amyloid aggregates is a general property of the polypeptide chain originating from its polymer nature, and not specific for certain amino acids or sequences [51,52]. Nevertheless the formation of amyloids is (for most proteins) an abnormal function of the protein. Instead, certain factors can increase the likelihood or formation rate. Common factors important for the formation of amyloid aggregates, both in vivo and in vitro, are protein concentration [53], protein stability [54], and chemical (micro)environment [55].

In most inherent amyloid diseases mutations are found that destabilizes the protein and/or renders it more prone to form the initial amyloid structures. Several such mutations exist for Alzheimer's disease [56], where for example mutations in the cleavage sites of the $\mathrm{A} \beta$ precursor peptide changes the ratio of $\mathrm{A} \beta(40)$ to $\mathrm{A} \beta(42)$ fragments produced. As $\mathrm{A} \beta(42)$ is more aggregationprone than $\mathrm{A} \beta(40)$ these mutation, that gives an increase in $\mathrm{A} \beta(42)$, are more likely to cause Alzheimer's disease.

Chemical factors known to affect the formation of amyloid aggregates are for example $\mathrm{pH}$ [57, ionic strength [51], and presence of specific ions such as $\mathrm{Zn}^{2+}[58]$ or $\left.\mathrm{Cu}^{2+} 59\right]$. Also, the presence of shear flow can induce aggregation 60 .

\subsection{Pathogenesis}

The pathogenesis, i.e. the disease mechanism, for amyloid-related diseases shows significant variation depending on the protein and the aggregation location. Common themes can however be distinguished, primarily based on the localization of the aggregation, i.e. if the disease is systematic or local and, if local, to what organ. 


\subsubsection{Neurophatic Amyloid Diseases}

For amyloid-caused diseases occurring in the brain, such as Alzheimer's and Parkinson's, the observation of mature, highly organized, and fibrillar aggregates initially lead to the theory that the presence of aggregates was the causative agent for the observed loss of neurons and synapses. Further, A $\beta$ fibrils were found to be toxic to cultured neural cells [61] and cause neuronal damage when injected in monkeys 62. Later studies have shown that the characteristics of Alzheimer's disease is better correlated to the existence of prefibrillar species of $\mathrm{A} \beta$ such as oligomers and protofibrils, than the formation of mature plaques [4]. The recent focus for research on Alzheimer's and other amyloid diseases has therefore shifted to understanding the neurotoxic nature of these smaller aggregates 63.

Although not yet fully understood, one likely explanation for the toxicity of these prefibrillar species is the non-native folds they expresses, which will present chemical and structural motifs normally only found inside folded proteins [48]. These non-native structures can be expected to cause abnormal interactions with surrounding environments, such as with the membranes, other proteins, and intra- and extracellular components. These interactions might cause functional failure of the associated component or trigger a chain of protective events and reactions, eventually leading to cell damage or apoptosis. As smaller aggregates have relatively more exposed surface than mature fibrils the former are expected to be more toxic.

\subsubsection{Non-Neurophatic and Systematic Amyloid Disease}

For localized amyloid diseases found in other tissues than the brain, and for systematic diseases, the pathogenicity of prefibrillar species is less evident and the disease is often attributed to large amount of amyloid deposits. The amount of deposits for some systematic amyloid diseases can sometimes be in the kilogram-range [64, and is thus highly likely a main factor for pain, tissue damage, and organ failure.

\subsubsection{Functional Amyloids}

Additionally to the diseases that amyloids most often are associated with, it should also be noted that the formation of amyloid aggregates sometimes have beneficial effects. Examples include the membrane protein Pmel1, for which the amyloid form is involved in pigmentation of the skin [65], and storage of protein hormones in form of amyloid-like structures [66].

\subsection{Detection Methods}

The fine fibrillar structures of amyloids can be studied at high resolution using microscope techniques such as atomic force microscopy [67] or transmission electron microscopy 68. These techniques can be used to characterize the morphology of the fibers down to the nm-scale. For finer resolution details, and in order to determine the arrangement of the protein chains within the fibers, X-ray diffraction 69 or solid-state nuclear magnetic resonance 70 are used. 
Optical probes that exhibit a change in optical properties in the presence of amyloid fibrils or protofibrils have also been described [71]. These probes are typically insensitive to the nature of the amyloid deposit, i.e. the constituting protein or environment the amyloid was formed, and are instead specific for some general property of amyloid fibrils, such as extended $\beta$ sheets. The traditional detection method for amyloid aggregates is staining with the dye Congo red (Figure 4.7a. Congo red binds to amyloid fibrils 72 , and can be detected as a green birefringence when viewed with microscope under cross-polarized light. Another widely used optical probe is thioflavin (ThT) Figure 4.7b, which when bound to fibrils shows enhanced blue-green fluorescence $[73]$.

A novel approach is to use synthetic luminescent conjugated polymers (LCPs) or luminescent conjugated oligomers (LCOs) such as pentamer formyl thiophene acetic acid (p-FTAA) (Figure 4.7c), as fluorescent probes for amyloid detection $[74]$. These can be synthesized with specificity for binding to amyloid fiber structures. When bond to a $\beta$ sheet-containing fiber the backbone of the probe molecule adopts a conformation that increases the conjugation length. This changes the fluorescent properties of the probe, and

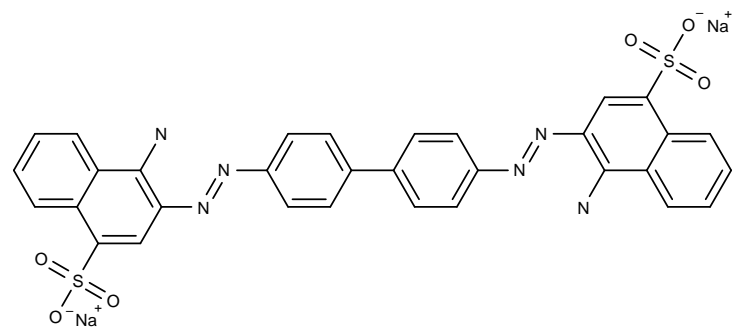

(a) Congo red<smiles>Cc1ccc2c(c1)SC(=C1C=CC(=[N+](C)C)C=C1)N2C</smiles>

(b) ThT<smiles>[NH3+]OC(=O)Cc1cc(-c2ccc(C(=O)O[Na])s2)sc1-c1ccc(-c2sc(-c3ccc(C(=O)O[Na])s3)cc2CC(=O)O[Na])s1</smiles>

Figure 4.7: Optical probes for amyloid detection. 
an enhanced fluorescent emission and a longer peak wavelength is observed. Such probes have increased sensitivity to detect the early stages in amyloid fibrillogenesis as compared to ThT 75]. A library of different LCOs, with different fluorescent spectra and amyloid specificity, can also be used to

distinguish between different types of amyloid aggregates 76 .

\subsection{Amyloids as Nano-Structural and Functionalized Material}

Due to its stable and ordered nature, high aspect ratio structure, and possibilities for chemical functionalization, the amyloid fibril motif has raised interest as an advanced building material 77. for nano-devices 78. For example, amyloid fibers can be coated with metals and used as nm-sized conducting wires 79, with CPS to create electrochemically active wires for transistors [80], or with conjugated polyelectrolytes to form fluorescent wires 81.

Patterning, a crucial step for manufacturing complex devices and circuits, of amyloid fibrils can be performed through lithographic patterning of biotinavidin-motifs and selective attachment of fibers through peptide anchors attached to the biotin 82 .

\subsection{Lab-on-a-Chip Technology in Amyloid Research}

Lab-on-a-chip technology aims at producing miniaturized highly controlled and detectable reactions for life science and chemical applications. In such applications, microfluidic channels are typically used to deliver and mix reagents, and sensors can be incorporated to measure relevant chemical or biological events. Small volumes, high throughput, and high sensitivity allow lab-on-a-chip devices to be useful tools for drug discovery [83] as well as a general technique within life science [84]. Lab-on-a-chip systems have also been used for amyloid research to, for example, miniaturize and control aggregation 85 87], study the effect of metal ions and drugs 87, 88], study kinetics [89, and test toxicity of fibrillar species on cultured cells [90, 91].

But as amyloid fibrillogenesis can be influenced by shear flow $|60|$ the use of microfluidic flows to induce, control, or maintain a fibrillation process might be problematic. For example, the morphology of insulin aggregates formed in a microfluidic channel was found to be dependent on the flow rate, where low flow rate produced spherulites and high flow rate resulted in more fibrillar structures [92]. The use of non-fluidic delivery devices is therefore attractive to, with control, stimulate the formation of amyloid structures by creating a suitable chemical environment without an associated flow 93 . 


\section{Chapter 5}

\section{Organic Bioelectronics}

Ions are ubiquitous in living organisms - the aqueous environment in and around cells is a complex electrolyte. Cells are constantly pumping ions across their membrane to create the concentration gradients that produce the membrane potential. Most biomolecules contain acidic or alkali functional groups and can thus be ionically charged depending on $\mathrm{pH}$. For example, signaling in a cholinergic brain synapse is mediated by tightly controlled release, diffusion, and detection of the positively charged molecule acetylcholine $(\mathrm{ACh})[94$.

Because of the importance of ions in biology, one prime advantage in using CPs to interface with biology is the combined electronic and ionic conductivity these materials provide. Combined with an oxide-free interface and strong coupling between ions (as dopant) and the $\mathrm{CP}$ this allows for an intimate interface with the biological milieu [95]. Additional advantages of CPs for bioelectronic applications include their biocompatibility 96 . and softness [97], making them both biologically and mechanically suited for contact with tissues. Further, their organic chemistry allows chemical tailoring by decoration with suitable biomolecules to be more attractive for their intended biological environment [98]. A research field where organic electronic materials are used for bioelectronic applications has therefore developed, called organic bioelectronics 99 .

In this chapter the use of CPS in bioelectronic applications is described. First, the problem of sensing biological events is addressed. Second, various schemes for stimulating biological systems are shown.

\subsection{Sensors}

Sensing of biological signals can be either electronic, i.e. measuring electric potential, or chemical, i.e. measuring the presence of chemical species. Metal electrodes are often used to measure changes in electric potential, for example around neurons as they fire their action potentials [100]. The electrode is then implanted in close proximity to the volume under study, and the potential measured vs. a counter electrode placed further away. By using a 2D or 3D array of electrodes, as in the Michigan 101] or Utah 102 electrodes, neuronal activity can be mapped with high spatial resolution.

However, in vitro implantation of metal electrodes has some challenges, most notably scar formation around the implant 103 resulting in tissue damage and reduced sensor performance. The main cause of scar formation is the large difference in elastic modulus (stiffness) between metals and tissues 103. Softer CP materials have therefore successfully been explored as an alternative to hard metals for use in sensor electrodes 104 and to build arrays of electrodes [105]. A further advantage with $\mathrm{CP}$ electrodes is their 
low impedance, a property that increases measurement quality. Polymer electrodes have also been created in situ in animals by polymerization of the $\mathrm{CP}$ within the physiological environment 106.

In comparison with electrical signals, chemical signals are more specific to a given biological event, due to the uniqueness and vast number of signaling substances present in biological systems. Thus, measuring chemical signals requires some kind of selectivity to the target signal molecule. Often, an electrochemical reaction at an electrode senses the target molecule through oxidation or reduction of the molecule. The recorded current is then correlated to the target molecule concentration. In certain situations, e.g. for measurement of dopamine in certain regions of the brain [107], such a simple arrangement works as the target molecule is the major electrochemically active chemical species present at that location and potential.

In the more general case, chemical specificity is needed in the electrochemical reaction. This is most often achieved by immobilizing an enzyme onto the electrode [108]. Enzymes are protein-based catalysts for specific reactions involving specific molecules. For example, the enzyme glucose oxidase (GOx) catalyzes the oxidation of glucose to form gluconate and hydrogen peroxidase (Figure 5.1). The sensor electrode is then used to electrochemically measure the byproducts of the enzymatic activity, sometimes through additional electrochemically active mediators. By using a $\mathrm{CP}$ electrode, the enzyme, and also mediators, can easily and intimately be combined within the electrode, for example by including these elements during polymer synthesis or by covalent or affinity binding to the polymer 109]. This efficiently traps the enzyme on or in the electrode. This is attractive as the $\mathrm{CP}$ can then function both as a carrier and a signal transducer for the immobilized enzyme. Alternatively, chemical sensing can be obtained by including a binding molecule, such as an antibody or a DNA strand, on a $\mathrm{CP}$ surface and measuring the change in electronic properties as the target molecule binds to the surface [110].

Often, the electronic signal from the sensing electrode is weak and can be hard to detect. Coupling the sensing mechanism to the gate of a transistor can improve the sensitivity. In this way, the recognition of the target molecule at the gate is amplified by the transistor. Organic electronic transistors, either field-effect $\left(\mathrm{OFET}_{\$}\right)$ or electrochemical $\left(\mathrm{OECT}_{\$}\right)$, have successfully been used to improve both sensing of electric potentials and chemical signals [11].

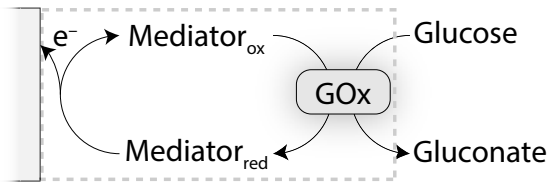

Figure 5.1: Enzymatic sensing with GOx The electron gained by oxidizing glucose is transferred through a redox cycle of a mediator to the electrode. The specificity of GOx ensures that only glucose is sensed. 


\subsection{Actuators}

As with bioelectronic sensing, a wide variety of actuators are needed for stimulation of biological systems to trigger desired signals or events.

\subsubsection{Electronic Stimulation}

Application of a potential at an electrode can trigger membrane depolarization of surrounding cells 112]. The size of the effect and the range of influence is dependent on the potential, but to avoid water hydrolysis, the electrode is typically only used in the polarizable regime, i.e. the voltage range where only a capacitive current due to formation of an EDL is obtained and no electrochemical reactions occur [11. This can become problematic if scar formation around the implanted electrode occurs, as the distance to the target cells increases and the ability to affect those cells might be limited by the potential range of the polarizable regime of the electrode. Further, to increase spatial resolution of a matrix of electrodes, the size of the electrodes must shrink 113]. This puts more demand on the amount of charge to be injected per electrode area, and again the charge obtainable in the polarizable regime of the electrode can be limiting 114 .

Similar to sensing using electrodes, the use of $\mathrm{CP}$ electrodes offers an advantage compared to metal electrodes in their softness, thus decreasing mechanical mismatch between actuator and tissue. Further, $\mathrm{CP}$ electrodes can provide a higher charge injection limit [115], i.e. the amount of charge that can be delivered within the potential region where no adverse effects such as water hydrolysis are observed. To further improve the mechanical match between stimulating electrode and tissue, the $\mathrm{CP}$ can be mixed into a hydrogel 116 .

\subsubsection{Mechanical Actuators}

Electrochemical doping/de-doping of a $\mathrm{CP}$ in an electrolyte is accompanied by the movement of ions between electrolyte and polymer to maintain charge balance 117]. This electronically controlled flux of ions, and the associated water in their hydration shell, can cause volume change and, depending on the geometry, shape change of the CP electrode. Such volume or shape changes are attractive to use for mechanical stimulation of cells $[118$ or for micromanipulation of objects [119].

The mechanism for the volume change due to redox reactions in a $\mathrm{CP}$ can be divided into two cases (Figure 5.2), primarily dependent on the dopant ion species used during synthesis of the polymer 120, 121]. If the polymer is synthesized together with a mobile doping ion species, e.g. small salt ions, these mobile ions can move almost freely in and out of the film during doping or de-doping. As a potential is applied at the $\mathrm{CP}$ electrochemical doping/de-doping of the polymer results in increase/decrease of charges in the $\mathrm{CP}$ accompanied by a flux of ions (and water). When the doping level is increased additional counter-ions move into the polymer, resulting in a volume increase, and vice versa for de-doping.

If an immobile doping ion, such as a polyelectrolyte, is used, these cannot move out of the film during de-doping. Instead, the de-doping event is 

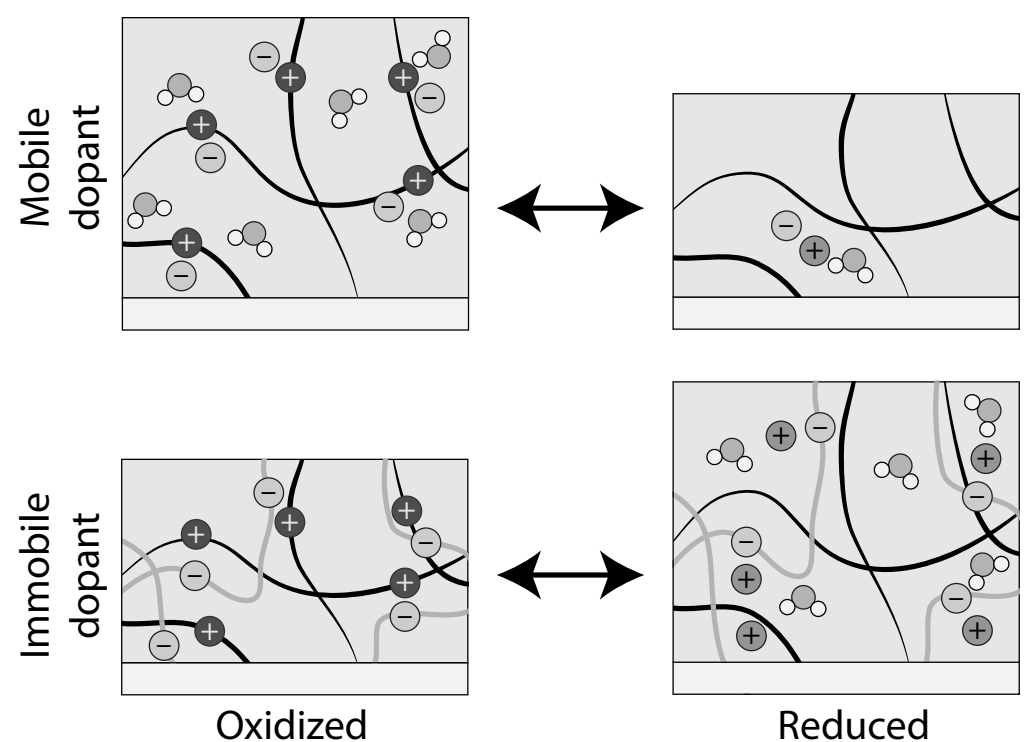

Figure 5.2: Mechanical actuation through oxidation/reduction of a $\mathrm{CP}$. The electronic charges in the $\mathrm{CP}$ (positive, dark grey) are either compensated (doped) by small (mobile) or large (immobile) ions (anions, light grey). By reduction, mobile ions are removed, leading to volume decrease, while immobile ions are compensated by an influx of ions, leading to volume increase.

accompanied by a flux of mobile ions from the electrolyte to compensate for the surplus of ionic charge from the polyelectrolyte. Thus the volume change vs. doping level is reversed, and the volume of the actuator decreases with the doping level. The use of immobile ion species as a dopant has been reported to improve the reproducibility of the actuation 122 .

\subsubsection{Surface Switches}

Surface properties of a $\mathrm{CP}$ electrode, such as charge density and wettability [123, can change as a result of doping or de-doping of the $\mathrm{CP}$ and these changes can be exploited to create surface switches. Such switches can, for example, be used to create smart cultivation surfaces where cell growth can be controlled electronically.

Surface properties changed by redox switching have, for example, been used in vitro to control the shape and growth of cells 124], cell migration [125], and cell adhesion and density 126 . Further, by converting the redox-active surface into a channel of an OECT surface gradients can be formed, allowing spatial control of cell growth [127].

One commonly described mechanism for the observed cell responses after redox switching of a $\mathrm{CP}$ surface is induced changes in concentration, orientation, and/or folding of proteins on the surface. Extracellular proteins, such as fibronectin, play an important role in the attachment of cells to surfaces, and can be electronically controlled through surface switches 128. 
With a similar concept, the bioavailability of heparin-binding growth factors, needed for differentiation of stem cells, can be modulated by controlling the exposure of heparin binding sites on a heparin-doped PEDOT electrode [129].

\subsubsection{Drug Delivery Systems}

For many signaling substances and pharmaceuticals, concentration, location, and timing are essential for their intended function. For example, a painkiller might be most effective and give the fewest side effects when administrated directly to the site where it is needed, at its therapeutic concentration, and only when needed. It is thus attractive to be able to electronically control the release of such substances in a highly-localized fashion.. The combination and coupling between electronic and ionic transport found in $\mathrm{CPs}$ makes $\mathrm{CP}$ electrodes well suited for conversion between electronic and ionic signals. As many drugs can be ions (e.g. through pH-sensitive groups), these materials can be leveraged for electronic drug delivery.

A simple yet elegant way of using CPs for drug delivery is to incorporate the drug as a dopant ion into the CP $\mid 130]$. Upon de-doping of the polymer, the dopant, i.e. the drug, is released (Figure 5.3). The drug can either be present during the polymerization of the polymer, or exchanged with the initial doping ion trough cyclic redox switching of the polymer after polymerization 131 .

To improve the delivery rate, especially for larger substances, the drug can be inserted and trapped into a hydrogel penetrated by a network of CP 132. Through the expansion of the CP during electrochemical switching, the hydrogel becomes less dense, and allows release of the drug.

As an alternative to using the electrochemical release of doping species as drug delivery method, $\mathrm{CP}$ have also been used to construct electronically controlled valves for $\mu \mathrm{m}$-sized drug-containing reservoirs on a silicon substrate 133. Here, the valve functions similar to a mechanical actuator. Another approach includes using a conducting PEDOT cladding around drug-impregnated polymeric fibers 134 (Figure 5.4). Upon switching of the PEDOT layer, the drug is released, through an assumed mechanism of squeezing of the inner fiber and cracking of the PEDOT film. A similar approach has been reported using drug-filled carbon nanotubes where the
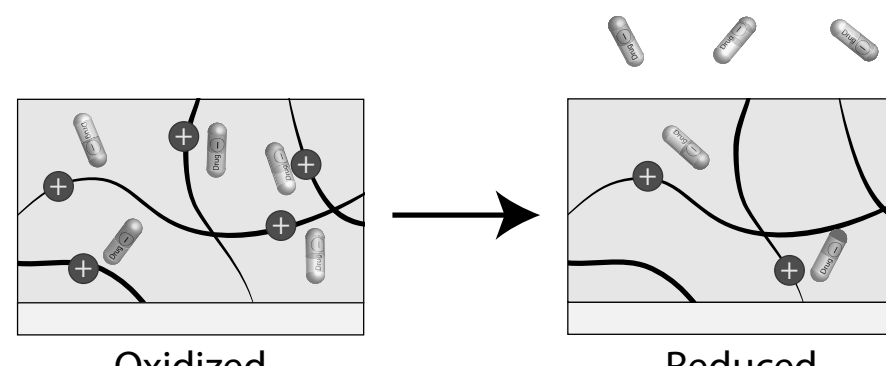

Oxidized

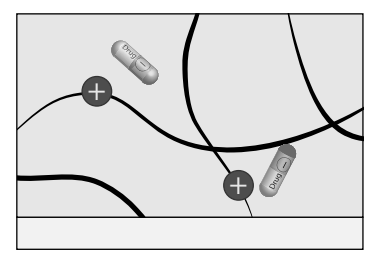

Reduced

Figure 5.3: $\mathrm{CP}$ drug delivery. The drug is loaded into the $\mathrm{CP}$ as a dopant ion, and can be released through switching the redox state of the $\mathrm{CP}$ 
open ends are coated with polypyrrole to electrochemically control the drug release 135 .

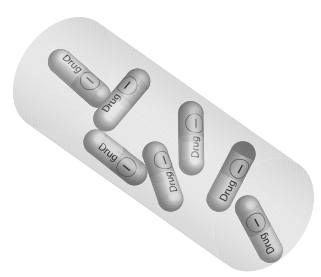

(a) Drug-loaded fiber

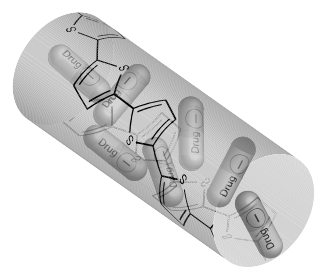

(b) CP.cladding

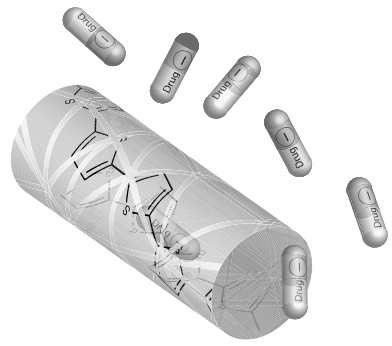

(c) Drug release

Figure 5.4: (a) Impregnating of drugs into (b) CP coated fibers. (c) Switching of the $\mathrm{CP}$ allows the drug to escape the fiber.

The drug delivery methods described above are primarily driven by diffusion, where the $\mathrm{CP}$ controls the diffusion rate. Such release is well suited for drugs acting over long time and/or distance, but can be limiting if faster chemical signal transduction is needed, such as when trying to replicate synaptic signaling [94]. The addition of ion migration into the delivery method can improve the temporal control of the release as the driving electric field can be switched on or off. In the organic electronic ion pump (OEIP) 136], CP electrodes control the migration of charged drugs through an IEM a method that is discussed further in Chapter 7 


\section{Chapter 6}

\section{Experimental Methods}

\subsection{Microfabrication Techniques}

\subsubsection{Spin coating}

Spin coating is a method to deposit materials from solution onto flat substrates 137. A spin coater consists of an axis, onto which the substrate can be attached to, connected to a motor with programmable rotational speed (Figure 6.1). A fluid, containing the material to be deposited in a solvent, is applied onto the substrate typically manually using a pipette or from an automatic dispensing pipe.

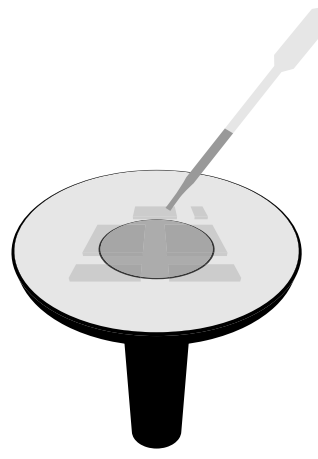

(a) Deposition

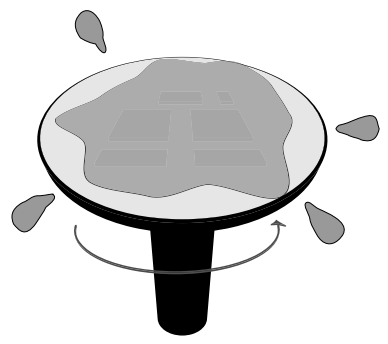

(b) Spin

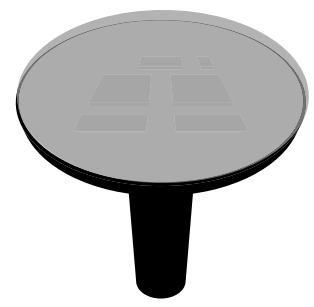

(c) Final

Figure 6.1: Deposition of a thin film by spin coating.

A first spin step spreads the deposited fluid across the whole substrate using a short (couple of seconds) and slow (around $500 \mathrm{rpm}$ ) spin rate. Next, the rotation speed is increased, typically to $1000-6000 \mathrm{rpm}$, and held constant for $10-60 \mathrm{~s}$. This step produces a homogeneous film and in a controllable manner reduces the film thickness to the desired thickness.

Initially, the high rotational speed forces the deposited fluid to escape the edge of the substrate by the centrifugal force, thus thinning the film [138]. As the film becomes thinner the flow is reduced and the solvent evaporation starts to dominate the film thinning, i.e. the film dries. After this step the spin coater is stopped, and a uniform film of the deposited material, with much less solvent content, has been produced along the substrate surface. A baking step or additional spin steps at lower speed are typically used to further remove solvent from the film.

The main advantage of the spin coating method is its repeatability. Using the same experimental conditions in a controlled environment, uniform films with the same thickness can routinely be produced. Further, the film 
thickness can be precisely controlled, typically by changing concentration of deposited fluid (lower concentration results in thinner films) or changing the spinning speed (higher speed results also in thinner films). Spin coating polymers from solution can generate a range of film thicknesses, from $10 \mathrm{~nm}$ up to $100 \mu \mathrm{m}$, and is therefore well suited for deposition of photoresists and other polymer materials during microfabrication processing. Disadvantages with spin coating include sensitivity to particles in the deposition solution or on the surface of the substrate, and the requirement of a flat substrate for uniform films. Substrates with non-flat topographies can, for example, induce variations in the film obtained thickness.

\subsubsection{Photolithography}

Photolithography is used to transfer a designed pattern from a template to a substrate [139. This is done using a light source, a mask containing the desired pattern, and a light-sensitive polymer, the photoresist (Figure 6.2). The photoresist is usually deposited onto the substrate using spin coating to produce a film with a desired thickness. A chemical reaction is initiated inside the photoresist upon exposure to ultraviolet (UV) light. By positioning a transparent mask, onto which the pattern to be transferred is defined by opaque features, between the light source and the substrate, only parts of the photoresist are exposed.

After exposure, and sometimes a baking step to further accelerate the chemical reaction in the photoresist, the photoresist is exposed to a developer solution. For a positive photoresist, UV exposure renders the photoresist more soluble in the developer solution. The exposed areas are then selectively removed from the substrate, leaving the unexposed photoresist remaining on the substrate. A positive photoresist is used in most of the manufacturing steps described in section 6.3 For a negative photoresist, the exposure to UV light typically induces a cross-linking reaction. The cross-linked photoresist is unsolvable in the developer while the unexposed photoresist is dissolved. Depending on the photoresist, the photoresist layer can be removed after it has served its purpose using a remover solution.

UV - photolithography can be used to pattern features down to and below the $\mu \mathrm{m}$-scale. For high-resolution patterning, a mask aligner is used in the exposure step. This tool controls, very precisely, both the position of the substrate in relation to the mask and the exposure dose. Additionally, multiple photolithographic layers can be aligned with respect to each other to produce stacks of patterned layers.

\subsubsection{Dry Etching}

In dry etching, bombardment and chemical reactions from species in plasma is used to remove material from a substrate (Figure 6.3). The plasma can be composed of different gases, such as oxygen, fluorocarbons, and/or argon, and is chosen to efficiently remove, sometimes with high selectivity, the desired material. For etching of polymers, oxygen or oxygen/flourocarbon plasma is usually efficient 140]. By masking the substrate using a patterned photoresist, which selectively protects parts of the underlying substrate 


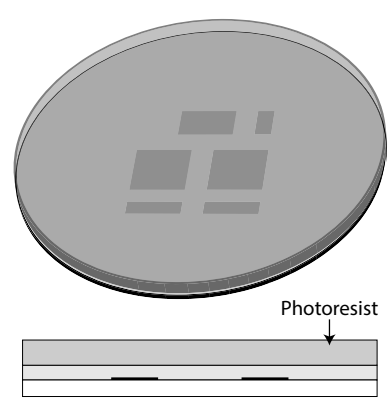

(a) Photoresist

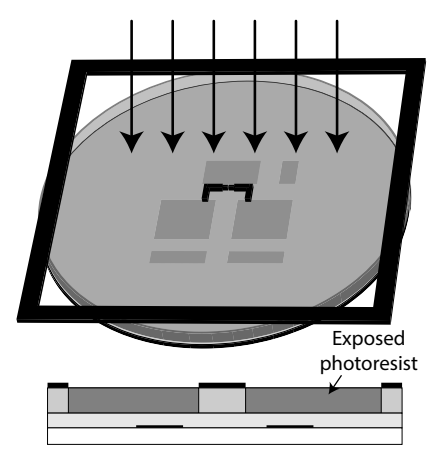

(c) Exposure

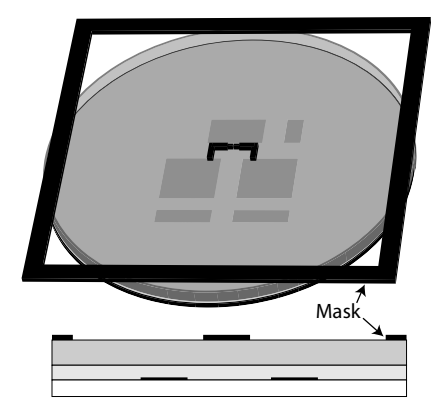

(b) Mask alingment

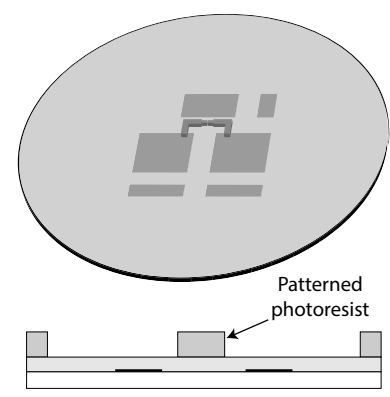

(d) Development

Figure 6.2: Patterning of a spin coated positive photoresist using photolithography.

from the plasma, the pattern can be transferred from the photoresist to the substrate.

The etching mechanism can be either isotropic, giving the same etch rate in all directions, or anisotropic, i.e. being faster in one direction, depending on the plasma parameters (applied power, pressure, and gas mixture) and the equipment used. Vertical anisotropic etching is preferred for patterning of fine features as it results in steeper edge profiles. In a reactive ion etcher (RIE) positive ions are generated in the plasma and attracted towards the substrate by an applied bias to produce anisotropic etching.

\subsubsection{Inkjet Printing}

An alternative deposition and patterning technique to spin coating and photolithography is the inkjet printing technique. Here, a material is dissolved into an ink solution and loaded in an inkjet cartridge. The cartridge contains nozzles that can produce controlled formations of ink droplets and deposit these on the substrate. By moving the cartridge, in relation to the substrate, and then control the production of droplets desired patterns are obtained. The patterning resolution is heavily dependent on droplet sizes and how the droplet spread along the substrate surface or into the bulk. The surface 
wettability characteristics typically limit the resolution of the technique to tenths of $\mu \mathrm{m}$ [141.

Compared to the global deposition, patterning and selective removal approach of photolithography, inkjet printing instead offers a direct deposition and patterning approach. This advantageous for materials and/or substrates incompatible with photolithography techniques, e.g. that are destroyed or dissolved in photolithography solvents or on substrates with pronounced surface topography.

\subsection{Synthesis of Anion Exchange Membranes}

AEMs are often synthesized by chemical modification of side groups on a hydrophobic polymer to produce a positively charged polymer [19]. For example, the alkylation reaction between poly(vinylbenzyl chloride) (PVBC) and a tertiary amine can be used to synthesis new [AEM materials [142]. PVBC is a hydrophobic polymer with pendant benzyl chloride groups attached to the vinyl backbone. A tertiary amine has three bond carbon atoms and one free electron pair. In the alkylation reaction between PVBC and a tertiary amine the free electron pair of the amine forms a bond to the benzyl side group of the polymer by replacing chlorine (Figure 6.4a). The reaction results in a covalently bound quaternary amine that is positively charged regardless of the $\mathrm{pH}$, and is thus suitable for AEM materials. This approach is advantageous as it is simple and a wide array of side group modifications can be obtained depending on the amine used.

The incorporation of positive charges into the polymer renders the polymer more hydrophilic, and highly charged polymers are soluble in water. To improve the water stability, hydrophobic interaction, both in the backbone and on side groups, as well as cross-linking is important 17]. Increased hydrophobic interaction can be obtained by a hydrophobic polymer backbone and/or amines with hydrophobic pendant groups, for example benzyl groups.

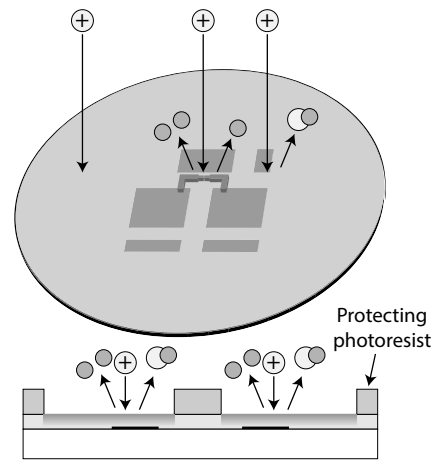

(a) Dry etching



(b) Clean up

Figure 6.3: Removal of exposed material using dry etching. 




(a) Quaternization of PVBC<smiles>CC(C)Cc1ccccc1</smiles>

(b) BDMA

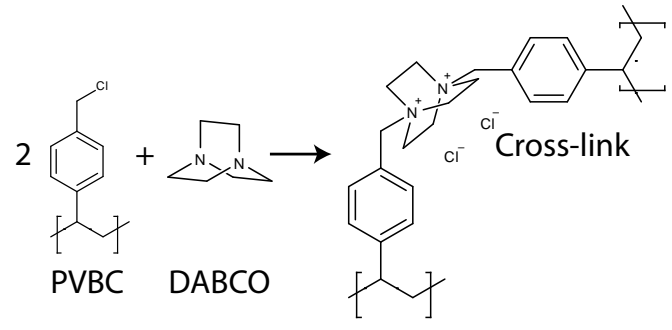

(c) Cross-linking of PVBC

Figure 6.4: Synthesis of AEMs by alkylation between $\mathrm{PVBC}$ and tertiary amines.

Cross-linking can be obtained by using a diamine, a molecule with two amines that can react with two polymer chains, thus fixating them.

The first AEM used in this work, the quaternized poly(vinylbenzyl chloride) (qPVBC), was synthesized by reacting PVBC/with the amine benzyldimethylamine (BDMA) (Figure 6.4b) and cross-linked with the diamine 1,4-diazabicyclo[2.2.2] octane (DABCO) (Figure 6.4c). BDMA was chosen as it has two small and one large hydrophobic (the benzyl) pendant group, offering low steric hindrance for the alkylation reaction as well as some stabilizing hydrophobic interaction. Also, hydrophobic pendant groups have been shown to give increased resistivity to alkali-mediated breakdown of the amine from quaternary to tertiary 143. DABCO was chosen as a crosslinker [144] due to its non-toxicity, high boiling point, and high reactivity. The high boiling point allows DABCO to remain in the film during spin coating.

A non-amine based AEM material, poly(vinylbenzyl triphenylphospine) $\left(\mathrm{PVBPPh}_{3}\right)$, was obtained by exchanging the alkylating amine to tertiary phosphine triphenylphosphine (Figure 6.5). Triphenylphosphine is know to react well with alkyl halides 145 as well as being air stable.

\subsection{Fabrication of Ion Pumps, Diodes, and Transistors}

The fabrication of the devices studied in the included papers all involves similar microfabrication steps, presented in Figure 6.6 The starting point is a sheet of $200 \mathrm{~nm}$ thick poly(3,4-ethylenedioxythiophene):polystyrene sulfonate 


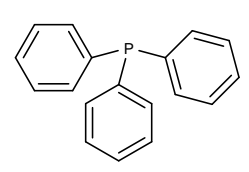

Figure 6.5: Triphenylphospine.

(PEDOT:PSS) on $125 \mu \mathrm{m}$ thick polyethylene terephthalate (PET) foil cut into wafer-sized substrates.

\section{Patterning of electrodes and CEM channels}

In the first processing step electrodes and CEM channels are formed. A photoresist is deposited and patterned using spin coating and photolithography, and the resulting pattern is transferred to the PEDOT:PSS layer using RIE Residual photoresist is removed using photoresist remover.

\section{Overoxidation}

The second step involves selective overoxidation of PEDOT:PSS to form CEM channels. A layer of photoresist is patterned to cover the electrodes but leaves the CEM channels open for exposure. $\mathrm{T}$ the substrate is then immersed into the bleaching agent $\mathrm{NaCOO}$. By controlling the immersion time and NaCOO concentration the conjugation bonds in PEDOT is broken [146], resulting in a cation conductive but electron non-conductive polymer film.

\section{Encapsulation}

In the third step, an encapsulation layer of the negative cross-linkable photoresist SU8 is patterned over the CEM channels. The cross-linked SU8 is resistant against most solvents and conditions used in microfabrication techniques, and the layer thus becomes a permanent inert part of the device. Holes can be patterned into the SU8 to form via-structures between IEM layers. For devices with only a CEM layer the encapsulation then defines the final microfabrication step.

\section{AEM layer}

In the forth step the AEM layer is deposited and patterned. This step involves four sub-steps: i. Deposition and patterning of a photoresist layer to protect the underlying structure. ii. Depositing of the AEM material by spin coating. iii. Deposition and patterning of a photoresist to define the AEM channels. iv. Removal of exposed AEM material using dry etching.

\section{Second encapsulation}

A second layer of SU8 is used to encapsulate the AEM channels. In devices where a third, neutral, layer separates the IEM layers, a via-structure is patterned to accommodate this layer. Otherwise this is the last microfabrication step.

\section{Inkjet printing of neutral electrolyte}

Neutral electrolyte is deposited using inkjet printing. Depending on the size of the junction a set number of drops of polyethylene glycol (PEG) dissolved in 
cyclopentanone is printed to fill the via in the SU8. As SU8 is hydrophobic the inkjetted drops self-aligns into the junction. The cyclopentanone evaporates, leaving the PEG behind. The junction is sealed using a painted polydimethylsiloxane (PDMS) layer. As a last step, silver contacts are manually painted onto the electrodes to produce a good electronic contact between probes and the electrodes.
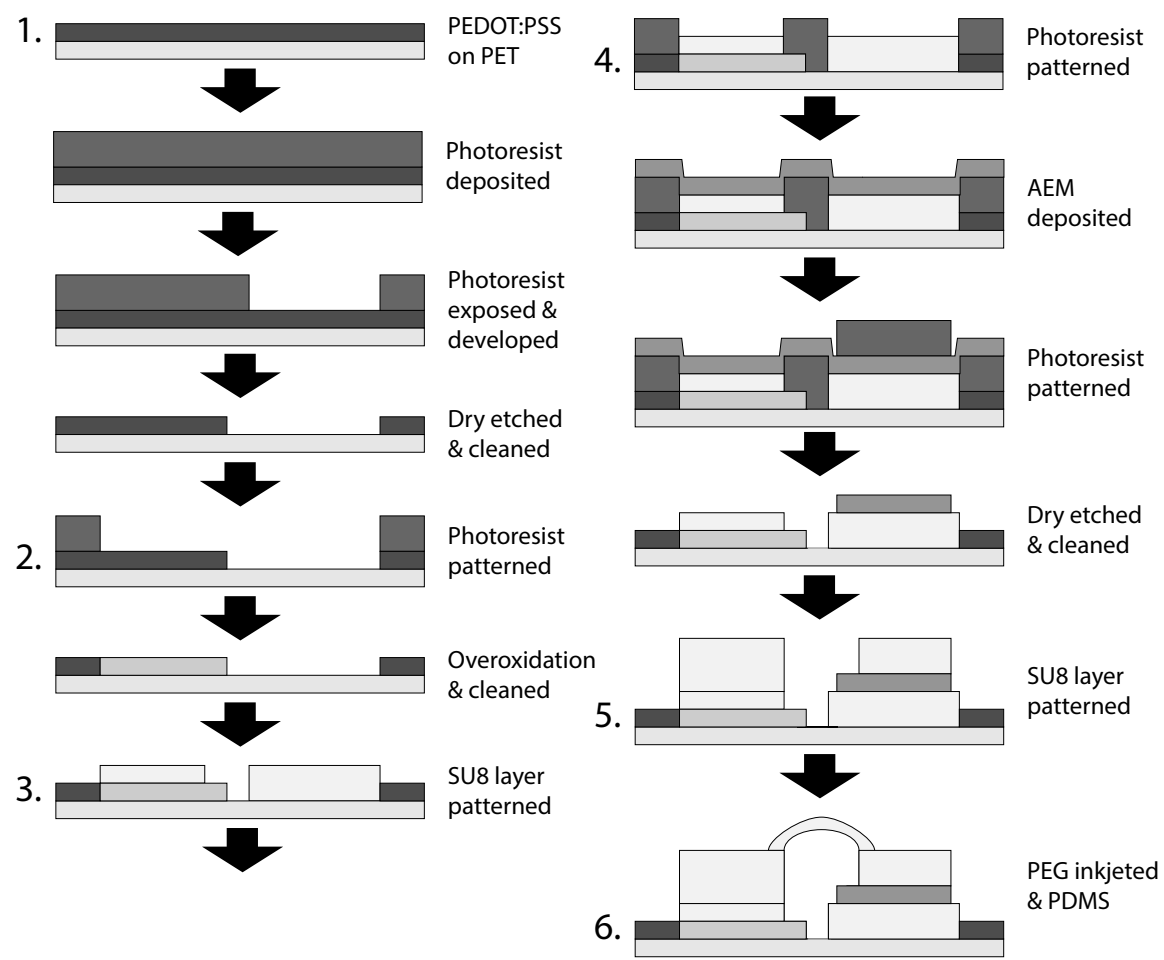

Figure 6.6: Fabrication steps for OEIPs (step 1-3) and BM-based devices (step $1-6)$. 



\section{Chapter 7}

\section{Devices in Papers}

A problem for many drug delivery devices is the lack of precise control of the delivery (where, when, how much, and how often). Also, drug delivery devices based on microfluidics produce, by their nature, convection in the receiving system, which might interfere with the establishment of well-defined microenvironments. These problems were addressed by Isaksson et al., who introduced the OEIP as a drug delivery device for electronically controlled stimulation of cultured neuronal cells [136]. Further development lead to drug delivery devices capable of delivery of neurotransmitters with single cellresolution 147] and in vivo stimulation 148. Additionally, devices similar in construction to the OEIP but with non-linear characteristics have been developed, namely ion bipolar membrane diodes (IBMDs) and ion bipolar junction transistors (IBJTs)

This chapter describes the background, structure, and function of the OEIP IBMDs, IBJTs, and circuits built from IBMDs

\subsection{General Design}

The devices presented in the included papers I-VI all have some common characteristic features regarding appearance, dimensions, materials, etc. The devices are fabricated on flexible transparent PET substrates using photolithography and other techniques described in Chapter 6 The function of the device, i.e. drug delivery, diode, or transistor function, is primarily mediated by thin-films $(200-1000 \mathrm{~nm})$ of IEMs encapsulated by a $10 \mu \mathrm{m}$ thick hydrophobic SU8 barrier, while PEDOT:PSS electrodes are used to electronically connect the device.

\subsection{Organic Electronic Ion Pumps}

The OEIP is an electrophoretic drug delivery device based on polymeric and organic IEMs and electrodes [136]. To drive the drug delivery an external voltage is applied between the electrolyte-immersed electrodes located on either side of the IEMs (Figure 7.1). At the electrodes, electric charge is converted into ionic charge through oxidation/reduction of PEDOT:PSS which results in release or uptake of ions from the surrounding electrolyte. To compensate for the movement in/out of the electrodes, ions must also move between the electrolytes. This transport is facilitated by the IEM channel. The ion-selectivity ensures that only cations or anions, depending on the selectivity, can move between the electrolytes. Thus, for the correct applied voltage polarity, the ion transport is unidirectional, going from source electrolyte, through the channel, and out in to the target electrolyte. An electrolyte containing the ion species to be transported (a metal ion or a 


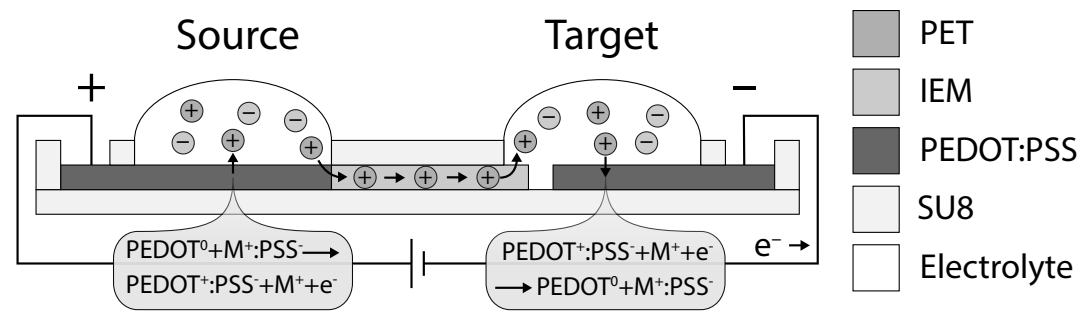

Figure 7.1: Electrophoretic transport through an OEIP driven by electrochemical reactions at the PEDOT:PSS felectrodes. The ionic flux from the source electrolyte is directed through the IEM to the target electrolyte.

charged biomolecule) is applied at the source while the target electrolyte contains the biological system to be stimulated.

Due to the coupling between applied electric current and flow of ions through the OEIP it is possible to electronically turn the delivery on/off and control the drug delivery rate (through the applied current level). Further, by defining the outlet of the channel with high-resolution lithography, the drug release can be performed with high spatial control.

\subsubsection{In Vitro Stimulation of Cells}

The OEIP is, due to its planar geometry and the biocompatibility of the included materials, well suited for stimulation of cultured cells. In the first reported experiment, $\mathrm{HCN}-2$ cells, located in the target electrolyte, were loaded with a fluorescent probe for measurement of intracellular $\mathrm{Ca}^{2+}$ concentration 136. By delivery of $\mathrm{K}^{+}$to the target electrolyte, cells located closest to the outlet showed increased intracellular $\mathrm{Ca}^{2+}$-concentration. This was explained by depolarization of the cell membrane due to the elevated $\mathrm{K}^{+}$-concentration, which opened up ion channels in the membrane and allowed $\mathrm{Ca}^{2+}$ to enter the cell. In another experiment, delivery of $\mathrm{H}^{+}$by short pulses produced oscillations in the target electrolyte, detectable as $\mathrm{pH}$ changes 149 .

The spatiotemporal control of the OEIP was further improved by decreasing the outlet width to $10 \mu \mathrm{m}$ and introducing a pre-loading mechanism for the delivery channel 147 . This device was used to initiate a $\left[\mathrm{Ca}^{2+}\right]$ response in cultured SH-SY5Y cells by pulsed delivery of the neurotransmitter ACh. with temporal resolution as low as $200 \mathrm{~ms}$. Depending on the amplitude and duration of the pulse, cells at specific distance from the outlet could be selectively stimulated.

\subsubsection{In Vivo Stimulation of Tissues}

An implantable version of the OEIP was manufactured by converting the original planar design into a pen-shaped and fully encapsulated device [148]. The device was implanted into the cochlea of guinea pigs in an attempt to demonstrate selective stimulation of specific cells within auditory system, the inner (and not the outer) hair cells. While hearing is mediated by both the 
inner and outer hair cells, only the inner hair cells are sensitive to stimulation by the neurotransmitter glutamate (Glu)

Through delivery of Glu, the hearing response of the guinea pigs was reduced. This was verified by histology as visible damage (exocytosis) of the inner hair cells, while no effect was seen at the outer hair cells or for the control experiment involving proton delivery. Thus, delivery of Glu by the implanted OEIP selectively stimulated inner hair cells through the biological action of the neurotransmitter without mechanically disturbing the sensitive cochlea with fluid flow.

\subsubsection{Formation of Amyloid-Like Aggregates (Papers I-II)}

The non-fluidic OEIP is an attractive alternative to microfluidic devices for study of amyloid aggregation, as the shear produced by a fluid flow can alter the kinetics of the aggregation 92 and possibly distort the results. For this reason, OEIPs with 30-70 $\mathrm{mm}$ outlets were investigated as a platform for electronically controlled amyloid aggregation in Papers I-II.

\section{Aggregation of polyglutamic acid}

In Paper I formation of amyloid-like aggregates was initiated by delivery of either $\mathrm{H}^{+}$or $\mathrm{Na}^{+}$to a solution containing the simple polypetide polyglutamate (Poly-E) The aggregation was followed in real-time as a fluorescent response of the amyloid-specific probe p-FTAA. Additionally, post-experiment studies with scanning electron microscope (SEM) revealed both $\mu \mathrm{m}$-sized spherulites and twisted, 200-500 nm thick, and $\mu \mathrm{m}$ long rods. Aggregation was limited to the area around the outlet, and the distribution was controlled by the magnitude of the applied delivery current as well as the choice of delivered ion.

Further, fluorescently labeled Poly-E allowed the kinetics of the aggregation to be studied in more detail. For $\mathrm{H}^{+}$delivery, this revealed an initial accumulation of Poly-E prior to formation of amyloid-like aggregates, while for $\mathrm{Na}^{+}$-delivery the accumulation and aggregation occurred simultaneously.

Lastly, the OEIP was used to form layers of Poly-E aggregates decorated with different conjugated molecules, where the initial fluorescence of a $\mathrm{p}$ FTAA-decorated layer was later quenched by a second PEDOT-S-decorated layer.

\section{A $\beta$ aggregation}

In Paper II similar results were obtained for the more biologically relevant $\mathrm{A} \beta$ (40) peptide. Aggregation of $\mathrm{A} \beta$ (40) was faster, compared to Poly-E even though a lower peptide concentration was used. The use of labeled $\mathrm{A} \beta$ (40) hinted at a similar accumulation mechanism as for Poly-E but where accumulation and aggregation occurred simultaneously. These results are likely due to the relative stability difference between $\mathrm{A} \beta$ and Poly-E, where the former is more prone to aggregate. Aggregation of $\mathrm{A} \beta(42)$ was also studied, and reveled a more granular and more intense p-FTAA fluorescence compared $\mathrm{A} \beta$ (40). This suggests that the chemical conditions provided by the OEIP can differentiate the aggregation between the two $\mathrm{A} \beta$ peptides. 
SEM reveled the presence of $\mu \mathrm{m}$-long amyloid-like fibrils with widths in the $10 \mathrm{~nm}$ range at the perimeter of the aggregation zone. Closer towards the inlet, the aggregates were denser and less fibril-like, which might be due to too high $\mathrm{A} \beta$ concentration.

Together, the spatiotemporal control of the aggregation of both Poly-E and $\mathrm{A} \beta$ obtained with the OEIP demonstrates the possibility of using OEIP technology for both life science and material studies of amyloid aggregates.

\subsection{Ion Diodes}

A diode is a two terminal device where conductivity through the device is dependent on applied bias or current direction, defined as forward and reverse bias or direction. The ability to conduct current in (primarily) one direction is called rectification, and the diode's ability to rectify can be characterized by dividing the forward with the reverse current to give the rectification ratio. Several types of ion diodes have been presented, and most can be assigned into one of three groups: nanofluidic, electrolyte, or BM (i.e. IBMDs based. In all of these types of diodes, the rectification originates from production of a volume with low ion concentration in the device during reverse bias. As ionic conductivity is dependent on ion concentration, this zone will limit the current through the diode. In forward bias the volume is filled with ions, giving high conductivity. However, as is described below, the mechanisms for the bias-dependent ion concentration difference varies for the different types of ion diodes. Additionally, a fourth type of ion diode has been described, where the rectification mechanism originates from an asymmetry in the reactions occurring at electrodes.

\subsubsection{The IBMDs (Papers III-IV)}

BMs were early identified as having non-linear current-voltage properties, and have thus been described as ion diodes [150]. Miniaturized ion diodes based on BMs polymerized inside microfluidic channels were reported by Han et al. and were used to build simple diode logics [151]. Further, Tybrandt et al. combined two BMs patterned by photolithography to build IBJTs, where the individual $\overline{\mathrm{BMs}}$ also functioned as ion diodes [152]. In Papers III-IV, the effect of different structures (Figure 7.2a) and materials (Figure 7.2b) in IBMDs were studied with the goal of improving the performance of ion diodes.

\section{The water dissociating IBMD1}

In the first structure, the CEM and the AEM are in direct contact with each other through an overlap of the layers. The structure resembles an elongated and thin BM and is similar to the microfluidic structure used by Han et al. [151. As also described by Han et al. 151], this structure behaves well within $\pm 1 \mathrm{~V}$, but, as extensively reported in the literature on BMs 27] and later also reported for microfluidic BMs [153], this structures experiences EFE water dissociation for reverse bias exceeding $\sim-1 \mathrm{~V}$ (Figure 7.3a). This deteriorates the rectification ratio to 3 at $\pm 4 \mathrm{~V}$. The narrow usable voltage 


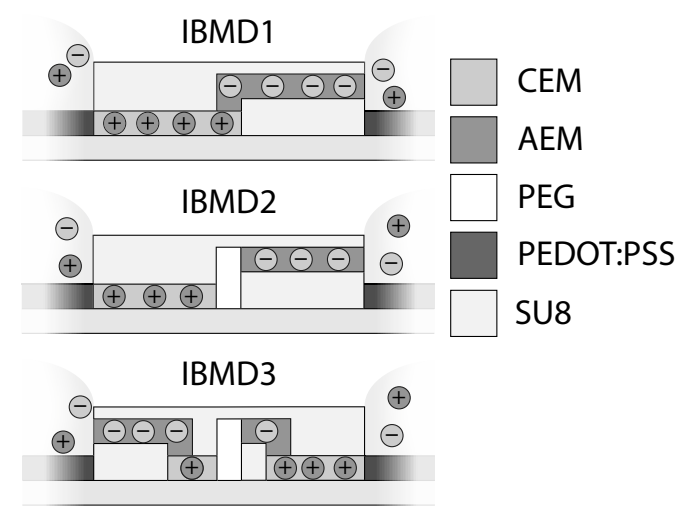

(a) Designs

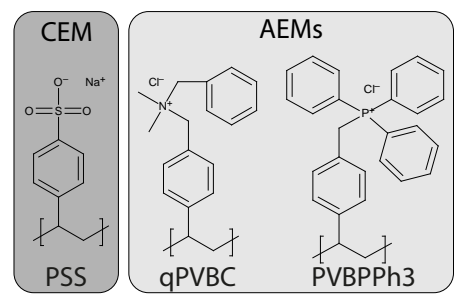

(b) Materials

Figure 7.2: (a) Designs used in IBMDs. IBMD2 includes a PEG electrolyte not found in IBMD 1. IBMD $\beta$ is composed of three BMs two IBMD 1s on either side of an IBMDR. (b) Materials tested in IBMDs, IBMD 1-3 uses polystyrene sulfonate (PSS) and $\mathrm{qPVBC}$ while the phosphonium-based IBMD uses PSS and $\mathrm{PVBPPh}_{3}$

range limits the use of this diode, especially when considering that most diode based-logic gates degrade the input voltage. The structure is useful however, as shown by Cheng and Chang [153], for generating $\mathrm{pH}$ gradients from in situ-formed $\mathrm{H}^{+}$and $\mathrm{OH}^{-}$.

\section{The ion-storing IBMD2}

To reduce EFE water dissociation in microfabricated BMs Tybrandt et al. introduced a neutral PEG spacer in the BM [152], and a similar approach was used to construct the IBMD2 structure. The IBMD2 only shows two operational regimes, forward and reverse bias, has a rectification ratio of 200 at $\pm 4 \mathrm{~V}$, and is therefore a better diode than IBMD 1 . Unfortunately, the PEG layer introduces hysteresis upon switching to reverse bias due to accumulation of ions during forward bias (Figure 7.3b. This results in an increasingly slow switch back to reverse bias the longer the forward bias state lasts, e.g. the time to switch to reverse bias after $120 \mathrm{~s}$ in forward bias was $108 \mathrm{~s}$. 


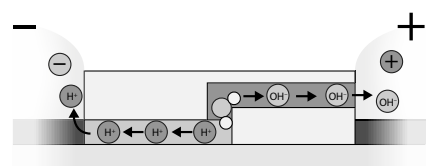

(a) EFE water dissociation

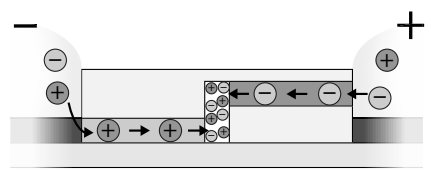

(b) lon storage

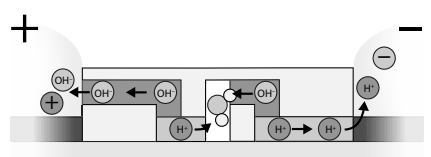

(c) Water dissociation and recombination

Figure 7.3: Characteristic features for (a) IBMD1, (b) IBMD2, and (c) IBMD 3 .

\section{The combined IBMD 3}

One simple way to avoid the hysteresis in the IBMD2 device is to use strong acidic and alkali electrolytes at the $\mathrm{CEM}$ and $\mathrm{AEM}$ side, respectively. $\mathrm{H}^{+}$ and $\mathrm{OH}^{-}$will then recombine in the neutral layer to form water and thus avoid extended ion accumulation. The use of electrolytes with extreme $\mathrm{pH}$ is however discouraged in bio-applications. An alternative is to place reverse orientated $\mathrm{H}^{+} / \mathrm{OH}^{-}$-producing IBMD 1 devices on either side of an IBMD2, giving the IBMD $\beta$ device. In forward bias, the produced $\mathrm{H}^{+}$and $\mathrm{OH}^{-}$will feed into the neutral layer of the IBMD2 and neutralize to water (Figure 7.3c). As with single IBMD 1 devices, $\mathrm{pH}$ changes will also occur in the electrolytes surrounding the IBMD 3 . In reverse bias, only a small amount of ions needs to be depleted from the neutral layer to decrease the conductivity of the IBMD 3. Thus, both good diode behavior (rectification 300 at $\pm 8 \mathrm{~V}, \sim 4 \mathrm{~s}$ switching) and low hysteresis are obtained. The drawbacks of this solution are primarily that the $\mathrm{pH}$ changes in the electrolytes might be unwanted, and the structure has a much larger footprint than IBMD1 or IBMD2.

\section{The simpler, polyphosphonium-based IBMD}

The neutral layer was introduced in IBMD2 to prevent EFE water dissociation, and the complex design of IBMD 3 was introduced to decrease the hysteresis effect caused by the neutral layer. It is thus apparent that a simpler diode could be produced using an alternative route for avoiding EFE water dissociation. As EFE water dissociation is absent for AEMs not containing tertiary amines [32, 33], polyphosphonium, an amine-free AEM, was tested in the simple IBMD 1 -structure. This device proved to not exhibit any detectable EFE water dissociation. Further, both the static and the dynamic performance of the diode were comparable to other IBMDs The junction of 


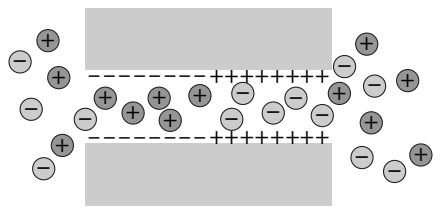

(a) Nanofluidic diode

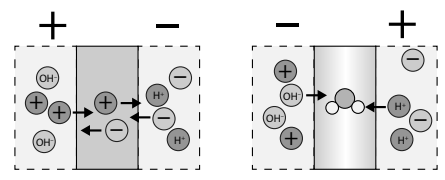

(b) Electrolytic diode

Figure 7.4: (a) lon distribution in a bipolar nanofluidic diode. (b) Forward and reverse bias of an electrolytic diode.

a polyphosphonium-based IBMD 1 structure was also miniaturized to $10 \mu \mathrm{m}$, which reduced the switching speed to $4 \mathrm{~s}$ and improved the rectification ratio to 800 at $\pm 4 \mathrm{~V}$.

\subsubsection{Alternatives to IBMDs}

\section{Nanofluidic diodes}

A nanofluidic diode utilizes an open electrolyte-filled channel where the width and/or height of the channel is in the nanometer range. The ends of the channel connect to separate electrolytes containing electrodes. The channel walls are made positively or negatively charged and will attract counter-ions and repel co-ions. The small dimension of the channel allows the surface charges to affect the ion composition through the bulk of the channel. The charged nanochannel can thus be regarded as having the same function as an IEM. To construct a diode the channel is, similar to a BM. dived into two parts with opposite polarity (Figure 7.4a). Other approaches can be used, such as varying the geometry of the channel to only be ion-selective in one end or to use asymmetric electrolytes, but these are typically less effective 154. A nanofluidic diode also functions similar to a BM diode, i.e. in forward bias counter-ions enter the nanochannel from both sides while in reverse bias co-ions are repelled from entering.

The ability of the charged sidewalls to efficiently repel co-ions is crucial for the rectification effect of a nanofluidic diode. The distance away from the walls for which the charges at the sidewalls are effective at proving ion-selectivity is dependent on the Debye screening length of the electrolyte. Nanofluidic diodes thus operate optimally at low electrolyte concentration (typically $<1-10 \mathrm{~mm}$ ), put poorly in physiologically relevant concentrations 155,156 , as the Debye screening length is decreased to $\sim 1 \mathrm{~nm}$ at $100 \mathrm{~mm}$.

\section{Electrolytic diodes}

Electrolytic diodes are composed of a medium, either a gel or a membrane, separating two electrolytes with immersed electrodes $157-159$. Typically, a neutral gel and strongly acidic and alkali (e.g. $\mathrm{HCl}$ and $\mathrm{KOH}$ ) electrolytes are used (Figure 7.4b). Forward bias operation is obtained by applying a bias at the electrodes so that $\mathrm{K}^{+}$and $\mathrm{Cl}^{-}$move into and through the gel. At reverse bias operation, $\mathrm{OH}^{-}$and $\mathrm{H}^{+}$will instead enter the gel and recombine to form water. This eliminates ions, and thus reduces the ion concentration at the site of water recombination. Thus, although $\mathrm{H}^{+}$and $\mathrm{OH}^{-}$generally have higher 
mobility than $\mathrm{K}^{+}$and $\mathrm{Cl}^{-}$, the conductivity through the gel is decreased. Consequently, the current through the electrolytic diode becomes smaller in reverse bias, i.e. rectification occurs. The main limitation of electrolytic diodes in biological application is the need for specific electrolytes to ensure their proper function. The requirement of acidic/alkali electrolytes is very difficult to combine with physiological conditions.

\section{Diodes based on asymmetric electrode reactions}

For this type of diode, rectification does not originate from depletion of ions in a zone in the electrolyte between the electrodes, but instead from asymmetry in the forward and reverse electrochemical reactions at the electrodes. An example of such a diode is the liquid metal/hydrogel/platinum stack presented by So et al. [160]. In reverse bias, an oxide film is formed at the liquid metal electrode, effectively blocking ion transport and resulting in ion current rectification. A similar device, based on nanoporous $\mathrm{SiO}_{2}$ on a Si substrate, a hydrogel, and fluorine-doped tin oxide, showed a rectification ratio of $3.8 \times 10^{4}$, ms-switching between forward and reverse bias, and high stability 161]. Additionally, the effect of asymmetric electrode reactions have also been modeled and shown to be significant for BM-based diodes when the electrode area is similar to the area of the $\mathrm{BM}$ 162. Unfortunately, the transfer of the rectification mechanism from the (poly)electrolyte(s) to the electrodes is disadvantageous when constructing integrated ionic circuits, as diodes and transistors no longer can be connected through ionic flow.

\subsection{Ion Diode AND Gate (Paper III)}

To further expand the spatial control of drug delivery through IEMs, it would be beneficial to produce a $2 \mathrm{D}$ array of delivery pixels. The addressing of pixels in a NxM array is simplified if some form of addressing circuitry is used, as this minimizes the number of input connectors needed. For example by using an AND function in each pixel, the number of input connectors can be reduced from NxM to $\mathrm{N}+\mathrm{M}$. Ionic AND gates have been reported using both diodes [151] and transistors [163].

\section{A pH pixel}

In Paper III an alternative AND gate based on three IBMDs forming a T-shaped junction is presented (Figure 7.5a). Two IBMDs are connected to input PEDOT:PSS electrodes while a third is connected to a target output electrolyte containing a grounded PEDOT:PSS electrode. The use

of IBMD 3 s minimizes hysteresis in the circuit and results in in situ $\mathrm{H}^{+}$and $\mathrm{OH}^{-}$production.

Through the arrangement of the rectifying diodes, only two current pathways are possible in the circuit, either between input 1 and input 2 (Path 1) or between the output and input 2 (Path 2) (Figure 7.5a). The delivery of ions through the output only occurs if the potential at the Tjunction puts the output diode in forward bias. When used in a matrix, the modified AND gate ensures that cross talk is not produced between pixels 


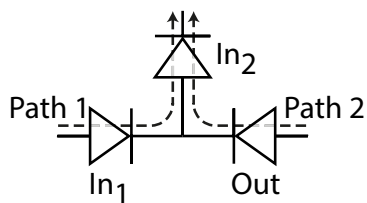

(a) Circuit

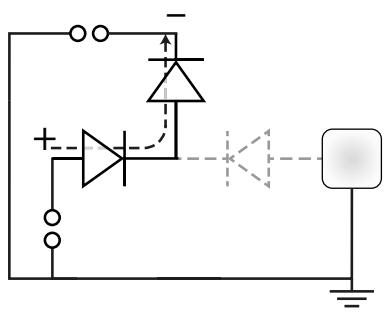

(c) Combination iii

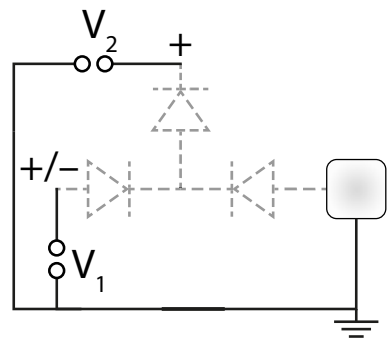

(b) Combinations i/ii

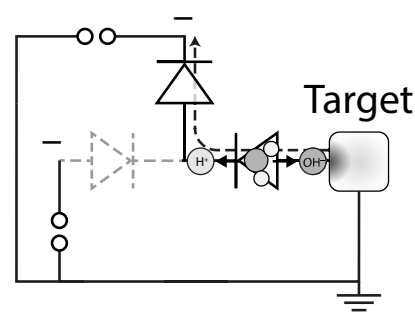

(d) Combination iv

Figure 7.5: The ion diode AND gate. (a) Two paths are possible in the diode circuit. (b) All diodes are reversed biased $\left(\mathrm{V}_{1}<\mathrm{V}_{2}\right)$. (c) Diodes in Path 1 are forward biased. The potential at the T-junction is positive, giving reverse bias at the output diode. (d) Reversal of (c) results in a current trough Path 2 and $\mathrm{OH}^{-}$delivery to the target, i.e. the on-mode of the pixel.

through the common grounded output-diodes, as would otherwise occur if a simpler diode circuit was used.

Two complementary configurations are possible depending on the orientation of the diodes - either a $\mathrm{H}^{+}$or $\mathrm{OH}^{-}$delivery pixel. figures $7.5 \mathrm{~b} 7.5 \mathrm{~d}$ illustrates the addressing of the $\mathrm{OH}^{-}$pixel, using four input bias combinations (i-iv), and the expected currents through the device.

\section{D pH gradients}

The in situ $\mathrm{H}^{+} / \mathrm{OH}^{-}$production renders this AND gate suitable for creation of $\mathrm{pH}$ gradients across a 2D array. Such matrices might be constructed by connecting the input terminals of a $2 \mathrm{D}$ array of pixels to row and column connectors. To control the array, pixels in on-mode would be addressed with combination (iv), off-pixels in the same row or column with combination (ii) or (iii), and all other off-pixels with combination (i). This scheme allows for addressing of single pixels, pixels in columns or rows, and continuous 2D arrays. It is however not possible to address multiple pixels with arbitrary position. Further, pixels addressed with (iii) require a significant Path 1 current, which is a non-ideal situation as it consumes unnecessary electrode capacity. 


\subsection{Ion Diode Full-Wave Rectifier (Paper V)}

Many life science technologies are based on the separation of molecules using electrophoresis, especially in lab-on-a-chip applications 164, 165]. Such techniques require a constant ionic direct current (DC) to drive the movement of the ionic species in the sample. The generation of ionic DCs is however problematic, as it requires continuos electrochemical reactions at the electrodes. For example, the use of metal electrodes produce unwanted reactions that cause fluctuations in $\mathrm{pH}$ and formation of gases and/or toxic species 166 168, which can be devastating for sensitive proteins, cells, or tissues.

$\mathrm{CP}$ electrodes can increase the usable electrochemical capacity range where side reactions are avoided [169, 170, but still have finite capacity. Within their capacity range they can however be cycled repeatedly 171 , 172. Thus it is attractive to convert an alternating current (AC) obtained by cycling redox reactions at $\mathrm{CP}$ electrodes to an ionic $\mathrm{DC}$ In conventional electronics, a full-wave rectifier circuit based on a scheme of four connected diodes, often called a diode bridge, typically performs such conversion. Using ion-conducting diodes, the same circuit can be made for rectification of ionic currents, as shown in Paper V.

\section{An ionic diode bridge}

In a diode bridge, an $\mathrm{AC}$ is applied at the two input terminals. The network of diodes connecting the inputs to the outputs ensures that regardless of applied input current polarity, the current between the output terminals is in the same direction, i.e. an input $\mathrm{AC}$ is converted to an output $\mathrm{DC}$ (Figure 7.6a and Figure 7.6b). In the ion diode bridge, polyphosphoniumbased IBMDs are used as diodes, together with PEDOT:PSS electrodes for conversion between electronic and ionic currents at the terminals. Two versions of the ion diode bridge are presented in Paper V and the versions differ by the nature of the output connection.

\section{Electronic output}

In the first version (Figure 7.6c), PEDOT:PSS electrodes located at the output terminals convert the rectified ionic current back to a measurable electronic current to demonstrate the concept of the device. Here, the two input electrodes are cycled between oxidized and reduced state by an input voltage of $\pm 4 \mathrm{~V}$, producing an output $\mathrm{DC}$ of $\sim 380 \mathrm{nA}$ that continuously reduces or oxidizes the output electrodes. The conversion efficiency at steady-state (calculated as $I_{D C} /\left|I_{A C}\right|$ ) was $95 \%$.

\section{Ionic output}

In the second version (Figure 7.6d), the rectified ionic current flows between the output terminals through an IEM] Here, cycling of the input electrodes (input voltage $\pm 8 \mathrm{~V}$ ) provides a near-undisrupted DC through the IEM. The bridge was used to demonstrate delivery of the neurotransmitter $\mathrm{ACh}$ beyond the normal redox capacity of the electrodes $(1.1 \mathrm{mC}$ delivered vs. $120 \mu \mathrm{C}$ electrode capacity). Based on the second version, a future generic version might be designed where any ionic circuit that requires a driving $\mathrm{DC}$ 


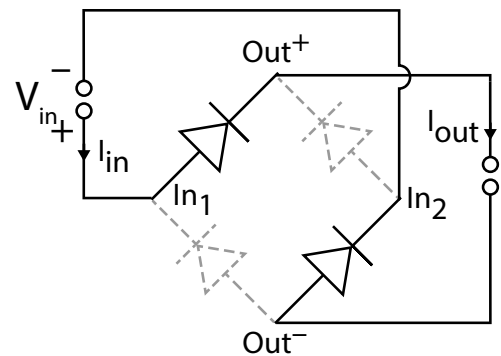

(a) $V_{\text {in }}>0$

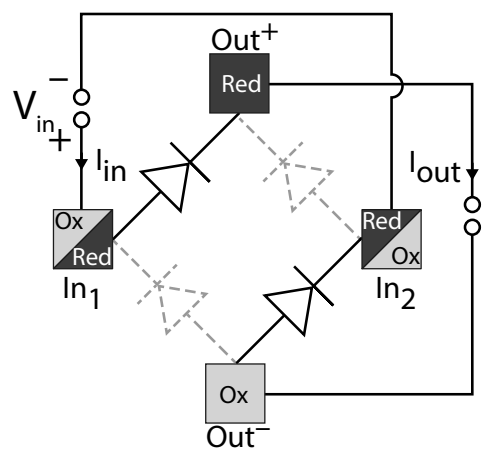

(c) Electronic output

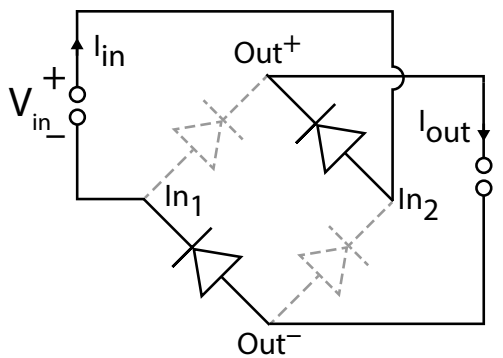

(b) $V_{\text {in }}<0$

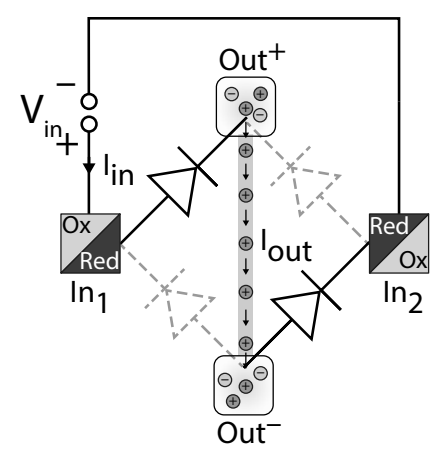

(d) lonic output

Figure 7.6: The ionic full-wave rectifier circuit. (a-b) An input $A C$ is rectified into an output $[\mathrm{DC}$ by the diode network. (c) Conversion of the ionic DC]to electronic current by PEDOT:PSS electrode at the output. (d) Electrophoretic DC transport of ACh between the output terminals. Dashed diodes are reverse biased.

replaces the IEM The generation of ionic DC from cycling CP reactions is a significant advantage for both miniaturized lab-on-a-chip and implantable devices as the electrode space can be minimized and electrode side-reactions avoided.

\subsection{Ion Bipolar Junction Transistors (Paper VI)}

Considering the vast opportunities for creating logic circuits available when using transistors, it is highly interesting to develop ion-conducting transistors. Similar to ion diodes, several types of ion transistors have been reported, and these can be divided into similar categories: nanofluidic [173, 174], electrolytic [157], and BM-based transistors [IBJTs [152, 175]. The first two categories suffer the same limitations for application in biological settings as their diode counterparts and will thus not be discussed further.

In an electronic bipolar junction transistor, the doped emitter (E) and collector (C) electrodes form a T-shaped junction (J)] with the oppositely doped base (B) electrode. The flow of electrons or holes between $\mathrm{E}$ and $\mathrm{C}$ is modulated by the charge density in J which can be controlled by the bias at 
B For the IBJT, the doped semiconductors are exchanged with IEMs The J then resembles two BMs formed between emitter and base (EB) and collector and base (CB) The npn-IBJT modulates anion currents between the anionselective $\mathrm{E}$ and $\mathrm{C}$, and a cation current in the cation-selective $\mathrm{B}$ controls the ion charge concentration in the J(Figure 7.7a). In the complementary pnp-IBJT that can modulate cation currents, the ion selectivity is reversed Figure 7.7b). Apart from that, the function of the pnp- and the npn-IBJT is similar, and the npn-IBJT is described below.

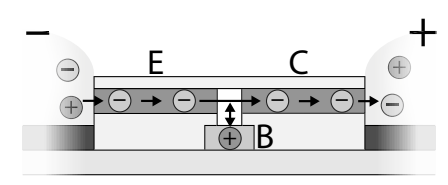

(a) npn-IBJT

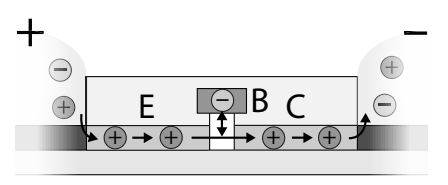

(b) pnp-IBJT

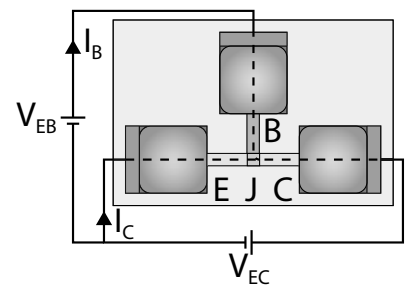

(c) Biasing

Figure 7.7: Modulation of (a) anionic and (b) cationic current by [BJT (c) Addressing of the $\mathrm{E} B$ and $\mathrm{C}$ in a npn $\mathrm{IBJT}$

\section{Active mode}

The anion transport from $\mathrm{E}$ to $\mathrm{C} \sqrt{\text { collector current }\left(\mathrm{I}_{\mathrm{C}}\right)}$ in a npn-IBJT is driven by an applied emitter-collector voltage $\left(\mathrm{V}_{\mathrm{EC}}\right)$ (Figure $7.7 \mathrm{c}$ ) and can be modulated from high (on-mode) to low (off-mode) by going from high to low ion concentration inside the The applied emitter-base voltage $\left(\mathrm{V}_{\mathrm{EB}}\right)$ controls the ion concentration in J If the potential at the $\mathrm{B}$ is higher than the potential at the J (i.e. positive $\mathrm{V}_{\mathrm{EB}}$, a positive base current $\left(\mathrm{I}_{\mathrm{B}}\right)$ will insert cations (from $\mathrm{B}$ ), and anions (from $\mathrm{E}$ ) into the J (Figure 7.8a). This is equivalent to forward bias of the $\mathrm{EB}$. The increased ion concentration enables anions to move from $\mathrm{E}$ to $\mathrm{C}$ resulting in high $\mathrm{I}_{\mathrm{C}}$ In the active mode, $\mathrm{CB}$ is reversed biased. Therefore the ion concentration profile inside $\mathrm{J}$ is not flat, but linearly decreasing from $\mathrm{E}$ to $\mathrm{C}$ as anions are removed at the C. This causes an ion-depleted region at $\mathrm{C}$ that increases with applied $\mathrm{V}_{\mathrm{EC}}$ and is responsible for the main voltage drop inside the J. Additionally, a fraction of the applied $\mathrm{V}_{\mathrm{EC}}$ is lost due to the resistive characteristics of the E and C channels.

\section{Saturation mode}

For an IBJT with geometrically symmetric $\mathrm{E}$ and $\mathrm{C}$ the potential at the $J$ is approximately $\mathrm{V}_{\mathrm{EC}} / 2$. Further injection of ions into the $\mathrm{J}$ by an $\mathrm{I}_{\mathrm{B}}$ is 


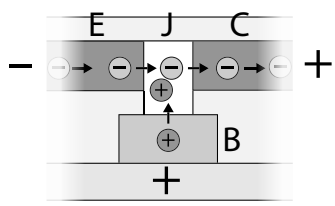

(a) Active mode

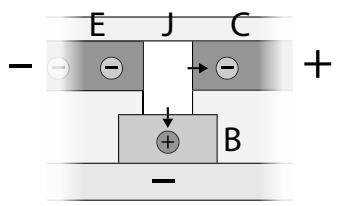

(b) Cut-off mode

Figure 7.8: Concentration changes in the Jbetween (a) active and (b) cut-off mode modulates the current through the IBJT.

prevented in the active mode if the applied $\mathrm{V}_{\mathrm{EB}}$ is less than the potential at the J (i.e. $\mathrm{V}_{\mathrm{EB}}<\mathrm{V}_{\mathrm{EC}} / 2$ ), as this ensures that $\mathrm{CB}$ is reversed biased. For higher $V_{\mathrm{EB}} \mathrm{CB}$ becomes forward biased, which leads to ion accumulation in the J. This operation mode is called saturation mode, and is preferably avoided in IBJTs as the volume change of the Jue to high ion concentration can damage the device.

\section{Cut-off mode}

If the potential at the $\mathrm{B}$ is lower than the potential at the (i.e. negative $\mathrm{V}_{\mathrm{EB}}$, a negative $\mathrm{I}_{\mathrm{B}}$ removes cations from the $\mathrm{J}$ (Figure 7.8b). Charge neutrality in $J$ is then maintained by simultaneous removal of anions, primarily through the higher biased C The lower ion concentration in Jleads to a decreased ion conductivity, a lower $\mathrm{I}_{\mathrm{C}}$ and the cut-off mode of the IBJT In the cut-off mode the main voltage drop occurs across the ion-depleted J]

Both pnp- 152 and npn-IBJTs 175 have been reported, and have also been integrated into ion-based logic circuits 163 and modeled using the Poisson-Nernst-Planck equations [176]. These IBJTs used a neutral PEG electrolyte in the junction. Paper VI describes an npn-IBJT where the $\mathrm{E}$-C-distance is reduced by removing the $\mathrm{PEG}$ layer. This improved the dynamic performance of the device, and $2 \mathrm{~s}$ switching was obtained. 



\section{Chapter 8}

\section{Concluding Remarks}

\subsection{From Amyloids to Full-Wave Rectification}

Since the first report of the OEIP there has been numerous further developments and applications of IEM-based organic bioelectronic devices. My first experiment in the field of organic bioelectronic was to use the OEIP in order to try to control the formation of amyloid-like aggregates. After a couple of explorative tests to familiarize myself with the devices, I meet with the amyloid-experts Peter Nilsson and Per Hammarström in Linköping for an initial experiment involving peptides. We sat in the dark microscopy room, connected our device to a potentiostat, and were amazed by the green "amyloid" fluorescence that appeared in the oculars. To me, it was truly inspiring to be able to produce these ordered aggregates in a controlled fashion, and I spent several days exploring the effects of the current level and the kind of ions delivered.

I also worked on further developing the OEIP technology. There was a need for microfabrication compatible AEMs not only for anion-conductive OEIPs but also for IBJTs Klas Tybrandt and I explored several options before we found that quaternizing a hydrophobic polymer resulted in good film quality and sufficient anion conductivity. The new anion-OEIP never resulted in a publication, but the material was used for both npn-IBJT 175] and to develop the IBMDs

During my experiments with the IBMDs I found that acidic and alkali electrolytes improved device performance and stability. But these extreme pHs would not work for studies with amyloids or cells. Earlier, Magnus Berggren had suggested connecting an IBMD1 and an IBMD2 to give a forward bias threshold. I realized that adding another IBMDI removed the need for specific electrolytes, and the resulting IBMD $\beta$ device performed satisfactory at $\mathrm{pH} 7$.

In the first IBMDs the PEG layer is crucial for preventing EFE water dissociation. I spent much effort on finding a way to eliminate the need for PEG as this layer limited the possibility of miniaturization. In the end, after being inspired by Ornelas-Megiatto et al. [145], I was able to produce fully functional, non-PEG polyphosphonium-based IBMDs and npn-IBJTs with junctions smaller than $10 \mu \mathrm{m}$. The fact that non-amine AEMs does not show EFE water dissociation was already known 33. Nevertheless, the simplicity and high performance of these new devices are important improvements, especially for the development of the ion diode full-wave rectifier.

The possibility of constructing an ion diode full-wave rectifier was early discussed during the study of IBMDs, but it was not obvious what advantage such circuit could offer over the electronic counterpart or single IBMD components. Neither could we find chemical or biological ionic AC signals that 
required conversion to DC It was first when I connected the output terminals with an IEM channel that we realized that this enabled extended generation of an ionic DC circumventing the risk of running out of electrochemical capacity at the addressing electrodes. As a coincidence, this last discovery would have been of great interest during my first studies with amyloids, where the electrodes often reached their capacity limit over the several hour-long experiments.

\subsection{Major Findings}

The aim of this thesis, as given in the Introduction, was to study the use of IEMs in conjunction with organic electronic materials for controlling ion fluxes within biological applications. During the work towards this aim, as described in Chapter 7 and the included papers, monopolar IEMs and BMs have been used for controlling amyloid aggregation or for constructing ion diodes, transistors, and circuits. The following section highlights the results that I find most important.

In Papers I-II, ion fluxes produced by an OEIP is directed into peptide solutions to initiate formation of amyloid-like structures. These experiments demonstrate the biological importance of ions and the strength of the OEIP. the electronically controlled elevation in ion concentration induces a chemical condition for peptide aggregation. Further, chemical specificity is shown, as the aggregation kinetic and morphology is dependent on the delivered ion. Together, the convection-free and highly controllable method for studying amyloids in vitro presented in these papers is an important finding in this thesis.

Non-linear ion conducting devices based on BMs e.g. diodes and transistors, can be constructed using a manufacturing protocol similar to the ones used for the OEIP This was first accomplished by Tybrandt et al., who built a pnp-IBJT using pre-fabricated AEMs 152]. To enable full microfabrication in the next generation of devices, a new AEM material was developed. This material was first used in npn-IBJTs 175 later on also in the IBMDs (Paper III). The latter paper significantly improved our understanding of the diode behavior of BM, and specifically reported on important limitations for IBMDs, such as EFE water dissociation and hysteresis. These limitations illustrates that $\overline{B M}$ junctions cannot be expected to behave exactly like its electronic counterpart. Nevertheless an IBMD was designed that circumvented these limitations, that shows a rectification ratio of $>300$, and switching speed of $\sim 4 \mathrm{~s}$. The obtained stable dynamic performance was crucial for the integration of IBMDs into diode-based logic circuits.

Paper IV reports on IBMDs where a phosphonium-based AEM material is used. This material exhibits no detectable EFE water dissociation, and therefore avoids the problems found in previous generation of IBMDs. This discovery is important for the development of faster and more stable IBMDs and IBJTs as the BM junction can be simplified and its dimensions can now be considerably reduced. The advantage in speed is illustrated for an IBMD in Paper IV and a npn-IBJT in Paper VI, with switching speeds of $4 \mathrm{~s}$ and 
$2 \mathrm{~s}$, respectively. Further, in Paper V, circuits with polyphosphonium-based IBMDs are operated for hours without noticeable performance degradation.

Electrolysis or similar electrochemical electrode reactions are often undesired, limiting electrodes to only be operated in their polarizable regime. In Paper VIBMDs are used to build a full-wave rectifier for ionic currents. The importance of this circuit is in how the input electrodes can be addressed: An ionic DC output can be generated from an electronic AC input without exceeding the polarizable capacity of the electrodes. Thereby, the ion current delivered is now decoupled from the capacity of the electrodes, which is shown by that we can transfer $1.1 \mathrm{mC}$ of ions using only $120 \mu \mathrm{C}$ of electrode charge.

Together, I think these findings clearly illustrate that adding IEMs and BMs to bioelectronic devices is a fruitful method for controlling ion currents. Additionally, I hope that the reported ion-conducting devices and circuits, as well as materials and methods for producing these, will be useful for further development in the field of IEM based organic bioelectronics.

\subsection{Future Outlook}

The use of IEMs in bioelectronic devices is still not a fully mature technology, especially when it comes to applying the technology to answer specific biological questions. Hopefully, the development presented in this thesis can be used to realize further, more advanced, biological applications. For example, the experiments showing electronic control of amyloid aggregation using the OEIP has been basic and simple. Nevertheless the reported results show that the OEIP is a promising platform for future studies of amyloids and amyloid-like structures. Early data suggests that by minimizing the delivery outlet width down to single $\mu \mathrm{m}$ brings further spatial control of the aggregation, and that delivery of the multivalent cation $\mathrm{Zn}^{2+}$ is a potent inducer for in vitro $\mathrm{A} \beta$ aggregation. Together, I think these settings can make the OEIP method more faithful to the in vivo fibrillogenesis. Further, it should be possible to use the OEIP to produce amyloid-like fibrils in the vicinity of cells to study the fibrils cytotoxic effect. By adding aggregation inhibitors or drugs the OEIP might even provide insight towards a cure for amyloid diseases.

When it comes to chemical circuits, i.e. circuits where ion diodes and/or transistors are used to modulate ion currents and to perform logic functions, it is important to consider why such circuits are needed. As the ionic components are inherently slow as compared to their electronic counterparts, the inclusion of ion conductivity must bring a critical advantage for intended application. Such comes for example, when the signal carried by the circuit is an ion of certain chemical or biological relevance, as in the OEIPs Relevant future uses of chemical circuits are therefore, for example, to extend the function of OEIPs, e.g. to produce matrixes of delivery points using ionic AND gates or to provide long term in vivo stimulation using ion full-wave rectifiers. 
Although the speed of IBMDs and IBJTs will always be slow, I find the possibility to create faster ionic components interesting. The key parameters to increase the speed appear to be the length of the junction and the resistance of the connecting channels. Therefore it would be interesting to continue to miniaturize the junction length to below $1 \mu \mathrm{m}$ by, for instance, the use of soft lithography.

Finally, even tough it is difficult to predict what impact IEM-based organic electronic devices might have for future bioelectronic applications, the improved control over ion fluxes such devices can enable will probably be of importance in biological studies, since all living processes and organisms include ionic signals of various kinds. 


\section{References}

[1] Yves Jean and François Volatron. "Introduction to atomic and molecular structure". In: An introduction to molecular orbitals. Ed. by Jeremy Burdett. New York: Oxford University Press.

[2] Yves Jean and François Volatron. "Building up molecular orbitals and electronic structure". In: An introduction to molecular orbitals. Ed. by Jeremy Burdett. New York: Oxford University Press.

[3] Peter Atkins and Julio de Paula. "Molecular structure". In: Physical Chemistry. New York: W.H. Freeman.

[4] M Fahlman and W R Salaneck. "Surfaces and interfaces in polymerbased electronics". Surface Science 500, pp. 904-922, 2002.

[5] Jean Luc Bredas and G Bryan Street. "Polarons, bipolarons, and solitons in conducting polymers". Accounts of Chemical Research 18, pp. 309-315, 1985.

[6] A Assadi et al. "Field-effect mobility of poly(3-hexylthiophene)". Applied Physics Letters 53, pp. 195-197, 1988.

[7] Iain McCulloch et al. "Liquid-crystalline semiconducting polymers with high charge-carrier mobility". Nat Mater 5, pp. 328-333, 2006.

[8] A Moliton and R C Hiorns. "Review of electronic and optical properties of semiconducting $\pi$-conjugated polymers: Applications in optoelectronics". Polymer International 53, pp. 1397-1412, 2004.

[9] Hideki Shirakawa et al. "Synthesis of electrically conducting organic polymers: halogen derivatives of polyacetylene, (CH) x". Journal of the Chemical Society, Chemical Communications, pp. 578-580, 1977.

[10] Paul J Nigrey, Alan G MacDiarmid, and Alan J Heeger. "Electrochemistry of polyacetylene, $(\mathrm{CH}) \mathrm{x}$ : electrochemical doping of $(\mathrm{CH}) \mathrm{x}$ films to the metallic state". Journal of the Chemical Society, Chemical Communications, pp. 594-595, 1979.

[11] Maria Asplund, Tobias Nyberg, and Olle Inganäs. "Electroactive polymers for neural interfaces". Polymer Chemistry 1, pp. 1374-1391, 2010 .

[12] Carl H Hamann, Andrew Hamnett, and Wolf Vielstich. "Electrical Conductivity and Interionic Interactions". In: Electrochemistry. Weinheim: Wiley-VCH.

[13] Kyösti Kontturi, Lasse Murtomäki, and José A Manzanares. "Transport equations". In: Ionic Transport Processes: in Electrochemistry and Membrane Science. Oxford: Oxford University Press. 
[14] Petr Vanýsek. "Ionic conductivity and diffusion at infinite dilution". In: Handbook of Chemistry and Physics. Ed. by W M Haynes. Boca Raton: CRC Press.

[15] Carl H Hamann, Andrew Hamnett, and Wolf Vielstich. "Electrode Potentials and Double-Layer Structures at Phase Boundaries". In: Electrochemistry. Weinheim: Wiley-VCH.

[16] Kyösti Kontturi, Lasse Murtomäki, and José A Manzanares. "Transport in membranes". In: Ionic Transport Processes: in Electrochemistry and Membrane Science. Oxford: Oxford University Press.

[17] R K Nagarale, G S Gohil, and Vinod K Shahi. "Recent developments on ion-exchange membranes and electro-membrane processes". Advances in Colloid and Interface Science 119, pp. 97-130, 2006.

[18] Heiner Strathmann. "Electrochemical and thermodynamic fundamentals". In: Ion-Exchange Membrane Separation Processes. Elsevier, 2004.

[19] M Kumar et al. "Recent Developments in Ion-Exchange Membranes and Their Applications in Electrochemical Processes for in situ Ion Substitutions, Separation and Water Splitting". Separation and Purification Reviews 42, pp. 187-261, 2013.

[20] Nallanna Lakshminarayanaiah. "Counterion transference numbers in ion-exchange membranes". The Journal of Physical Chemistry 73, pp. 97-102, 1969.

[21] J J Krol, M Wessling, and H Strathmann. "Concentration polarization with monopolar ion exchange membranes: Current-voltage curves and water dissociation". Journal of Membrane Science 162, pp. 145-154, 1999.

[22] V M Aguilella et al. "Current-voltage curves for ion-exchange membranes. Contributions to the total potential drop". Journal of Membrane Science 61, pp. 177-190, 1991.

[23] Vincent J Frilette. "Preparation and Characterization of Bipolar Ion Exchange Membranes". The Journal of Physical Chemistry 60, pp. 435-439, 1956.

[24] S Mafe and P Ramirez. "Electrochemical characterization of polymer ion-exchange bipolar membranes". Acta Polymerica 48, pp. 234-250, 1997.

[25] Ji-Hyung Han et al. "Ion Flow Crossing Over a Polyelectrolyte Diode on a Microfluidic Chip". Small 7, pp. 2629-2639, 2011.

[26] E O Gabrielsson, K Tybrandt, and M Berggren. "Ion diode logics for pH control". Lab on a Chip 12, pp. 2507-2513, 2012.

[27] P Ramirez et al. "Current-voltage curves of bipolar membranes". J. Appl. Phys. 72, pp. 259-264, 1992.

[28] R Simons. "Strong Electric-Field Effects on Proton-Transfer between Membrane-Bound Amines and Water". Nature 280, pp. 824-826, 1979. 
[29] Tongwen Xu. "Development of bipolar membrane-based processes". Desalination 140, pp. 247-258, 2001.

[30] Moon-Sung Kang et al. "Enhancement of water splitting in bipolar membranes by optimized composite anion-exchange layer and alkalitreated polyacrylonitrile catalytic junction". Journal of Membrane Science 229, pp. 137-146, 2004.

[31] Koji Shimizu and Akihiko Tanioka. "Effect of interface structure and amino groups on water splitting and rectification effects in bipolar membranes". Polymer 38, pp. 5441-5446, 2003.

[32] R Simons. "Origin and Elimination of Water Splitting in Ion-Exchange Membranes during Water Demineralization by Electrodialysis". Desalination 28, pp. 41-42, 1979.

[33] I Rubinstein et al. "Elimination of Acid-Base Generation (WaterSplitting) in Electrodialysis". Desalination 51, pp. 55-60, 1984.

[34] R Simons and G Khanarian. "Water dissociation in bipolar membranes: experiments and theory". Journal of Membrane Biology 38, pp. 11-30, 1978.

[35] Salvador Mafé, Patricio Ramirez, and José A Manzanares. "How does a transition zone affect the electric field enhanced water dissociation in bipolar membranes?" Berichte der Bunsengesellschaft für physikalische Chemie 98, pp. 202-205, 1994.

[36] Akihiko Tanioka and Koji Shimizu. "Reduction of Water Splitting Effect in Bipolar Membranes". Bulletin of the Society of Sea Water Science, Japan 51, pp. 205-212, 1997.

[37] J D Sipe and A S Cohen. "Review: history of the amyloid fibril". Journal of Structural Biology 130, pp. 88-98, 2000.

[38] Per Westermark et al. "A primer of amyloid nomenclature". Amyloid 14, pp. 179-183, 2007.

[39] J D Sipe. "Amyloidosis". Annual Review of Biochemistry 61, pp. 947975, 1992.

[40] Ron Brookmeyer et al. "Forecasting the global burden of Alzheimer's disease". Alzheimer's \& Dementia 3, pp. 186-191, 2007.

[41] Jeremy M Berg, John L Tymoczko, and Lubert Strye. "Protein Structure and Function". In: Biochemistry. New York: W.H. Freeman.

[42] Geoffrey Kwai-Wai Kong et al. "Structure of Alzheimer's disease amyloid precursor protein copper-binding domain at atomic resolution." Acta crystallographica. Section F, Structural biology and crystallization communications 63, pp. 819-824, 2007.

[43] Ian W Hamley. "Peptide Fibrillization". Angewandte Chemie - International Edition 46, pp. 8128-8147, 2007.

[44] J C Rochet and P T Lansbury Jr. "Amyloid fibrillogenesis: themes and variations". Curr Opin Struct Biol 10, pp. 60-68, 2000. 
[45] Melanie R Nilsson. "Techniques to study amyloid fibril formation in vitro". Investigating Protein Folding, Misfolding and Nonnative States: Experimental and Theoretical Methods 34, pp. 151-160, 2004.

[46] A Lomakin et al. "On the nucleation and growth of amyloid $\beta$-protein fibrils: Detection of nuclei and quantitation of rate constants". Proceedings of the National Academy of Sciences of the United States of America 93, pp. 1125-1129, 1996.

[47] J T Jarrett and P T Lansbury Jr. "Seeding 'one-dimensional crystallization' of amyloid: A pathogenic mechanism in Alzheimer's disease and scrapie?" Cell 73, pp. 1055-1058, 1993.

[48] F Chiti and C M Dobson. "Protein misfolding, functional amyloid, and human disease". Annual Review of Biochemistry 75, pp. 333-366, 2006.

[49] L F Lue et al. "Soluble amyloid $\beta$ peptide concentration as a predictor of synaptic change in Alzheimer's disease". American Journal of Pathology 155, pp. 853-862, 1999.

[50] J D Harper et al. "Assembly of A $\beta$ amyloid protofibrils: An in vitro model for a possible early event in Alzheimer's disease". Biochemistry 38, pp. 8972-8980, 1999.

[51] Fabrizio Chiti et al. "Designing conditions for in vitro formation of amyloid protofilaments and fibrils". Proceedings of the National Academy of Sciences 96, pp. 3590-3594, 1999.

[52] C E MacPhee and C M Dobson. "Formation of mixed fibrils demonstrates the generic nature and potential utility of amyloid nanostructures". Journal of the American Chemical Society 122, pp. 1270712713, 2000.

[53] W P Esler et al. "In vitro growth of Alzheimer's disease $\beta$-amyloid plaques displays first-order kinetics". Biochemistry 35, pp. 749-757, 1996.

[54] D R Booth et al. "Instability, unfolding and aggregation of human lysozyme variants underlying amyloid fibrillogenesis". Nature 385, pp. 787-793, 1997.

[55] Kateri F DuBay et al. "Prediction of the Absolute Aggregation Rates of Amyloidogenic Polypeptide Chains". Journal of Molecular Biology 341, pp. 1317-1326, 2004.

[56] Noel D Lazo et al. "The Amyloid $\beta$-Protein". In: Amyloid Proteins. Ed. by J D Sipe. Weinheim: Wiley-VCH.

[57] P E Fraser et al. "pH-dependent structural transitions of Alzheimer amyloid peptides". Biophysical Journal 60, pp. 1190-1201, 1991.

[58] A I Bush et al. "Rapid induction of Alzheimer A $\beta$ amyloid formation by zinc". Science 265, pp. 1464-1467, 1994. 
[59] C S Atwood et al. "Dramatic aggregation of alzheimer by $\mathrm{Cu}(\mathrm{II})$ is induced by conditions representing physiological acidosis". Journal of Biological Chemistry 273, pp. 12817-12826, 1998.

[60] E K Hill et al. "Shear flow induces amyloid fibril formation". Biomacromolecules 7, pp. 10-13, 2006.

[61] C J Pike et al. "In vitro aging of $\beta$-amyloid protein causes peptide aggregation and neurotoxicity". Brain Research 563, pp. 311-314, 1991.

[62] C Geula et al. "Aging renders the brain vulnerable to $26 \beta$-protein neurotoxicity". Nature Medicine 4, pp. 827-831, 1998.

[63] Bruce Kagan. "Oligomers and Cellular Toxicity". In: Amyloid Proteins. Ed. by Jean D Sipe. Weinheim: Wiley-VCH.

[64] Mireille Dumoulin, Vittorio Bellotti, and Christopher M Dobson. "Lysozyme". In: Amyloid Proteins. Ed. by J D Sipe. Weinheim: Wiley$\mathrm{VCH}$.

[65] J F Berson et al. "Proprotein convertase cleavage liberates a fibrillogenic fragment of a resident glycoprotein to initiate melanosome biogenesis". Journal of Cell Biology 161, pp. 521-533, 2003.

[66] Samir K Maji et al. "Functional amyloids as natural storage of peptide hormones in pituitary secretory granules". Science 325 , pp. 328-332, 2009 .

[67] J D Harper et al. "Observation of metastable A $\beta$ amyloid protofibrils by atomic force microscopy". Chemistry and Biology 4, pp. 119-125, 1997.

[68] T Shirahama and A S Cohen. "High-resolution electron microscopic analysis of the amyloid fibril." Journal of Cell Biology 33, pp. 679-708, 1967.

[69] M Sunde et al. "Common core structure of amyloid fibrils by synchrotron X-ray diffraction". Journal of Molecular Biology 273, pp. 729 739, 1997.

[70] A T Petkova et al. "A structural model for Alzheimer's $\beta$-amyloid fibrils based on experimental constraints from solid state NMR". Proceedings of the National Academy of Sciences of the United States of America 99, pp. 16742-16747, 2002.

[71] E E Nesterov et al. "In vivo optical imaging of amyloid aggregates in brain: Design of fluorescent markers". Angewandte Chemie - International Edition 44, pp. 5452-5456, 2005.

[72] W E Klunk, J W Pettegrew, and D J Abraham. "Quantitative evaluation of Congo red binding to amyloid-like proteins with a beta-pleated sheet conformation". Journal of Histochemistry and Cytochemistry 37, pp. 1273-1281, 1989. 
[73] H LeVine III. "Thioflavine T interaction with synthetic Alzheimer's disease $\beta$-amyloid peptides: Detection of amyloid aggregation in solution". Protein Science 2, pp. 404-410, 1993.

[74] K Peter R Nilsson and Per Hammarström. "Luminescent Conjugated Polymers: Illuminating the Dark Matters of Biology and Pathology". Advanced Materials 20, pp. 2639-2645, 2008.

[75] Andreas Åslund et al. "Novel Pentameric Thiophene Derivatives for in Vitro and in Vivo Optical Imaging of a Plethora of Protein Aggregates in Cerebral Amyloidoses". ACS Chemical Biology 4, pp. 673-684, 2009.

[76] T Klingstedt et al. "Synthesis of a library of oligothiophenes and their utilization as fluorescent ligands for spectral assignment of protein aggregates". Organic and Biomolecular Chemistry 9, pp. 8356-8370, 2011.

[77] E Gazit. "Self-assembled peptide nanostructures: The design of molecular building blocks and their technological utilization". Chemical Society Reviews 36, pp. 1263-1269, 2007.

[78] Charlotte A E Hauser, Sebastian Maurer-Stroh, and Ivo C Martins. "Amyloid-based nanosensors and nanodevices". Chemical Society Reviews 43, pp. 5326-5345, 2014.

[79] Thomas Scheibel et al. "Conducting nanowires built by controlled selfassembly of amyloid fibers and selective metal deposition". Proceedings of the National Academy of Sciences 100, pp. 4527-4532, 2003.

[80] Mahiar Hamedi et al. "Electrochemical devices made from conducting nanowire networks self-assembled from amyloid fibrils and alkoxysulfonate PEDOT". Nano Letters 8, pp. 1736-1740, 2008.

[81] Anna Herland et al. "Alignment of a conjugated polymer onto amyloidlike protein fibrils". Small 3, pp. 318-325, 2007.

[82] V Dinca et al. "Directed three-dimensional patterning of self-assembled peptide fibrils". Nano Letters 8, pp. 538-543, 2008.

[83] Pavel Neuži et al. "Revisiting lab-on-a-chip technology for drug discovery". Nature Reviews Drug Discovery 11, pp. 620-632, 2012.

[84] Leslie Y Yeo et al. "Microfluidic Devices for Bioapplications". Small 7, pp. 12-48, 2011.

[85] Joon Seok Lee et al. "Microfluidic Self-Assembly of Insulin Monomers into Amyloid Fibrils on a Solid Surface". Langmuir 24, pp. 7068-7071, 2008.

[86] Matthias Meier et al. "Plug-Based Microfluidics with Defined Surface Chemistry to Miniaturize and Control Aggregation of Amyloidogenic Peptides". Angewandte Chemie - International Edition 48, pp. 14871489, 2009.

[87] J S Lee, J Ryu, and C B Park. "High-throughput analysis of alzheimer's $\beta$-amyloid aggregation using a microfluidic self-assembly of monomers". Analytical Chemistry 81, pp. 2751-2759, 2009. 
[88] J S Lee and C B Park. "Microfluidic dissociation and clearance of Alzheimer's $\beta$-amyloid aggregates". Biomaterials 31, pp. 6789-6795, 2010 .

[89] T P J Knowles et al. "Observation of spatial propagation of amyloid assembly from single nuclei". Proceedings of the National Academy of Sciences of the United States of America 108, pp. 14746-14751, 2011.

[90] Yoon Jung Choi et al. "Neurotoxic amyloid beta oligomeric assemblies recreated in microfluidic platform with interstitial level of slow flow." Scientific Reports 3, p. 1921, 2013.

[91] A Ruiz et al. "Testing A $\beta$ toxicity on primary CNS cultures using drug-screening microfluidic chips". Lab on a Chip - Miniaturisation for Chemistry and Biology 14, pp. 2860-2866, 2014.

[92] Vito Foderà et al. "Microfluidics Reveals a Flow-Induced Large-Scale Polymorphism of Protein Aggregates". The Journal of Physical Chemistry Letters 3, pp. 2803-2807, 2012.

[93] E O Gabrielsson et al. "Spatially Controlled Amyloid Reactions Using Organic Electronics". Small 6, pp. 2153-2161, 2010.

[94] Berry W Connors. "Synaptic Transmission in the Nervous System". In: Medical Physiology. Ed. by Walter F Boron and Emilie L Boulpaep. Philadelphia: Elsevier Health Sciences.

[95] Jonathan Rivnay, Róisín M Owens, and George G Malliaras. "The Rise of Organic Bioelectronics". Chemistry of Materials 26, pp. 679685, 2014.

[96] Nathalie K Guimard, Natalia Gomez, and Christine E Schmidt. "Conducting polymers in biomedical engineering". Progress in Polymer Science 32, pp. 876-921, 2007.

[97] Dion Khodagholy et al. "Highly Conformable Conducting Polymer Electrodes for In Vivo Recordings". Advanced Materials 23, H268H272, 2011.

[98] N Gomez and C E Schmidt. "Nerve growth factor-immobilized polypyrrole: Bioactive electrically conducting polymer for enhanced neurite extension". Journal of Biomedical Materials Research - Part A 81, pp. 135-149, 2007.

[99] Magnus Berggren and Agneta Richter-Dahlfors. "Organic bioelectronics". Advanced Materials 19, pp. 3201-3213, 2007.

[100] Felix Strumwasser. "Long-Term Recording from Single Neurons in Brain of Unrestrained Mammals". Science 127, pp. 469-470, 1958.

[101] K D Wise, J B Angell, and Arnold Starr. "An Integrated-Circuit Approach to Extracellular Microelectrodes". Biomedical Engineering, IEEE Transactions on BME-17, pp. 238-247, 1970.

[102] P K Campbell et al. "A silicon-based, three-dimensional neural interface: manufacturing processes for an intracortical electrode array". Biomedical Engineering, IEEE Transactions on 38, pp. 758-768, 1991. 
[103] Vadim S Polikov, Patrick A Tresco, and William M Reichert. "Response of brain tissue to chronically implanted neural electrodes." Journal of Neuroscience Methods 148, pp. 1-18, 2005.

[104] M R Abidian et al. "Interfacing conducting polymer nanotubes with the central nervous system: chronic neural recording using poly(3,4-ethylenedioxythiophene) nanotubes". Advanced Materials 21, pp. 3764-3770-3722, 2009.

[105] D Feili, M Schuettler, and T Stieglitz. "Matrix-addressable, active electrode arrays for neural stimulation using organic semiconductors - Cytotoxicity and pilot experiments in vivo". Journal of neural engineering 5, pp. 68-74, 2008.

[106] Sarah M Richardson-Burns, Jeffrey L Hendricks, and David C Martin. "Electrochemical polymerization of conducting polymers in living neural tissue." Journal of neural engineering 4, pp. L6-L13, 2007.

[107] Y R Kim et al. "Electrochemical detection of dopamine in the presence of ascorbic acid using graphene modified electrodes". Biosensors and Bioelectronics 25, pp. 2366-2369, 2010.

[108] S J Updike and G P Hicks. "The Enzyme Electrode". Nature 214, pp. 986-988, 1967.

[109] S Cosnier. "Biomolecule immobilization on electrode surfaces by entrapment or attachment to electrochemically polymerized films. A review." Biosensors and Bioelectronics 14, pp. 443-456, 1999.

[110] M J Schöning and A Poghossian. "Recent advances in biologically sensitive field-effect transistors (BioFETs)". The Analyst 127, pp. 11371151, 2002.

[111] Peng Lin and Feng Yan. "Organic Thin-Film Transistors for Chemical and Biological Sensing". Advanced Materials 24, pp. 34-51, 2012.

[112] Edward G Mocydlowski. "Electrophysiology of the Cell Membrane". In: Medical Physiology. Ed. by Walter F Boron and Emilie L Boulpaep. Philadelphia: Elsevier Health Sciences.

[113] Ulises A Aregueta-Robles et al. "Organic electrode coatings for nextgeneration neural interfaces". Frontiers in Neuroengineering 7, p. 15, 2014.

[114] P Fattahi et al. "A review of organic and inorganic biomaterials for neural interfaces". Advanced Materials 26, pp. 1846-1885, 2014.

[115] R A Green et al. "Performance of conducting polymer electrodes for stimulating neuroprosthetics." Journal of neural engineering 10, p. 016009, 2013.

[116] Tobias Nyberg, Olle Inganäs, and Helena Jerregård. "Polymer Hydrogel Microelectrodes for Neural Communication". Biomedical Microdevices 4, pp. 43-52, 2002.

[117] E W H Jager, E Smela, and O Inganäs. "Microfabricating conjugated polymer actuators". Science 290, pp. 1540-1545, 2000. 
[118] Karl Svennersten et al. "Mechanical stimulation of epithelial cells using polypyrrole microactuators." Lab on a Chip 11, pp. 3287-3293, 2011.

[119] E W Jager, O Inganäs, and I Lundstrom. "Microrobots for micrometersize objects in aqueous media: potential tools for single-cell manipulation." Science 288, pp. 2335-2338, 2000.

[120] Katsuhiko Naoi, Mary Lien, and William H Smyrl. "Quartz Crystal Microbalance Study: Ionic Motion Across Conducting Polymers". Journal of The Electrochemical Society 138, pp. 440-445, 1991.

[121] Yong-Jian Qiu and John R Reynolds. "Dopant anion controlled ion transport behavior of polypyrrole". Polymer Engineering 8 Science 31, pp. 417-421, 1991.

[122] M R Gandhi et al. "Mechanism of electromechanical actuation in polypyrrole". Synthetic Metals 73, pp. 247-256, 1995.

[123] J Isaksson et al. "A Solid-State Organic Electronic Wettability Switch". Advanced Materials 16, pp. 316-320, 2004.

[124] Joyce Y Wong, Robert Langer, and Donald E Ingber. "Electrically conducting polymers can noninvasively control the shape and growth of mammalian cells." Proceedings of the National Academy of Sciences of the United States of America 91, pp. 3201-3204, 1994.

[125] Abdurrahman Gumus et al. "Control of cell migration using a conducting polymer device". Soft Matter 6, pp. 5138-5142, 2010.

[126] Carmen Saltó et al. "Control of Neural Stem Cell Adhesion and Density by an Electronic Polymer Surface Switch". Langmuir 24, pp. 14133-14138, 2008.

[127] Maria H Bolin et al. "Active Control of Epithelial Cell-Density Gradients Grown Along the Channel of an Organic Electrochemical Transistor". Advanced Materials 21, pp. 4379-4382, 2009.

[128] A Kotwal and C E Schmidt. "Electrical stimulation alters protein adsorption and nerve cell interactions with electrically conducting biomaterials". Biomaterials 22, pp. 1055-1064, 2001.

[129] Anna Herland et al. "Electrochemical Control of Growth Factor Presentation To Steer Neural Stem Cell Differentiation". Angewandte Chemie - International Edition 50, pp. 12529-12533, 2011.

[130] R Wadhwa, C F Lagenaur, and X T Cui. "Electrochemically controlled release of dexamethasone from conducting polymer polypyrrole coated electrode". Journal of Controlled Release 110, pp. 531-541, 2006.

[131] Darren Svirskis et al. "Electrochemically controlled drug delivery based on intrinsically conducting polymers". Journal of Controlled Release 146, pp. 6-15, 2010. 
[132] Luiz M Lira and Susana I Córdoba de Torresi. "Conducting polymerhydrogel composites for electrochemical release devices: Synthesis and characterization of semi-interpenetrating polyaniline-polyacrylamide networks". Electrochemistry Communications 7, pp. 717-723, 2005.

[133] L M Low et al. "Microactuators toward microvalves for responsive controlled drug delivery". Sensors and Actuators, B: Chemical 67, pp. 149-160, 2000.

[134] M R Abidian, D H Kim, and D C Martin. "Conducting-polymer nanotubes for controlled drug release". Advanced Materials 18, pp. 405409, 2006.

[135] X Luo et al. "Carbon nanotube nanoreservior for controlled release of anti-inflammatory dexamethasone". Biomaterials 32, pp. 6316-6323, 2011.

[136] Joakim Isaksson et al. "Electronic control of $\mathrm{Ca} 2+$ signalling in neuronal cells using an organic electronic ion pump". Nature Materials 6, pp. 673-679, 2007.

[137] K Norrman, A Ghanbari-Siahkali, and N B Larsen. "Studies of spincoated polymer films". Annual Reports on the Progress of Chemistry - Section C 101, pp. 174-201, 2005.

[138] W W Flack et al. "A mathematical model for spin coating of polymer resists". Journal of Applied Physics 56, pp. 1199-1206, 1984.

[139] A Pimpin and W Srituravanich. "Reviews on micro- and nanolithography techniques and their applications". Engineering Journal 16, pp. 37-55, 2012.

[140] Stephen J Pearton and David P Norton. "Dry Etching of Electronic Oxides, Polymers, and Semiconductors". Plasma Processes and Polymers 2, pp. 16-37, 2005.

[141] H Sirringhaus et al. "High-Resolution Inkjet Printing of All-Polymer Transistor Circuits". Science 290, pp. 2123-2126, 2000.

[142] W G Lloyd and T E Durocher. "Nucleophilic displacements upon poly(vinylbenzyl chloride)". Journal of Applied Polymer Science 7, pp. 2025-2033, 1963.

[143] E N Komkova et al. "Anion-exchange membranes containing diamines: preparation and stability in alkaline solution". Journal of Membrane Science 244, pp. 25-34, 2004.

[144] Ashok K Pandey et al. "Formation and characterization of highly crosslinked anion-exchange membranes". Journal of Membrane Science 217, pp. 117-130, 2003.

[145] C Ornelas-Megiatto, P R Wich, and J M J Frechet. "Polyphosphonium Polymers for siRNA Delivery: An Efficient and Nontoxic Alternative to Polyammonium Carriers". Journal of the American Chemical Society 134, pp. 1902-1905, 2012. 
[146] Payman Tehrani et al. "The effect of $\mathrm{pH}$ on the electrochemical overoxidation in PEDOT : PSS films". Solid State Ionics 177, pp. 35213527, 2007.

[147] Klas Tybrandt et al. "Translating Electronic Currents to Precise Acetylcholine-Induced Neuronal Signaling Using an Organic Electrophoretic Delivery Device". Advanced Materials 21, pp. 4442-4446, 2009.

[148] Daniel T Simon et al. "Organic electronics for precise delivery of neurotransmitters to modulate mammalian sensory function". Nat Mater 8, pp. 742-746, 2009.

[149] Joakim Isaksson et al. "Electronically controlled pH gradients and proton oscillations". Organic Electronics 9, pp. 303-309, 2008.

[150] B Lovreček, A Despić, and J O'M Bockris. "Electrolytic junctions with rectifying properties". Journal of Physical Chemistry 63, pp. 750-751, 1959.

[151] J H Han et al. "Ionic circuits based on poly electrolyte diodes on a microchip". Angewandte Chemie - International Edition 48, pp. 38303833, 2009.

[152] K Tybrandt et al. "Ion bipolar junction transistors". Proceedings of the National Academy of Sciences of the United States of America 107, pp. 9929-9932, 2010.

[153] L J Cheng and H C Chang. "Microscale $\mathrm{pH}$ regulation by splitting water". Biomicrofluidics 5, p. 046502, 2011.

[154] Gael Nguyen Siwy, Ivan Vlassiouk, and Zuzanna S. "Comparison of bipolar and unipolar ionic diodes". Nanotechnology 21, p. 265301, 2010 .

[155] Li-Jing Cheng and L Jay Guo. "Ionic current rectification, breakdown, and switching in heterogeneous oxide nanofluidic devices". Acs Nano 3, pp. 575-584, 2009.

[156] R Karnik et al. "Rectification of ionic current in a nanofluidic diode". Nano Letters 7, pp. 547-551, 2007.

[157] L Hegedus et al. "Electrolyte transistors: Ionic reaction - Diffusion systems with amplifying properties". Journal of Physical Chemistry A 102, pp. 6491-6497, 1998.

[158] Z Slouka et al. "Transient behavior of an electrolytic diode". Physical Chemistry Chemical Physics 9, pp. 5374-5381, 2007.

[159] Kristóf Iván et al. "Electrolyte diodes with weak acids and bases. I. Theory and an approximate analytical solution". The Journal of Chemical Physics 123, p. 164509, 2005.

[160] J H So et al. "Ionic current rectification in soft-matter diodes with liquid-metal electrodes". Advanced Functional Materials 22, pp. 625$631,2012$. 
[161] H J Koo, S T Chang, and O D Velev. "Ion-current diode with aqueous gel/sio2 nanofilm interfaces". Small 6, pp. 1393-1397, 2010.

[162] Tetsuya Yamamoto and Masao Doi. "Electrochemical mechanism of ion current rectification of polyelectrolyte gel diodes". Nature Communications 5, p. 4162, 2014.

[163] K Tybrandt, R Forchheimer, and M Berggren. "Logic gates based on ion transistors". Nature Communications 3, p. 871, 2012.

[164] Chuan-Hua Chen and J G Santiago. "A planar electroosmotic micropump". Journal of Microelectromechanical Systems 11, pp. 672-683, 2002.

[165] Rolf Hagedorn et al. "Electrophoresis in gel channels". Electrophoresis 26, pp. 2495-2502, 2005.

[166] Adrienne R Minerick, Agnes E Ostafin, and Hsueh-Chia Chang. "Electrokinetic transport of red blood cells in microcapillaries". Electrophoresis 23, pp. 2165-2173, 2002.

[167] Alexandre Persat, Matthew E Suss, and Juan G Santiago. "Basic principles of electrolyte chemistry for microfluidic electrokinetics. Part II: Coupling between ion mobility, electrolysis, and acid-base equilibria". Lab on a Chip 9, pp. 2454-2469, 2009.

[168] Tobias Revermann et al. "Quantitative analysis by microchip capillary electrophoresis - current limitations and problem-solving strategies". The Analyst 133, pp. 167-174, 2008.

[169] P G Erlandsson and N D Robinson. "Electrolysis-reducing electrodes for electrokinetic devices". Electrophoresis 32, pp. 784-790, 2011.

[170] Katarina Bengtsson, Sara Nilsson, and Nathaniel D Robinson. "Conducting Polymer Electrodes for Gel Electrophoresis". PLoS ONE 9, e89416, 2014.

[171] Gursel Sonmez et al. "A Red, Green, and Blue (RGB) Polymeric Electrochromic Device (PECD): The Dawning of the PECD Era". Angewandte Chemie - International Edition 43, pp. 1498-1502, 2004.

[172] Julio M D'Arcy et al. "Vapor-Phase Polymerization of Nanofibrillar Poly(3,4-ethylenedioxythiophene) for Supercapacitors". Acs Nano 8, pp. 1500-1510, 2014.

[173] H Daiguji, Y Oka, and K Shirono. "Nanofluidic diode and bipolar transistor". Nano Letters 5, pp. 2274-2280, 2005.

[174] R Karnik et al. "Electrostatic control of ions and molecules in nanofluidic transistors". Nano Letters 5, pp. 943-948, 2005.

[175] K Tybrandt, E O Gabrielsson, and M Berggren. "Toward Complementary Ionic Circuits: The npn Ion Bipolar Junction Transistor". Journal of the American Chemical Society 133, pp. 10141-10145, 2011.

[176] Anton V Volkov et al. "Modeling of Charge Transport in Ion Bipolar Junction Transistors". Langmuir, p. 140605120214005, 2014. 


\section{Acronyms}

A $\beta \quad$ amyloid beta

$\mathrm{AC} \quad$ alternating current

$\mathrm{ACh}$ acetylcholine

AO atomic orbital

B base

BDMA benzyldimethylamine

BM bipolar membrane

C collector

CP conjugated polymer

DABCO 1,4-diazabicyclo[2.2.2] octane

DC direct current

E emitter

EB emitter and base

EDL electric double layer

EFE electric field enhanced

Glu glutamate

HOMO highest occupied molecular orbital

$\mathrm{I}_{\mathrm{B}} \quad$ base current

IBJT ion bipolar junction transistor

IBMD ion bipolar membrane diode

$\mathrm{I}_{\mathrm{C}} \quad$ collector current

$\mathrm{J} \quad$ junction

LCO luminescent conjugated oligomer

LCP luminescent conjugated polymer

LUMO lowest unoccupied molecular orbital 
OECT organic electrochemical transistor

OEIP

organic electronic ion pump

PDMS polydimethylsiloxane

PEDOT:PSS poly(3,4-ethylenedioxythiophene):polystyrene sulfonate

PEG polyethylene glycol

PET polyethylene terephthalate

p-FTAA pentamer formyl thiophene acetic acid

Poly-E polyglutamate

PVBC poly(vinylbenzyl chloride)

RIE reactive ion etcher

SEM scanning electron microscope

ThT

thioflavin

$\mathrm{V}_{\mathrm{EB}}$

emitter-base voltage

$\mathrm{V}_{\mathrm{EC}}$

emitter-collector voltage 
Part II

Papers 



\section{Included Papers}

The articles associated with this thesis have been removed for copyright reasons. For more details about these see:

http://urn.kb.se/resolve?urn=urn:nbn:se:liu:diva-110406 